University of Tennessee Health Science Center UTHSC Digital Commons

\title{
Reverse Zoonosis of Pandemic A(H1N1)pdm09 Influenza Viruses at the Swine/Human Interface
}

Daniel Gene Darnell

University of Tennessee Health Science Center

Follow this and additional works at: https://dc.uthsc.edu/dissertations

Part of the Medical Microbiology Commons

\section{Recommended Citation}

Darnell, Daniel Gene (https://orcid.org/0000-0003-4489-5726), "Reverse Zoonosis of Pandemic A(H1N1)pdm09 Influenza Viruses at the Swine/Human Interface" (2019). Theses and Dissertations (ETD). Paper 501. http://dx.doi.org/10.21007/etd.cghs.2019.0564.

This Thesis is brought to you for free and open access by the College of Graduate Health Sciences at UTHSC Digital Commons. It has been accepted for inclusion in Theses and Dissertations (ETD) by an authorized administrator of UTHSC Digital Commons. For more information, please contact jwelch30@uthsc.edu. 


\title{
Reverse Zoonosis of Pandemic A(H1N1)pdm09 Influenza Viruses at the Swine/ Human Interface
}

\begin{abstract}
The 2009 pandemic influenza $A(H 1 N 1) p d m 09$ virus emerged from the swine population. Despite frequent zoonotic events, swine influenza viruses had not become established in humans previously and little is known about host-barriers which prevent swine influenza viruses from efficiently infecting humans. Thus, the emergence of the H1N1pdm09 viruses in humans and the subsequent reverse zoonoses back to swine offered an extremely valuable opportunity to expand current knowledge. We used our active swine farm surveillance platform in combination with viruses from the USDA surveillance program to look for evidence of interspecies transmission of H1N1pdm09 viruses in the US. We found phylogenetic evidence for multiple human to swine transmission events, all of which were transient suggesting that the human adapted viruses of swine origin had lost some fitness for swine. Based on our phylogenetic analysis we selected representative $\mathrm{H} 1 \mathrm{~N} 1 \mathrm{pdm} 09$ viruses from the tips of swine and human sub-lineages for further study. Intriguingly, we found that after being re-introduced into the swine population, the human H1N1pdm09 viruses rapidly lost replicative fitness in human cells. Together these data provide support for a model where transmission of viruses from human to swine leads to rapid adaptation for the swine host which comes at the expense of optimal fitness for human.
\end{abstract}

\section{Document Type}

Thesis

\section{Degree Name}

Master of Science (MS)

\section{Program}

Biomedical Sciences

\section{Research Advisor}

Richard J. Webby, Ph.D.

\section{Keywords}

A(H1N1), BEAST, Influenza, Pandemic, Phylogenetics, Zoonosis

\section{Subject Categories}

Medical Microbiology | Medicine and Health Sciences 


\title{
UNIVERSITY OF TENNESSEE HEALTH SCIENCE CENTER
}

\author{
MASTER OF SCIENCE THESIS
}

\section{Reverse Zoonosis of Pandemic A(H1N1)pdm09 Influenza Viruses at the Swine/Human Interface}

Author:

Daniel Gene Darnell
Advisor:

Richard J. Webby, Ph.D.

A Thesis Presented for The Graduate Studies Council of

The University of Tennessee Health Science Center

in Partial Fulfillment of the Requirements for the Master of Science degree from

The University of Tennessee

$$
\text { in }
$$

Biomedical Sciences: Microbiology, Immunology, \& Biochemistry

College of Graduate Health Sciences

December 2019 
Copyright (C) 2019 by Daniel Gene Darnell.

All rights reserved. 


\section{DEDICATION}

This thesis is dedicated to my loving wife, Stephanie, who has unwaveringly loved and supported me through this long, long journey. Thank you for having such great patience with me. I am lucky to call you my wife!

I also want to dedicate this thesis to my parents. Thank you for always encouraging and motivating me to chase my dreams. I love you both! 


\section{ACKNOWLEDGEMENTS}

I would like to thank my mentor, Dr. Richard Webby, for giving me the opportunity to work in his lab and for the excellent training I have received.

I would also like to thank my committee members, Dr. Justin Bahl, Dr. Stacey Schultz-Cherry, Dr. Kui Li, and Dr. Pat Ryan for their guidance and support during my studies.

Special thanks to Dr. Thomas Fabrizio, Dr. Sook-San Wong, Dr. Mark Zanin, and Jeri-Carol Crumpton for their continuous advice, support, and friendship.

Thanks also to all of the members of Dr. Webby's lab and to the FluGroup at St. Jude Children's Research Hospital.

This work was funded by the National Institute of Allergy and Infectious Diseases, the National Institutes of Health, Centers of Excellence for Influenza Research \& Surveillance (CEIRS) under contract number HSN272201400006C, and the American Lebanese Syrian Associated Charities (ALSAC). 


\begin{abstract}
The 2009 pandemic influenza A(H1N1)pdm09 virus emerged from the swine population. Despite frequent zoonotic events, swine influenza viruses had not become established in humans previously and little is known about host-barriers which prevent swine influenza viruses from efficiently infecting humans. Thus, the emergence of the H1N1pdm09 viruses in humans and the subsequent reverse zoonoses back to swine offered an extremely valuable opportunity to expand current knowledge. We used our active swine farm surveillance platform in combination with viruses from the USDA surveillance program to look for evidence of interspecies transmission of H1N1pdm09 viruses in the US. We found phylogenetic evidence for multiple human to swine transmission events, all of which were transient suggesting that the human adapted viruses of swine origin had lost some fitness for swine. Based on our phylogenetic analysis we selected representative H1N1pdm09 viruses from the tips of swine and human sub-lineages for further study. Intriguingly, we found that after being reintroduced into the swine population, the human $\mathrm{H} 1 \mathrm{~N} 1 \mathrm{pdm} 09$ viruses rapidly lost replicative fitness in human cells. Together these data provide support for a model where transmission of viruses from human to swine leads to rapid adaptation for the swine host which comes at the expense of optimal fitness for human.
\end{abstract}




\section{TABLE OF CONTENTS}

CHAPTER 1. INTRODUCTION .....................................................................................1

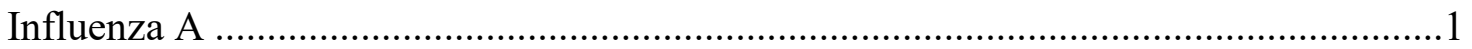

Viral Structure and Protein Components ............................................................. 1

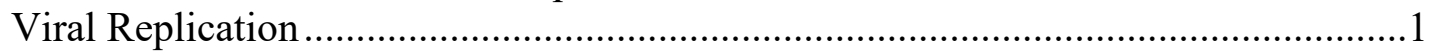

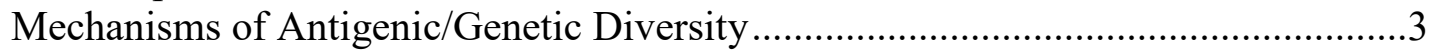

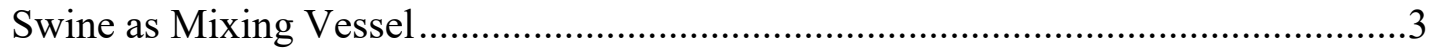

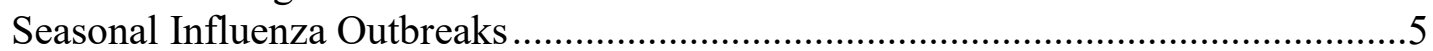

Pandemic Potential of Influenza Viruses ............................................................

Host Range Determinants ...............................................................................

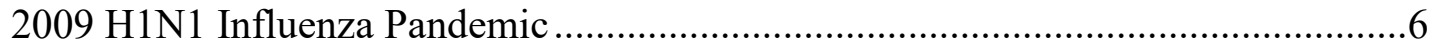

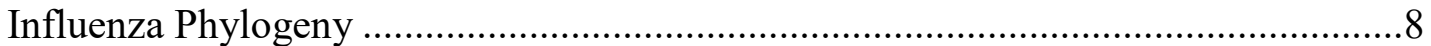

Scope of Thesis and Research Aims ........................................................................

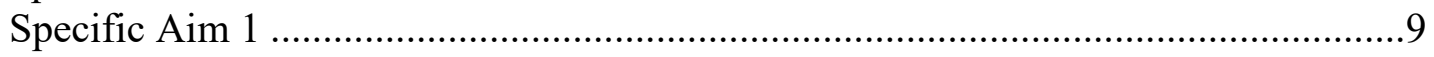

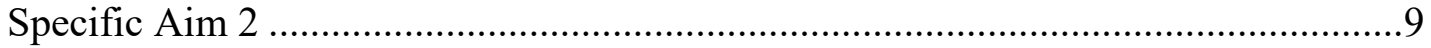

CHAPTER 2. MATERIALS AND METHODS.......................................................10

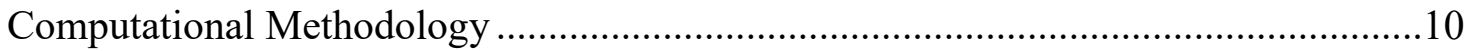

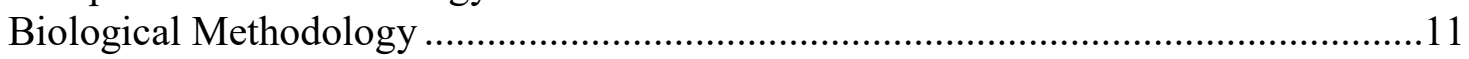

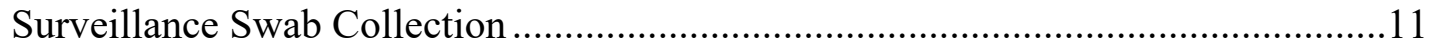

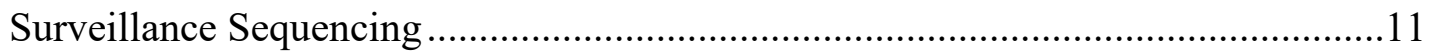

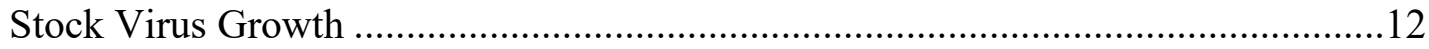

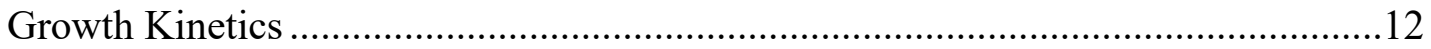

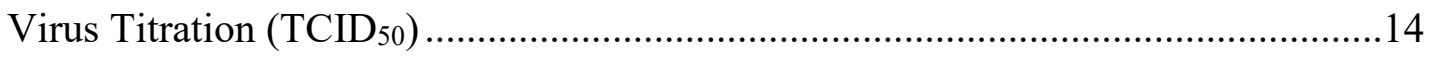

CHAPTER 3. RESULTS ......................................................................................15

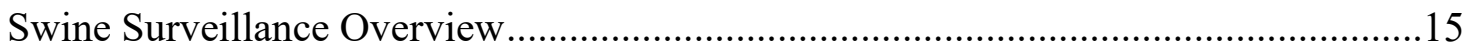

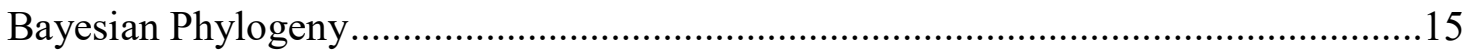

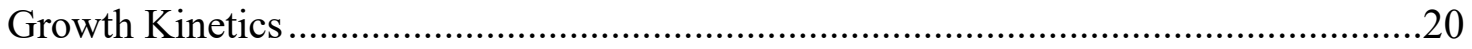

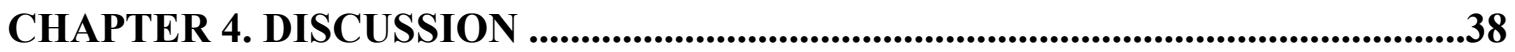

LIST OF REFERENCES....................................................................................................41

APPENDIX A. GENOME-WIDE COMPARISON BETWEEN SWINE AND

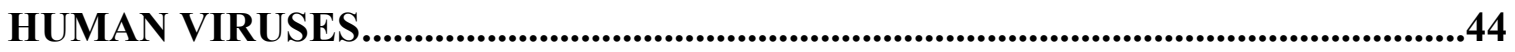

APPENDIX B. DATASET MASTERFILE FOR HA GENE (FASTA

SEQUENCE TRUNCATED FOR SPACE) ……………...................................................45

APPENDIX C. PROGRAM CODE USED WITHIN SCOPE OF THESIS.................65

Changes Made to BEAST XML Code to Calculate Empirical Trees.............................65

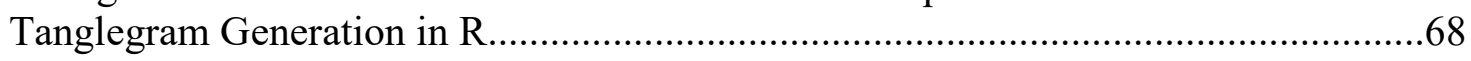




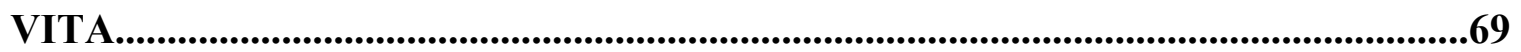




\section{LIST OF TABLES}

Table 2-1. Swine Viruses Used in Growth Kinetics Experiments. ...............................13

Table 3-1. Amino Acid Residues Present in All Swine Viruses Tested. ......................27

Table 4-1. Number of Either High- or Low-Growth Associated Changes in Swine

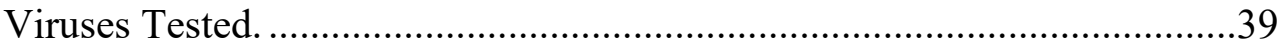




\section{LIST OF FIGURES}

Figure 1-1. ssRNA Genome of Influenza A Viruses....................................................2

Figure 1-2. Mechanisms of Genetic Diversity in Influenza Viruses. .............................4

Figure 1-3. Sialic Acid Linkages in Swine, Human, and Avian Hosts. ..........................

Figure 1-4. Host Range Determinants. ...............................................................

Figure 1-5. Origins of the 2009 H1N1 Pandemic Virus..............................................

Figure 3-1. Phylogenetic BEAST Tree for HA. .....................................................16

Figure 3-2. Phylogenetic BEAST Tree for NA. .........................................................17

Figure 3-3. Phylogenetic BEAST Tree for M. .................................................... 18

Figure 3-4. Phylogenetic BEAST Tree for NP...................................................19

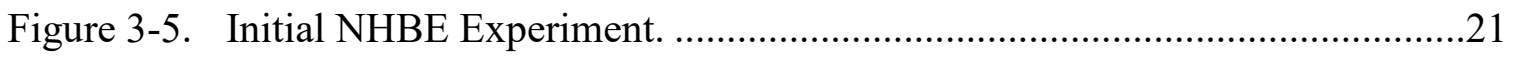

Figure 3-6. Pig Explant Growth Experiment...........................................................22

Figure 3-7. Follow-up NHBE Growth Experiment with Phylogenetically Chosen

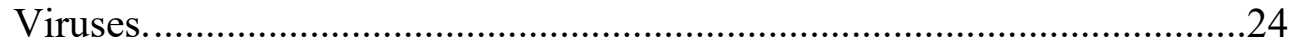

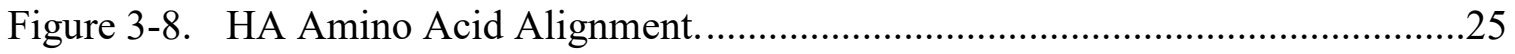

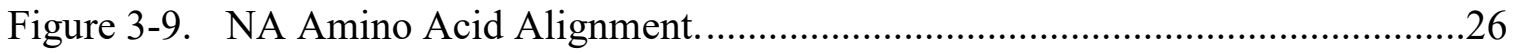

Figure 3-10. Empirical BEAST Tree for HA Position 38 .......................................28

Figure 3-11. Empirical BEAST Tree for HA Position 125 .......................................29

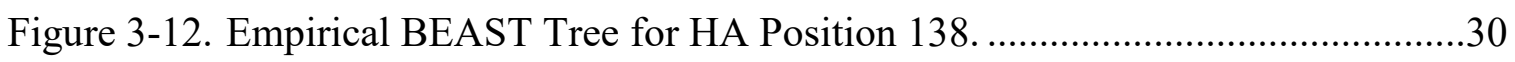

Figure 3-13. Empirical BEAST Tree for HA Position 259 ........................................31

Figure 3-14. Empirical BEAST Tree for All HA Positions............................................32

Figure 3-15. Empirical BEAST Tree for NA Position 14 ...........................................33

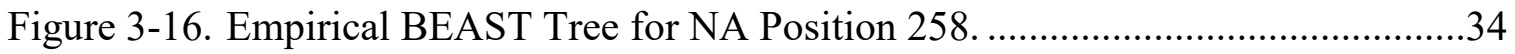

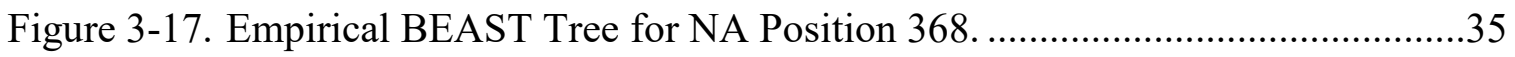

Figure 3-18. Empirical BEAST Tree for All NA Positions...........................................36 
Figure 3-19. HA, NA, M, NP Tanglegram. . 


\section{CHAPTER 1. INTRODUCTION}

\section{Influenza A}

Influenza viruses are members of the Orthomyxoviridae family. They are currently classified into three distinct antigenic classes: A, B, and C. ${ }^{1}$ Type A \& B viruses have a negative-sense RNA (-ssRNA) genome comprised of eight gene segments which code for eleven major proteins; while type $\mathrm{C}$ viruses have seven gene segments. ${ }^{1}$ Influenza A viruses are divided into subtypes based on the surface glycoproteins: hemagglutinin (HA) and neuraminidase (NA). Currently $18 \mathrm{HA}^{2}(\mathrm{H} 1-\mathrm{H} 18)$ and 11 NA (N1 - N11) subtypes have been identified. Influenza A viruses are subtyped based on which HA and NA are present on the surface of the virus (e.g. H1N1, H5N1).

\section{Viral Structure and Protein Components}

The RNA genome of Influenza viruses contains the following gene segments: 1polymerase basic 2 (PB2), 2-polymerase basic 1 (PB1), 3-polymerase acidic (PA), 4hemagglutinin (HA), 5-nucleoprotein (NP), 6-neruaminidase (NA), 7-matirx (M), and 8nonstructural (NS). Some gene segments code for multiple proteins utilizing multiple open reading frames: for example, PB1 can code for both PB1 and PB1-F2, M can code for M1 and M2 proteins, NS can code for NS1 and NEP (Figure 1-1). The HA protein is responsible for binding the virus to the proper host target cell through specific sialic acid interactions. ${ }^{3}$ Human influenza viruses preferentially bind to $\alpha 2-6$ linked sialic acid while avian influenza viruses preferentially bind to $\alpha 2-3$ sialic acid. Once the virus has infected a host cell through processes of endocytosis and $\mathrm{pH}$-dependent release of nucleoprotein encapsulated viral RNA (RNPs) into the cytoplasm, the RNPs are transported to the nucleus where the polymerase complex, made up of PB2, PB1, and PA, begin replicating the viral genome with the aid of host cell machinery (see below for more detail). The $\mathrm{M}$ gene codes for M1 and M2 proteins. ${ }^{4} \mathrm{M} 1$ is a structural component of the virion and lines the inside of the virion. M2 is an ion channel that acts to acidify the virus during replication..$^{5}$ After replication, NA allows the new progeny viruses to bud off from the host cell by cleaving HA-sialic acid bonds through its sialidase activity.

\section{Viral Replication}

Influenza A virus replication starts by binding of HA to the correct sialic acid receptor on the host cell surface. ${ }^{6}$ As detailed, and although a simplification, typically, human influenza viruses bind to sialic acids with $\alpha 2-6$ linkage while avian influenza viruses bind to sialic acid with $\alpha 2-3$ linkage. ${ }^{1}$ The entire Influenza virus is then internalized via clathrin receptor mediated endocytosis into the host cell. ${ }^{7}$ The increasingly acidic environment inside the endosome causes the HA protein to undergo a conformational change, releasing the fusion peptide which leads to fusion of virus and

cell membranes. ${ }^{8}$ The acidification of the virion interior releases RNPs from M1 binding 


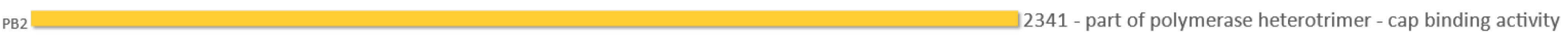

PB1 2341 - part of polymerase heterotrimer - polymerase activity

2233 - part of polymerase heterotrimer - endonuclease activity

$$
\text { HA }
$$

1775 - Hemagglutinin - receptor binding

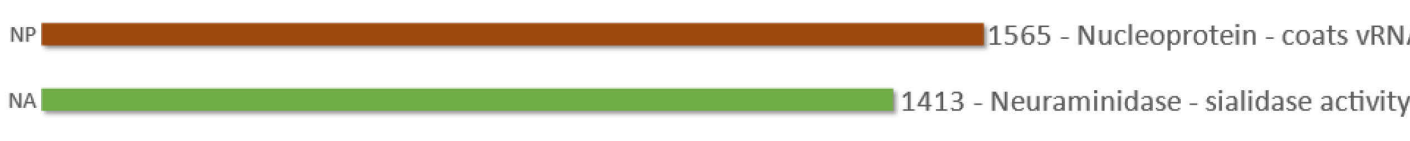

$\mathrm{M} \square 1027$ - Matrix - structural component of virion, ion channel

NS 890 - Non-structural - vRNA transport, translation, splicing

\section{Figure 1-1. ssRNA Genome of Influenza A Viruses.}


and subsequently delivers them into the cell cytoplasm. ${ }^{7}$ RNPs are transported to the nucleus where transcription and replication of the vRNAs occurs in the host cell nucleus. vRNAs are the source for both species of positive sense RNAs; mRNA and complementary RNA (cRNA). ${ }^{8}$ Capped mRNA, generated through a host cap-snatching mechanism utilizing PB2 cap binding and PA endonuclease activities, is exported to the cytoplasm for generation of additional viral proteins. cRNA acts as full-length template for progeny vRNA molecules. After replication and delivery of viral components to the host cell membrane, virions bud off in a M2-dependent manner. ${ }^{9}$ NA cleaves the progeny virus from the host infected cell. Lastly, new viral HA proteins must undergo proteolytic cleavage for subsequent fusion to occur upon entry into a new cell. This process is achieved using host cell proteases which play a role in determining the anatomical location in which a virus can replicate with most viruses utilizing trypsin-like proteases confined to the respiratory tract.

\section{Mechanisms of Antigenic/Genetic Diversity}

Influenza viruses continue to pose threats to veterinary and human health despite the availability of vaccines. ${ }^{10}$ A major reason for this is the ability of the virus to evade existing immunity through antigenic evolution. ${ }^{11}$ Influenza viruses can change into distinct antigenic variants via two primary mechanisms: antigenic drift and antigenic shift. Antigenic drift is a slow, gradual accumulation of amino acid (AA) changes introduced by the infidelity of the viral polymerase during replication. By chance some of these mutations can occur in antigenically important sites on HA or NA (the two major antigenic proteins of the influenza virus). ${ }^{12}$ In the face of existing immunity these variants are rapidly selected for, eventually leading to an antigenically distinct virus. Antigenic shift, however, is a rapid and more sudden process driven by the acquisition of completely new gene segments during replication. Antigenic shift can occur when two different Influenza viruses bind to and replicate in one single cell. During replication it is possible for gene segments from one virus to combine with gene segments from the other virus thereby producing a new virus called a reassortant ${ }^{13}$ (Figure 1-2). This mechanism is what led to the creation of the $2009 \mathrm{~A}(\mathrm{H} 1 \mathrm{~N} 1)$ pdm09 pandemic virus. The 2009 virus was created through at least three independent and temporally distinct reassortant events involving swine and avian viruses.

\section{Swine as Mixing Vessel}

Unlike humans and most avian species, swine have both $\alpha 2-6$ and $\alpha 2-3$ sialic acid residues in approximately equal proportion along their respiratory $\operatorname{tract}^{14}$ (Figure 1-3). Having both types of sialic acid theoretically allows a wider array of influenza viruses to infect the pig population than the human population. As mentioned in the section above, if an avian influenza virus and a human or swine virus were replicating in the same cell, there is the potential to create an array of reassortants, some of which that may have unique abilities to transmit and cause disease in humans. One of the worst influenza pandemics on record was the $1918 \mathrm{H} 1 \mathrm{~N} 1$ pandemic. This pandemic originated from a 
- Antigenic shift

Swine flu virus Human flu or bird flu virus

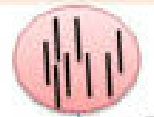

Flu RNA

Segments infectpig cells

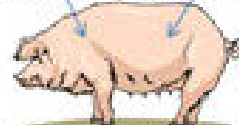

Many RNA segments replicated in one plizce

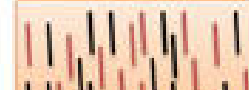

1|||||| $\mid$

Antigenic shift virps (w2) and other viruses then are assembled in a pig cell

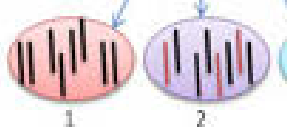

Swine flu virus $=1$

"New" Influenza virus $=2$

Human or bird virus $=3$
Antigenic drift

Human, swine or bird flu virus

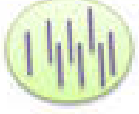

Flu RNA segments infect pig

cells and some of the many

RNA segments are altered (see circle below)
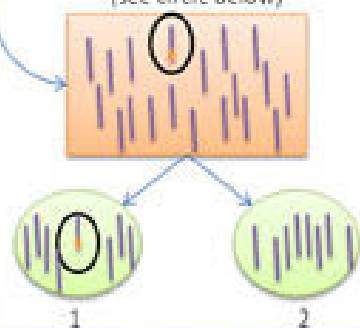

Human, swine or bird flu virus with antigenic drift (A1) and virus with no antigenic drift ( $=2)$

Figure 1-2. Mechanisms of Genetic Diversity in Influenza Viruses.

Reprinted with permission from AAAS. Garten, R.J., et al., Antigenic and genetic characteristics of swine-origin 2009 A(H1N1) influenza viruses circulating in humans. Science, 2009. 325(5937): p. 197-201. ${ }^{13}$

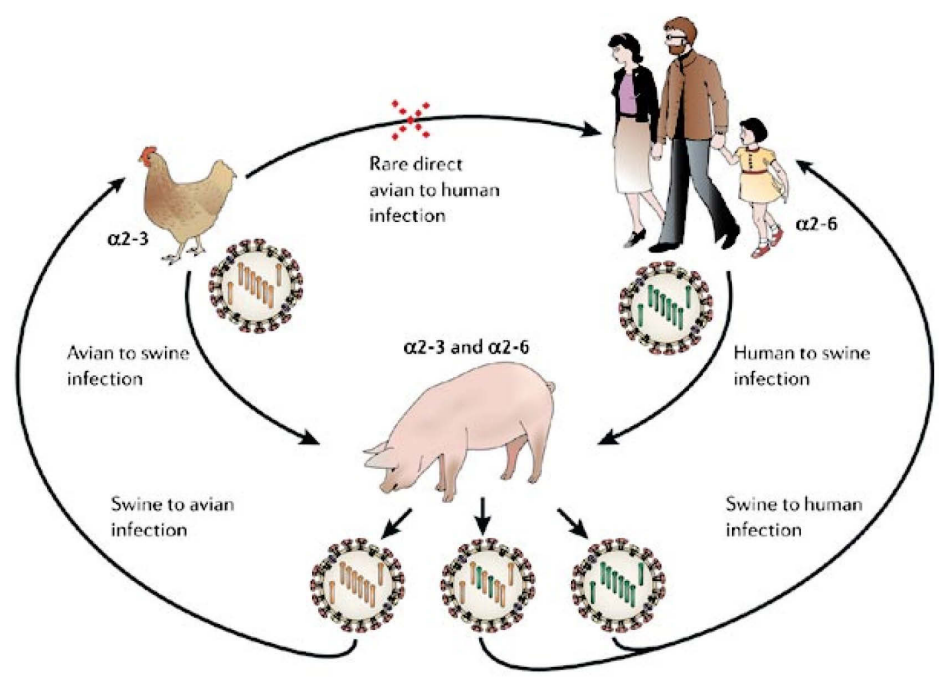

Figure 1-3. Sialic Acid Linkages in Swine, Human, and Avian Hosts.

Reprinted with permission from Springer Nature. Stevens, J., et al., Glycan microarray technologies: tools to survey host specificity of influenza viruses. Nature Reviews Microbiology, 2006. 4(11): p. 857-864. ${ }^{14}$ 
combination of human, swine, and avian influenza viruses. It is thought that multiple reassortment events led to the creation of the 1918 pandemic virus. In the case of the 2009 H1N1pdm09 virus, the final reassortment event between swine viruses of the Eurasian and American lineages led to a virus that has transmission properties not inherent in either parental virus. ${ }^{15,16}$

\section{Seasonal Influenza Outbreaks}

Seasonal influenza outbreaks occur every year and vary in timing based on geographical location. For the United States, the typical flu season runs from November to April. The CDC estimates that in the US alone between 12,000 and 56,000 deaths occur annually from influenza infection. ${ }^{17}$ The virulence, morbidity, and mortality depend partially on the virus itself but also the pre-existing immunity of the population. Influenza infections typically impact two age groups most severely: the young and the old. Immunocompromised patients also face more severe infections due to their weakened immune response. The strains that circulate seasonally are H1N1, H3N2, and $\mathrm{B}$ viruses, although it is typical for only one or two to be dominant in a given region in a given season. ${ }^{18}$ For this reason and our inability to predict which strain might dominate, the seasonal vaccine typically includes one representative from each strain above. The WHO hosts an influenza vaccine composition meeting (VCM) biannually where data from influenza labs around the world is analyzed to determine the optimal combination of strains to include in the seasonal vaccine.

\section{Pandemic Potential of Influenza Viruses}

Pandemic influenza is one of the largest infectious disease threats to the human population. ${ }^{19}$ Pandemics occur when a novel influenza A virus enters the human population and spreads; such events have the potential to cause catastrophic disease. ${ }^{20}$ Two scenarios must be present for a pandemic to emerge. First, the human population must have low overall immunity to the virus to aid in its spread through communities. Antigenic shift is a major factor in the genesis of pandemic influenza viruses. If a reassortant virus emerges with a new gene combination than the population has previously been exposed to, there will be little population immunity to that virus. ${ }^{21}$ Additionally, the virus must be able to transmit efficiently from human to human. ${ }^{22}$ The catastrophic potential of influenza pandemics is highlighted by the 1918 Spanish influenza pandemic that swept the globe, infecting $25-40 \%$ of the world's population ${ }^{23}$ and killing 20-100 million people. ${ }^{24}$ Influenza pandemics again emerged in 1957 and in 1968, each killing an estimated 1 million people during their first waves.

\section{Host Range Determinants}

Interspecies transmission is a central component of influenza ecology. While there have been a number of documented interspecies transmission events, influenza 
viruses typically have defined host ranges with transmission events the exception rather than the rule. It is also clear that the virologic markers that regulate zoonotic infection are different than those that regulate subsequent human-to-human spread. ${ }^{25}$ Zoonosis occurs when an influenza virus transmits from animals to humans. Reverse zoonosis occurs when an influenza virus transmits from humans to animals. ${ }^{26}$ Interspecies transmission, although rare, can also lead to pandemic viruses ${ }^{27}$ with zoonotic events mostly linked to birds and pigs. Transmission from birds to humans has remained confined to isolated cases in situations where individuals came into close contact with the infected birds. ${ }^{28}$ Swine to human transmission occurs slightly more often and was partially responsible for initiating the $2009 \mathrm{H} 1 \mathrm{~N} 1$ pandemic.

Several molecular determinants of host range specificity have previously been identified. ${ }^{28}$ One of the largest single amino acid residues that controls host range is the polymerase (PB2) $627 \mathrm{~K} .{ }^{29}$ This $\mathrm{PB} 2$ position plays a key role in the overall hostassociated genetic signature. A glutamic acid (E) is present in this position most avian isolates; alternatively, a lysine $(\mathrm{K})$ at this position can facilitate a virus of avian origin to replicate in mammalian cells and increase pathogenicity in mice. ${ }^{30}$ Another key determinant of host range is the HA protein. Specific amino acid substitutions within the receptor-binding site of HA can shift the receptor preference from $\alpha 2-3$ to $\alpha 2-6$ sialic acid (Figure 1-4). This receptor binding preference dictates where the virus will ultimately replicate in the host thereby also affecting transmission likelihood. ${ }^{3}$ For instance, human influenza viruses typically bind to $\alpha 2-6$ linkages which are present in the upper respiratory tract of humans. ${ }^{31}$ This makes transmission occur more readily than a virus that binds to $\alpha 2-3$ linkages which are more prevalent in the lower respiratory tract. The polymerase protein PA has also previously been shown to be a determinant of host range. ${ }^{32}$ Residues T85I, G186S and L336M have all been identified as host-associated signatures. ${ }^{32}$ One specific amino acid in the PB1 protein, AA 375 , has previously been identified as a host-range signature. ${ }^{33}$ Most avian viruses have an asparagine $(\mathrm{N})$ at this position, whereas most human influenza viruses have a serine (S). ${ }^{28}$ Although not an exhaustive list of all identified host-range signatures, these are some of the critically important host-range determinants. For an extensive overview of many previously identified host-range signatures, please refer to Cauldwell, Long [28].

\section{H1N1 Influenza Pandemic}

The 2009 H1N1pdm09 pandemic was caused by a novel influenza virus which emerged from the swine population with the direct ability to infect and transmit in humans (reassortant and zoonosis event). ${ }^{34}$ This pandemic virus emerged in Mexico in early 2009 (although it was first detected in Texas and California) but soon spread to the US and across the globe. ${ }^{35}$ The genome contained a unique combination of gene segments from presently circulating swine viruses ${ }^{13}$ (Figure 1-5). PB2, PB1, PA, HA, $\mathrm{NP}$, and NS segments all originated from the triple reassortant/classical swine lineage of swine virus that had been widespread in the Americas and Asia. ${ }^{36} \mathrm{NA}$ and $\mathrm{M}$ segments, however, originated from Eurasian swine lineage viruses that had previously only been detected in Asia and Europe. This virus combined gene segments from both lineages 

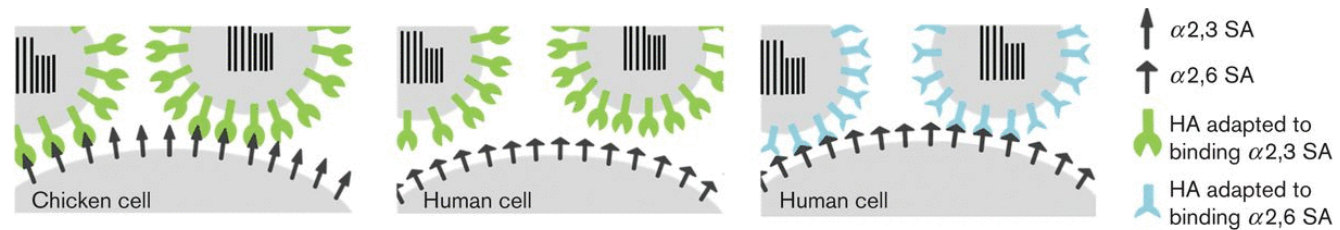

Figure 1-4. Host Range Determinants.

Reprinted with permission. Cauldwell, A.V., et al., Viral determinants of influenza A virus host range. Journal of General Virology, 2014. 95(6): p. 1193-1210. ${ }^{28}$

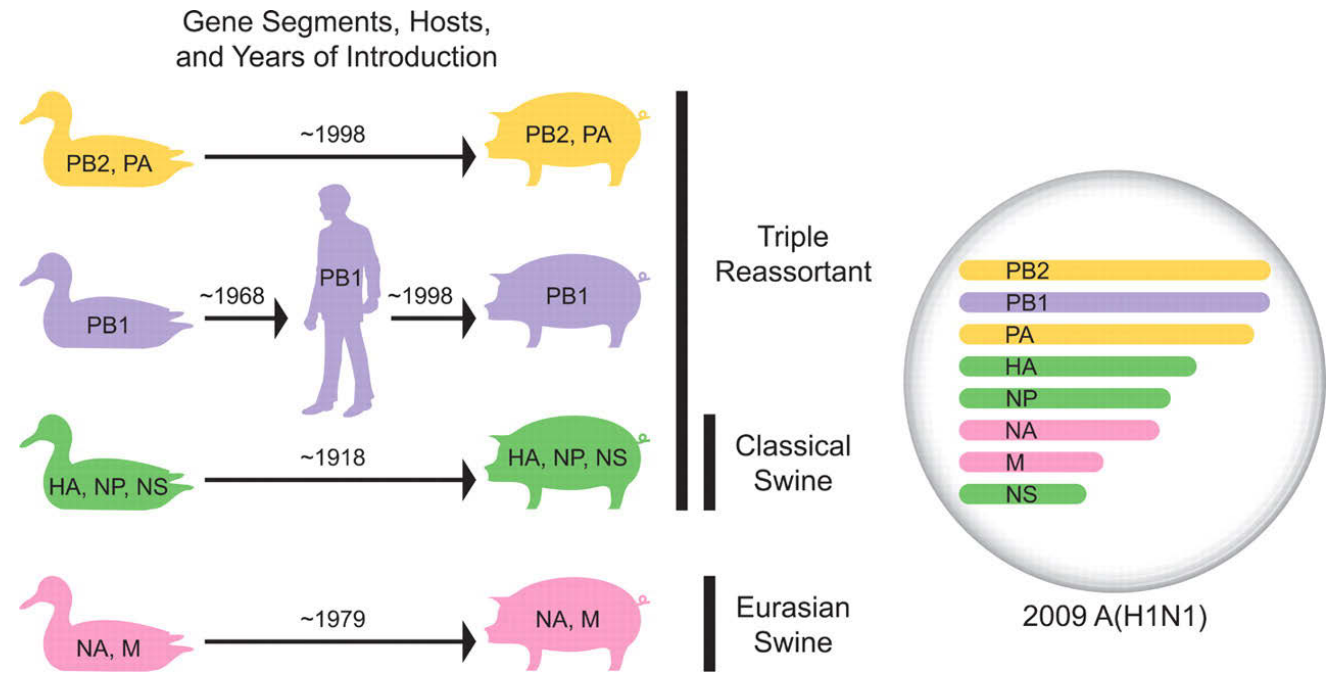

Figure 1-5. Origins of the 2009 H1N1 Pandemic Virus.

Reprinted with permission from AAAS. Garten, R.J., et al., Antigenic and genetic characteristics of swine-origin 2009 A(H1N1) influenza viruses circulating in humans. Science, 2009. 325(5937): p. 197-201. ${ }^{13}$ 
thereby producing an antigenically distinct virus via reassortment (antigenic shift). This reassortant event is thought to have occurred before the pandemic, possibly a number of years prior, but did not transmit to humans until April 2009 despite presumed circulation in the swine population. ${ }^{37}$ Due to a lack of swine influenza surveillance and subsequent virus sequencing from this timeframe (and prior) in Mexico and countries in Central and South America, it is not known exactly how long this virus was circulating prior to the first zoonosis event. From December 2005 - January 2009 (pre-pandemic) there were only 12 reported cases of humans directly infected with swine influenza viruses. By midApril of 2009 however, it was clear that a novel virus had emerged from the swine population with the ability for human transmission. On June 11, 2009 the WHO raised the threat level- signifying a global pandemic was occurring. This was the first influenza pandemic of the $21^{\text {st }}$ century.

Luckily, these viruses had low pathogenesis and only lead to approximately 77,000 cases resulting in 332 deaths worldwide. Subsequent genetic analysis of these viruses determined very few of the molecular markers predicted to facilitate human transmission or increase virulence were present in the viral genomes of these viruses.

\section{Influenza Phylogeny}

Although several methods exist to study the phylogeny of influenza viruses, Bayesian Evolutionary Analysis Sampling Trees (BEAST) ${ }^{38}$ is one of the most robust. Unlike traditional, nucleotide-only analyses, BEAST factors in a multitude of parameters to determine phylogenetic relationships. BEAST trees can be created based on time, geographical location, host, or any other parameter of interest. Bayesian analyses rely on Markov Chain Monte Carlo (MCMC) so that every tree generated is weighted based on posterior probability. BEAST is designed to create rooted, time-measured phylogenetic trees based on either strict or relaxed molecular clock models. It can be used to reconstruct prior phylogenies but is also a framework for testing evolutionary hypotheses.

\section{Scope of Thesis and Research Aims}

Host range specificity between human and swine influenza viruses is dictated via specific, identifiable nucleotide and amino acid residues that likely change rapidly during replication and transmission in each respective host. Despite the similarity of key host range markers between human and swine viruses as well as relatively frequent zoonotic events, it is clear that swine viruses require further changes to successfully establish in humans and that unidentified swine and human host range determinants exist. The 2009 pandemic has provided a setting with which to try and identify these markers. I propose the following Specific Aims to do so. 


\section{Specific Aim 1}

To conduct a thorough phylogenetic analysis of human and swine influenza viruses.

Specific Aim 1 hypothesis: There are distinct phylogenetic differences between H1N1pdm09 viruses of human and swine origin, caused by genetic changes associated with their host range specificity.

\section{Specific Aim 2}

To determine the phenotypic differences between human and swine influenza viruses.

Specific Aim 2 hypothesis: There are identifiable phenotypic differences between human and swine influenza viruses that can be observed in vitro despite identical sialic acid linkage preference. 


\section{CHAPTER 2. MATERIALS AND METHODS}

\section{Computational Methodology}

Data was obtained from the NIAID Influenza Research Database (IRD) [Zhang Y, et al. (2017)] through the web site at http://www.fludb.org. Complete influenza A genomes were restricted to only include $2009 \mathrm{pH} 1 \mathrm{~N} 1$ sequences. The timeframe downloaded was from 2009-2018 (downloaded updated dataset on 10/11/2018). Refer to Appendix B for a representative dataset. Repetitive sequences were excluded so as to allow efficient data analysis without unnecessary redundancy. Genomes downloaded were both human and swine pH1N1 influenza viruses. Gene-by-gene a master datafile was generated in Microsoft Excel that contained all the influenza sequences for that gene. A random number generator in Excel was used to reduce the database size. $20 \%$ of each year's sequences were kept thus producing the final FASTA file necessary to align and build the preliminary phylogenetic tree.

Prior to generation of the preliminary tree, the sequences were aligned in MUltiple Sequence Comparison by Log- Expectation (or MUSCLE for short). ${ }^{39}$ MUSCLE was called as follows:

\section{1. /Users/daniel/MUSCLE/muscle3.8.31_i86darwin64 -in
<input_filename>.fasta -out <output_filename_Aligned>.fasta}

The preliminary tree was produced in RAxML using the following call code:

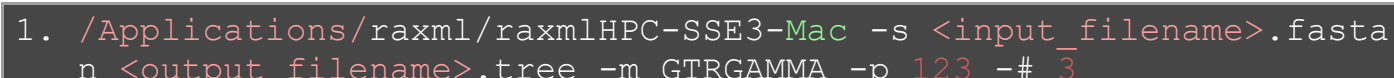

Clockliness of the tree was assessed and verified using TempEst v.1.5.1. Precise date calculations were included in the input FASTA file to allow for TempEst and BEAST to use time data as well as sequence data in evaluating and building the tree. A best-fitting root was calculated in TempEst to help identify any outliers present in the dataset. If any clear outliers were found, they were excluded from the downstream analyses and a new preliminary tree was produced in RAxML. Again, the best fitting root was calculated and if the date now matched what was expected (a root date of 2008 2009) then the dataset was deemed ready for BEAST.

The FASTA file used to generate the preliminary tree was imported into BEAUti v.1.10.1. Tip dates were parsed from the input FASTA file. Traits were added to identify the host of each sequence as either human or swine. A GTR substitution model was used and the site heterogeneity model was chosen as Gamma + Invariant Sites. ${ }^{40}$ The bestfitting clock estimate was determined to be the uncorrelated relaxed clock model. The best tree model was determined to be Bayesian Skyride. ${ }^{41,42}$ A random starting tree was calculated by BEAST rather than leading BEAST with a user-specified starting tree. The 
chain length was specified as 150,000,000 with a screen echo of 15,000 and a write to $\log$ every 15,000. Finally, the BEAST XML file was generated.

BEAST was run from the command line as follows:

1. java -Xmx8g -jar beast.jar -beagle -beagle_SSE -beagle_instances
2 -overwrite <input_BEAST_filename>.xml

The log was monitored over the course of several days to verify the run was proceeding as expected. Multiple runs of 150,000,000 chains were combined to generate the final maximum clade credibility (MCC) tree. In the case of both HA and NA the additional step of creating an empirical dataset and tree was performed to map the amino acid mutations identified in earlier work onto the tree. The specifics involved changing the XML code to prevent overall tree computation and focus solely on the discrete traits provided (i.e. which amino acid was present in the sequence). See Appendix $\mathbf{C}$ for relevant code snippets.

\section{Biological Methodology}

\section{Surveillance Swab Collection}

Our lab at St. Jude Children's Research Hospital (SJCRH) had established a collaboration with swine farmers in Georgia, Illinois, Oklahoma, and Nebraska. These farms collected nasal swabs in Phosphate Buffered Saline (PBS) and antibiotics from 3060 pigs each month and sent them to SJCRH for further testing by real-time PCR (rtPCR).

\section{Surveillance Sequencing}

Next generation sequencing technologies (illumina and Roche) have made it possible to sequence large numbers of samples with a short and simple method. Briefly, RNA was extracted from the swab samples sent to SJCRH using the KingFisher (ThermoFisher Scientific Inc., Worcester, MA, USA). The extracted RNA was tested for the presence of Influenza M gene via rtPCR using CDC approved primers and probes. All positive samples were sequenced using illumina MiSeq technology. The RNA from positive swab samples was converted to DNA using the SuperScript III RT-PCR kit (LifeTechnologies, Grand Island, NY, USA). DNA was then enzymatically fragmented in a process called tagmentation. Transposases, which include adapter sequences, were added to the sample DNA. The transposases both fragmented the DNA as well as added adapter tags to each sample in preparation for the addition of unique barcodes (or indices). Next, a PCR reaction added sample specific barcodes (a 12-nucleotide sequence) to the adapter tag making it possible to identify each sample after sequencing. Finally, the DNA-Adapter-Barcode construct was PCR purified using a MinElute PCR 
Purification KitC (QIAGEN / Germantown, MD). Sequencing was conducted on the illumina MiSeq platform at the Hartwell Center for Bioinformatics and Biotechnology at SJCRH.

\section{Stock Virus Growth}

All stock viruses (Table 2-1) used in this study were grown in Madin Darby Canine Kidney (MDCK) cells. Each virus was diluted to 1:100 in infection media (Gibco Minimum Essential Media $+1 \%$ vitamins $+1 \%$ antibiotics $+1 \%$ glutamine $+5 \%$ BSA). The infection media was supplemented with TPCK trypsin (ThermoFisher Scientific catalog 20233) at a concentration of 1:2000 as MDCK cells do not produce an endogenous protease. Viruses were incubated in a flask containing MDCK cells for 1 hour at $37^{\circ} \mathrm{C} / 5 \% \mathrm{CO}_{2}$. After 1 hour, the virus dilution inoculum was removed, and the cells were washed twice with PBS. New infection media containing TPCK trypsin was added to the flask. Cells were incubated at $37^{\circ} \mathrm{C} / 5 \% \mathrm{CO}_{2}$ for two days and virus was harvested on day 2 . Titers were determined as $\log _{10} \mathrm{TCID}_{50} / \mathrm{mL}$ using the Reed and Muench method. ${ }^{43}$

\section{Growth Kinetics}

Normal human bronchial epithelial (NHBE) cells (EpiAirway kit (AIR-100) MatTek Corp) were grown on 6.5-mm-diameter inserts and placed above $1 \mathrm{~mL}$ of growth medium (Dulbecco's Modified Eagle's Medium (DMEM) supplemented with epidermal growth factors, gentamicin $5 \mu \mathrm{g} / \mathrm{ml}$, Amphotericin B $0.25 \mu \mathrm{g} / \mathrm{ml}$, phenol red) in a 6-well tissue culture plate. The cells are grown such that the apical surfaces are exposed to air while the basal surfaces are exposed to the growth medium. NHBE cells were washed with sterile PBS to remove mucus secretions from the apical surface prior to infection. MOI was calculated by counting trypsinized cells using the Countess cell counter (Invitrogen catalog number C10227). Viruses were diluted accordingly to reach an MOI of 0.01 . Cells were then inoculated on the apical side with each virus dilution at $37^{\circ} \mathrm{C}$. After a 1-hour incubation, the inoculum was removed. Exogenous trypsin addition was unnecessary as NHBE cells secrete a protease similar to trypsin that allows for hemagglutinin cleavage. Progeny viruses released into the apical compartment of NHBE cells were harvested at 24, 48, and 72 hours post-infection by the addition and collection of $150 \mu \mathrm{l}$ of medium to the apical surface. The media was allowed to equilibrate for 30 min at $37^{\circ} \mathrm{C}$ before it was collected and stored at $-80^{\circ} \mathrm{C}$ for titration via $\mathrm{TCID}_{50}$ in MDCK cells. Titers were determined as $\log _{10}$ TCID $_{50} / \mathrm{mL}$ using the Reed and Muench method. ${ }^{43}$

Swine trachea explants were derived using previously described methods. ${ }^{44}$ Tracheal explants produced by punch biopsies were cultured in bronchial epithelial cell basal medium (BEBM) on transwell inserts (Corning, Tewksbury, MA, USA). Prior to infection, explants were washed four times with sterile PBS. Three explants were randomly selected for cell counting using the Countess cell counter (Invitrogen catalog number C10227) and averaged to calculate the MOI for each virus. Explants were then 
Table 2-1. Swine Viruses Used in Growth Kinetics Experiments.

\begin{tabular}{|c|c|}
\hline $\begin{array}{c}\text { Virus } \\
\end{array}$ & Accession Number \\
\hline A/swine/Illinois/A01047715/2010 & CY114668 \\
\hline A/swine/Illinois/10-001551-2/2009 & GU984402 \\
\hline A/swine/Illinois/21IL1207/2009 & SJCRH sequence \\
\hline A/swine/Illinois/35572/2009 & GU984390 \\
\hline A/swine/Illinois/A01049981/2011 & JX045997 \\
\hline A/swine/Indiana/30IN0428/2010 & SJCRH sequence \\
\hline A/swine/Iowa/21IA1207/2010 & SJCRH sequence \\
\hline A/swine/Iowa/44837-1/2009 & HQ424885 \\
\hline A/swine/Iowa/A01049128/2010 & JF833337 \\
\hline A/swine/Iowa/A01049980/2011 & JN863540 \\
\hline $\mathrm{A} /$ swine/Iowa/A01202854/2011 & JX092451 \\
\hline A/swine/Minnesota/130A/2009 & HQ840306 \\
\hline A/swine/Minnesota/25618/2011 & JN193422 \\
\hline A/swine/Minnesota/36MN1026/2011 & SJCRH sequence \\
\hline A/swine/Minnesota/36MN2142/2012 & SJCRH sequence \\
\hline A/swine/Minnesota/54354/2010 & HQ622586 \\
\hline $\mathrm{A} /$ swine/Minnesota/8762-2/2010 & GU984417 \\
\hline A/swine/Missouri/15534/2010 & HМ219624 \\
\hline A/swine/North Carolina/38/2009 & JQ638657 \\
\hline A/swine/North Carolina/A01049174/2010 & JF833344 \\
\hline A/swine/Oregon/A00700068/2011 & JN193425 \\
\hline A/swine/Texas/A01202511/2011 & JX092296 \\
\hline A/Tennessee/F2090/2011 & SJCRH sequence \\
\hline A/Tennessee/F3004/2010 & SJCRH sequence \\
\hline A/Tennessee/F3013/2012 & SJCRH sequence \\
\hline
\end{tabular}


incubated for 1 hour, in triplicate per virus, with an MOI of 0.01. Following the incubation period, explants were washed in triplicate with sterile PBS. At 24, 48, 72 hours post-infection (hpi), $300 \mu \mathrm{L}$ of infection media was added to the apical chamber of all trachea explants. The media was allowed to equilibrate for $30 \mathrm{~min}$ at $37^{\circ} \mathrm{C}$ before it was collected and stored at $-80^{\circ} \mathrm{C}$ for titration via $\mathrm{TCID}_{50}$ in MDCK cells. Titers were determined as $\log _{10} \mathrm{TCID}_{50} / \mathrm{mL}$ using the Reed and Muench method. ${ }^{43}$

\section{Virus Titration (TCID50)}

All of the growth kinetics time points collected previously were stored at $-80^{\circ} \mathrm{C}$ until viral $\mathrm{TCID}_{50}$ titers could be determined. All $\mathrm{TCID}_{50}$ titers were determined using MDCK cells by making 10-fold dilutions of each time point and infecting a single well of a 96 well plate with one dilution. Each time point was measured in quadruplicate using $0.5 \%(\mathrm{v} / \mathrm{v})$ turkey red blood cells in PBS. 


\section{CHAPTER 3. RESULTS}

\section{Swine Surveillance Overview}

In an effort to enhance our computational power, we utilized an existing swine surveillance program to increase the number of sequences from $\mathrm{H} 1 \mathrm{~N} 1 \mathrm{pdm} 09$ viruses in swine. The swab study conducted in collaboration with Lowe Consulting Ltd. sent 14,954 swabs to SJCRH for study over a one-year period. The epidemiologic aspects of this program have been previously published. ${ }^{45}$ From these nearly 15,000 swabs, 741 ( $\left.\sim 5.0 \%\right)$ tested positive for influenza $\mathrm{M}$ gene via rtPCR. Approximately 230 were sequenced and deposited into IRD and those that were H1N1pdm09 viruses were added to the dataset for this thesis. ${ }^{45}$

\section{Bayesian Phylogeny}

The primary purpose of our phylogenetic analysis was to identify regions of a combined tree that suggested interspecies transmission events where swine H1N1pdm09 viruses transmitted to humans and vice-versa. This was achieved by producing Bayesian phylogenies based on available human and swine sequences in public databases supplemented with additional swine virus sequences from our own surveillance. The phylogenies provided by BEAST gave us a unique perspective on the genetic diversity present in these influenza viruses. We were able to note several reverse zoonotic transmission events where the phylogenies strongly supported the likelihood that a human virus was re-introduced back into the swine population (Figures 3-1 through 3-4). Transmission events like these are a key component of producing potentially pandemic influenza viruses. Within the scope of this thesis, it appears that most reverse zoonotic events are transient, and the viruses do not become enzootic within swine. These data suggest that the human-adapted viruses have a reduced fitness for swine, consistent with our hypotheses. Similar findings have also previously been described. ${ }^{46}$ These transient events can be observed on the phylogenetic trees where a swine virus (green) appears with a red root node, signifying the original (ancestor) virus was from a human host. We identified approximately twenty reverse zoonotic events during our analyses of the HA gene. The majority of these events seem to be single human-to-swine transmission events that did not transmit to other swine. Of course, there is a chance that more transmission occurred than we are able to detect due to a lack of sensitivity of swine surveillance. Each reverse zoonotic event that we identified lasted only for one season/year and did not establish well enough to infect or transmit for longer periods. We were unable to find any phylogenetic evidence for swine-to-human (zoonotic) transmission.

Over time there was genetic drift in the 2009 A(H1N1)pdm09 pandemic virus genes as is to be expected for influenza viruses. Interestingly, this drift was limited in the first couple of years of the circulation of the virus with a marked increase from 2011 


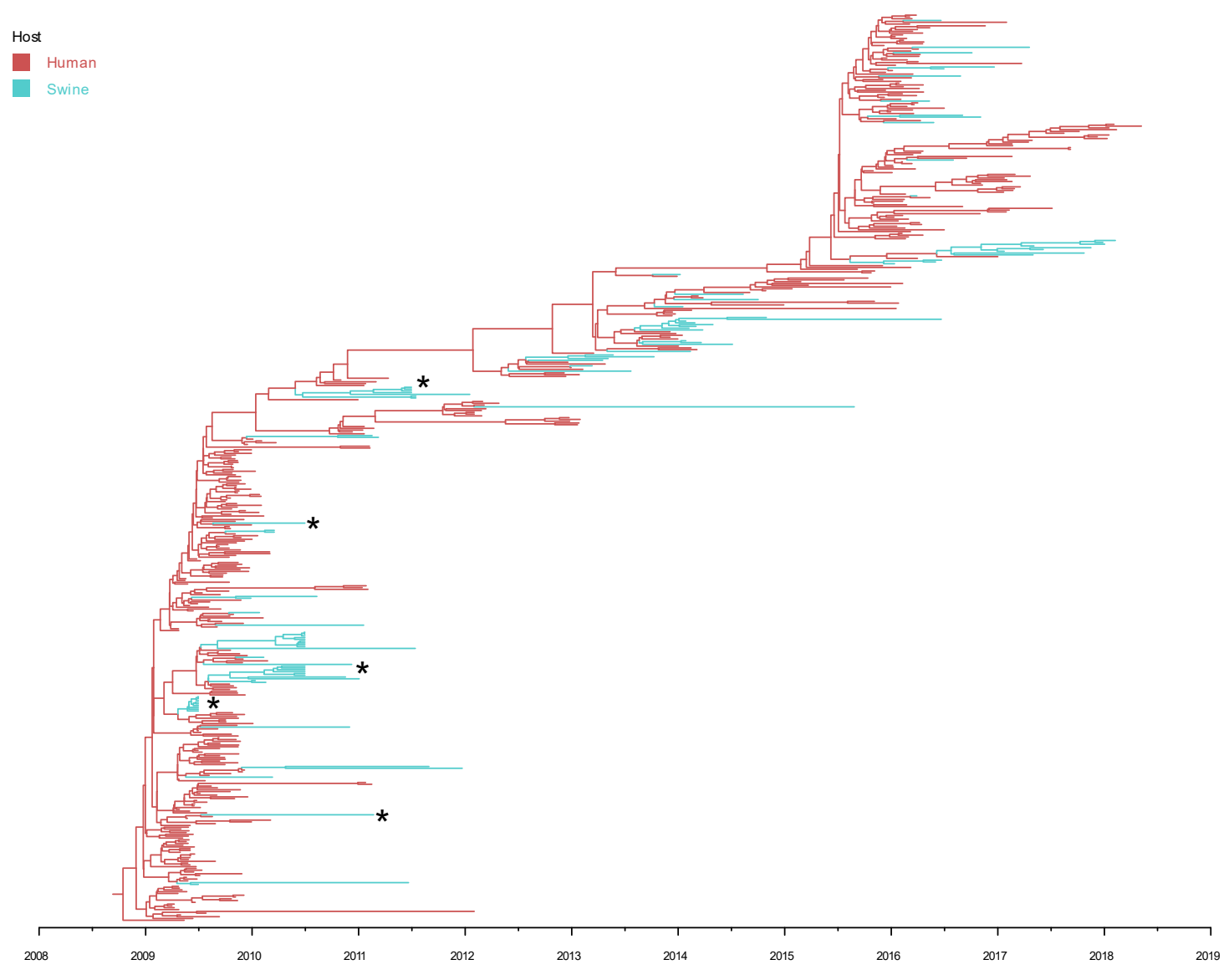

Figure 3-1. Phylogenetic BEAST Tree for HA.

Human sequences are colored in red and swine sequences are colored in green. Viruses used in growth characterization experiments are denoted with an asterisk (*). Diversity is present amongst both the swine and human sequences. There are several introduction events where humans introduce an influenza virus back into swine (reverse zoonosis). 


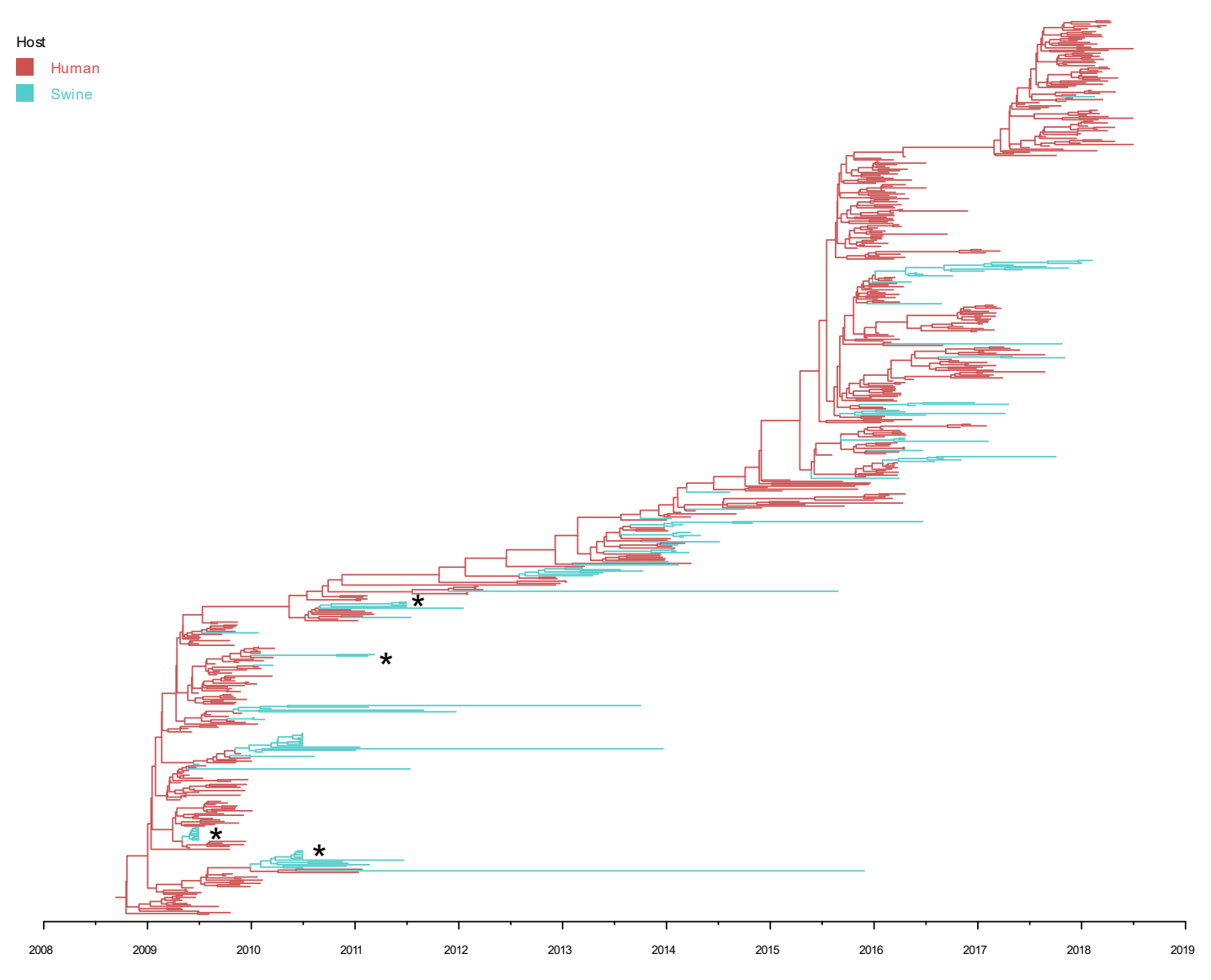

\section{Figure 3-2. Phylogenetic BEAST Tree for NA.}

Human sequences are colored in red and swine sequences are colored in green. Viruses used in growth characterization experiments are denoted with an asterisk $(*)$. Diversity is present amongst both the swine and human sequences. There are several introduction events where humans introduce an influenza virus back into swine (reverse zoonosis). 


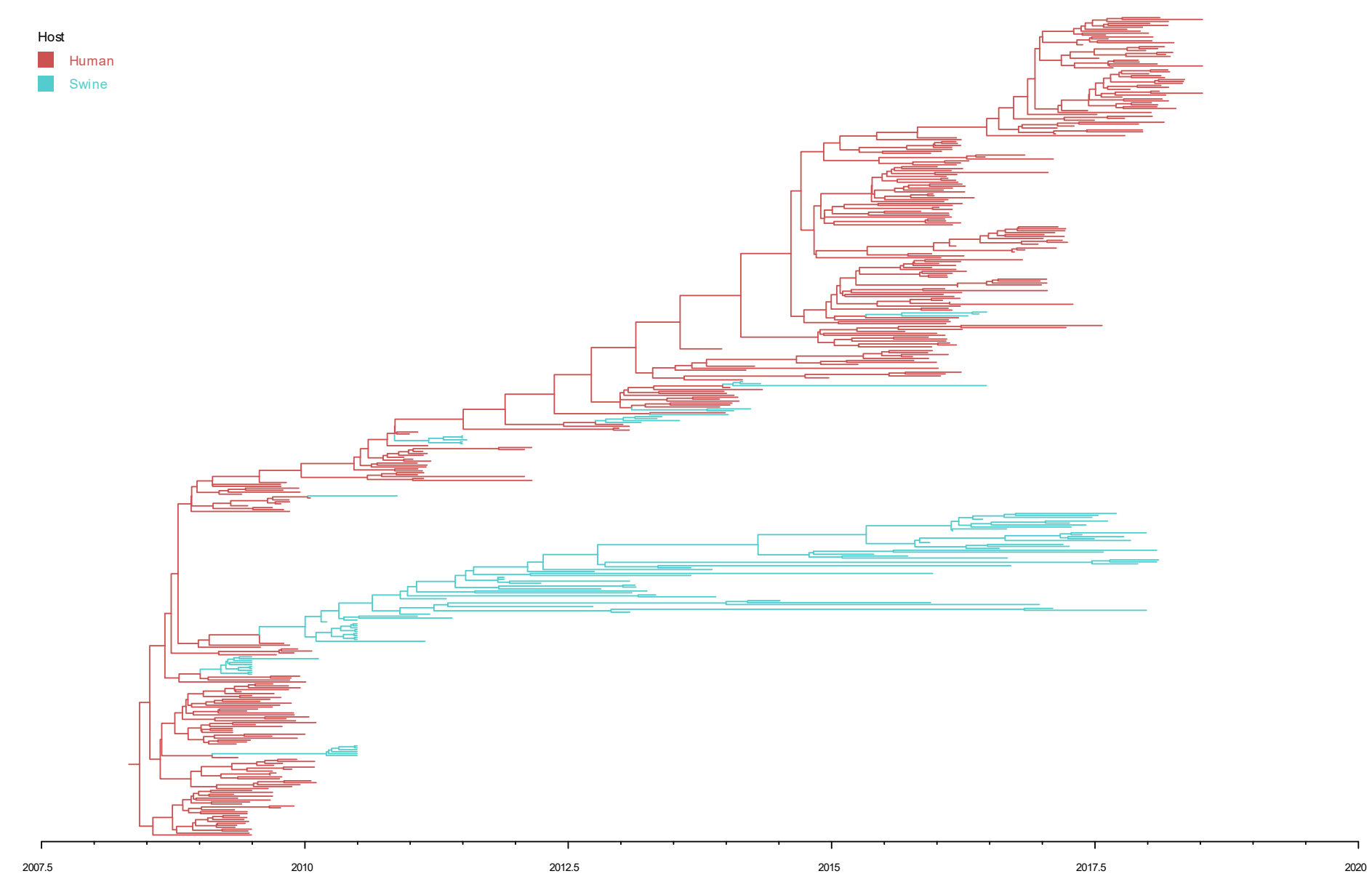

\section{Figure 3-3. Phylogenetic BEAST Tree for M.}

Human sequences are colored in red and swine sequences are colored in green. Diversity is present amongst both the swine and human sequences. There are several introduction events where humans introduce an influenza virus back into swine (reverse zoonosis). 


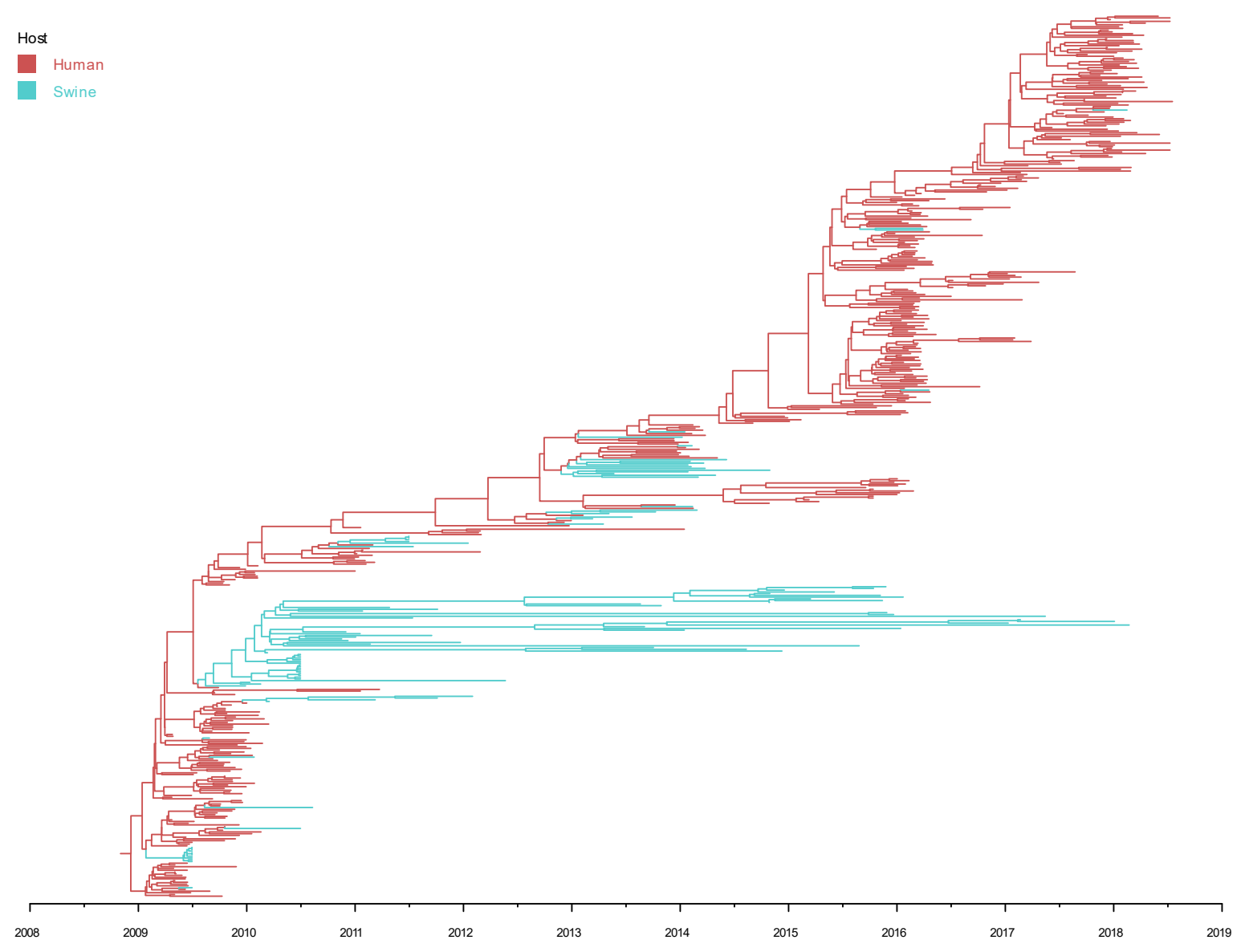

Figure 3-4. Phylogenetic BEAST Tree for NP.

Human sequences are colored in red and swine sequences are colored in green. Diversity is present amongst both the swine and human sequences. There are several introduction events where humans introduce an influenza virus back into swine (reverse zoonosis). 
onwards. Although speculation, it is probably that this was due to an accumulation of human population immunity to the virus with many naïve hosts available in the first two years (2009-2011). There were no obvious temporal differences in the number of reverse zoonoses events with human-to-swine transmission events apparent throughout the HA and NA trees.

\section{Growth Kinetics}

To test our hypothesis that there are identifiable phenotypic differences between human and swine H1N1pdm09 viruses, we initially selected three human and three swine pandemic viruses to test in cells of swine and human origin. The purpose of this was to determine if growth and transmission (albeit limited for swine) in swine or human populations influenced viral replication in cells from these respective hosts. The initial viruses chosen for growth kinetic experiments were essentially random based on easily obtainable viruses at SJCRH. The data from this first experiment is summarized in (Figure 3-5). Each virus was inoculated at a low MOI (0.01) onto NHBE cells present on Transwell inserts. While all six viruses were able to grow in the NHBE cells, we detected two different phenotypes. The human viruses grew to higher titers than the swine viruses (average human titer 7.39, average swine titer 5.37). Statistical analysis using the HolmSidak method $\mathrm{t}$ test ${ }^{47}$, with alpha $=0.05$ revealed statistically significant changes in $\mathrm{TCID}_{50}$ titer between the human and swine viruses ( $\mathrm{p}$ values listed in brackets below) [24hpi $\mathrm{p}<0.001,48$ and 72hpi $\mathrm{p}<0.01]$. The one exception was swine virus $\mathrm{A} / \mathrm{swine} / \mathrm{IL} / 21 \mathrm{IL} 1207 / 2009$ which also grew an average titer of 6.7 (similar to the human viruses tested) [24hpi $\mathrm{p}=0.053535$, 48hpi $\mathrm{p}=0.176644$, 72hpi $\mathrm{p}=0.259422$ ]. This initial experiment was the first indication that two distinct growth phenotypes might exist in the $2009 \mathrm{~A}(\mathrm{H} 1 \mathrm{~N} 1) \mathrm{pdm} 09$ viruses with swine-origin viruses replicating, in general, less well in human systems.

Based on the initial results in human cells, we next wanted to test the same six viruses in a swine cell model. A pig tracheal explant system was used. Each virus was again diluted to achieve a low MOI (0.01) and each explant was inoculated with one virus. The growth kinetics observed in the pig explants differed from the NHBE cells (Figure 3-6). All viruses (human and swine) grew to approximately equal titers (average human titer 5.96, average swine titer 6.26). Statistical analysis using the Holm-Sidak method $\mathrm{t}$ test ${ }^{47}$, with alpha $=0.05$ revealed no statistically significant difference between any swine virus and $\mathrm{A} / \mathrm{TN} / \mathrm{F} 2090 / 2011$.

After identifying the high and low growth phenotype in human cells we wanted to use our phylogenetic analyses to select an additional set of swine viruses to extend these observations. Going back to our BEAST trees (Figures 3-1 and 3-2) we selected another twenty swine viruses from throughout the HA tree to grow in NHBE cells. The selection of these viruses was chosen based on sequence similarity or dissimilarity to one of the initial three swine viruses (A/swine/IL/21IL1207/2009, A/swine/IN/30IN0428/2010, or $\mathrm{A} / \mathrm{swine} / \mathrm{MN} / 36 \mathrm{MN} 1026 / 2011)$. We were able to identify three more swine viruses with 


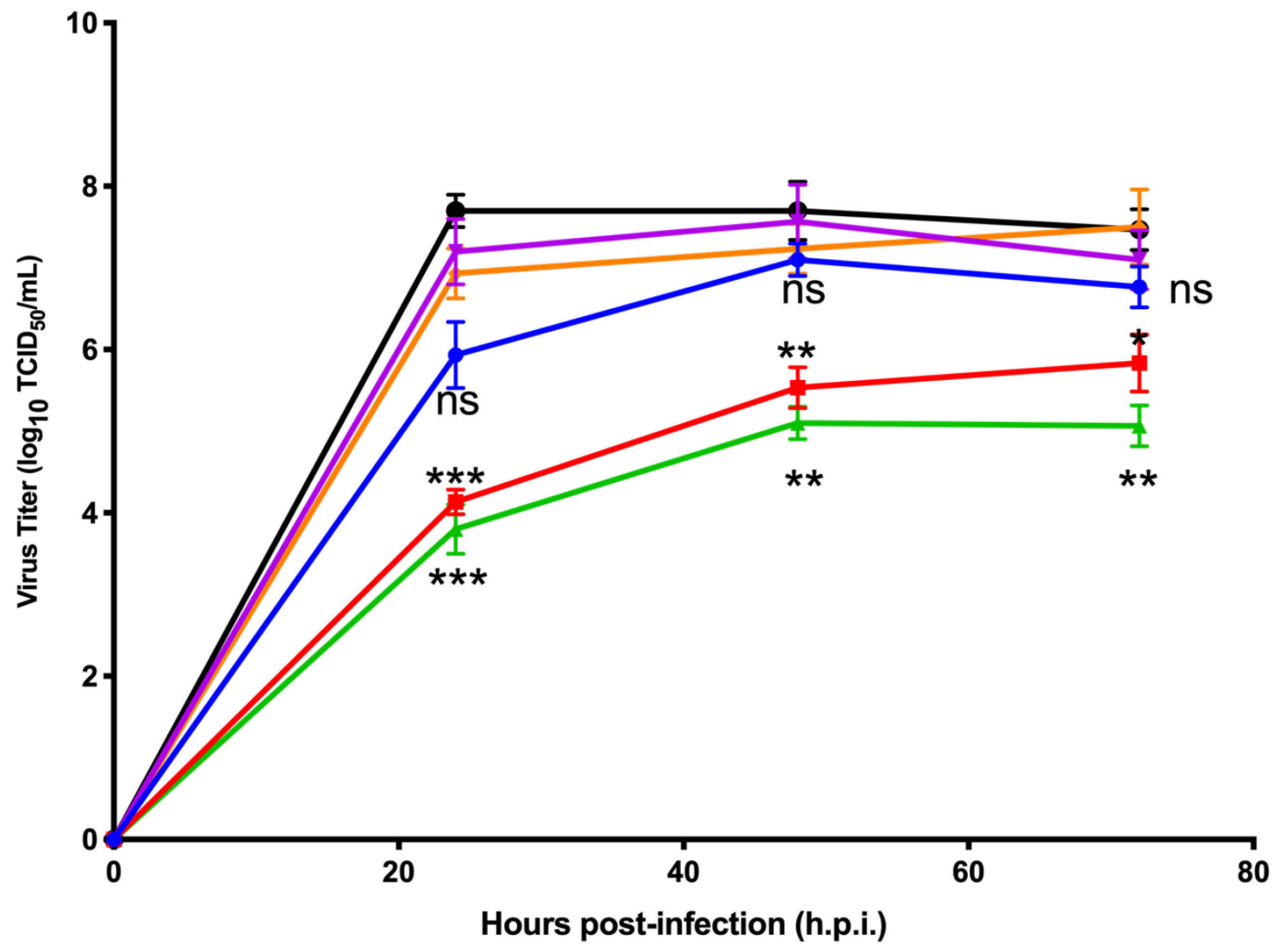

$\multimap$ A/swine/IL/21IL1207/2009

$=\mathrm{A} /$ swine/IN/30IN0428/2010

- A/swine/MN/36MN1026/2011

$\rightarrow$ ATN/F2090/2011

$\rightarrow$ A/TN/F3004/2010

- A/TN/F3013/2012

Figure 3-5. Initial NHBE Experiment.

MOI 0.01 at $37^{\circ} \mathrm{C}$ (* indicate significance as compared to A/TN/F2090/2011. Statistical significance determined using the HolmSidak method $t$ test ${ }^{47}$, with alpha $=0.05$.) 


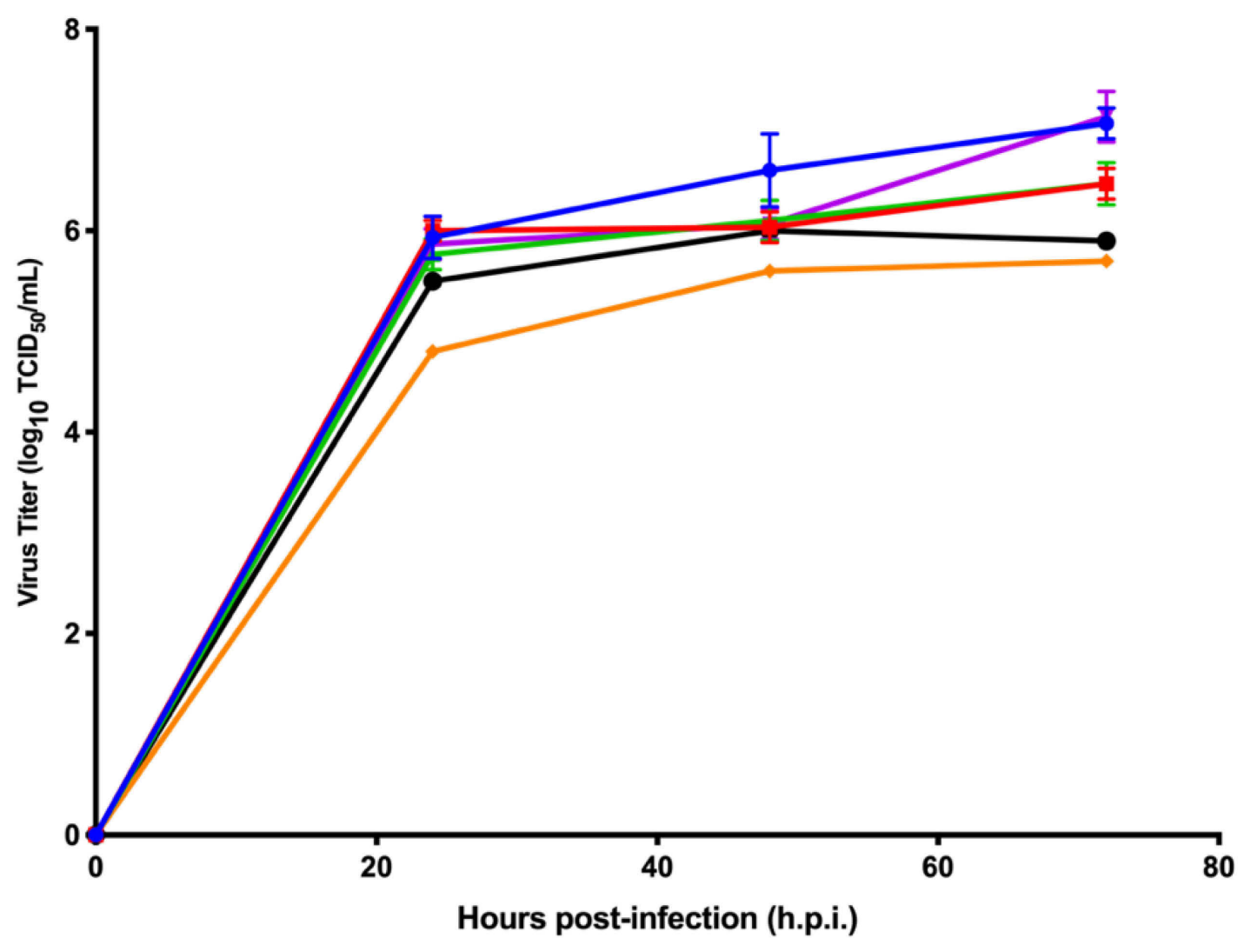

$\rightarrow$ A/swine/IL/21IL1207/2009

$\rightarrow$ A/swine/IN/30IN0428/2010

$\leftarrow$ A/swine/MN/36MN1026/2011

$\rightarrow$ ATTN/F2090/2011

$\rightarrow$ ATTN/F3004/2010

$\rightarrow$ A 1 TN/F3013/2012

\section{Figure 3-6. Pig Explant Growth Experiment.}

MOI 0.01 at $37^{\circ} \mathrm{C}$ (no significant differences detected as compared to A/TN/F2090/2011. Statistical significance determined using the Holm-Sidak method $\mathrm{t}$ test ${ }^{47}$, with alpha $=0.05$.) 
the high-growth phenotype and seventeen with the low-growth phenotype (Figure 3-7). Together these data provide support for a model where replication of a human-origin virus in swine leads to rapid adaptation for swine which comes at the expense of optimal fitness for the previous human host.

To further test our hypothesis of host adaptation leading to a lack of fitness for the previous host, we conducted an amino acid alignment of both the HA and NA proteins from a human pandemic virus (A/Tennessee/F2090/2011) and a swine pandemic virus (A/swine/Minnesota/36MN1026/2011) (selected based on growth phenotype in human cells). We were able to identify four changes in the HA protein and three changes in the NA protein that might be linked with host range and replicative fitness (Figures 3-8 and 3-9). The amino acid changes observed in HA were: N38D, N125S, H138Y, and R259K (Figure 3-8). The amino acid changes observed in NA were: S14N, S258T, and N368T (Figure 3-9). One of the lowest growing swine viruses that we tested was A/swine/Minnesota/36MN1026/2011. This particular virus possessed all seven of the changes listed above. A comparison of all studied viruses and their associated changes is included in Table 3-1. The presence and effect of these changes were explored further using a modified BEAST XML file.

Empirical trees can be calculated in BEAST by modifying the tree calculation parameters. Refer to Appendix $\mathbf{C}$ for relevant code modifications. Briefly, the code is altered to prevent overall tree calculation (as the tree has already been calculated previously). Instead code is added to allow BEAST to assign nodes based on presence or absence of certain characteristics, in our case, which amino acid was present at a specified location. We programmed BEAST with the amino acid residues and positions identified above. The empirical trees produced via this method gave us insight into how prevalent these changes are in human and swine. While each changed AA was noted a few times throughout the HA and NA trees, none established themselves in the population. It is important to note that all predicted "low growth" changes were only found in swine-origin viruses. It is thought this is due to the lack of fitness conferred by the presence of these mutations. Further, the only virus with all seven mutations is the A/swine/Minnesota/36MN1026/2011 virus. Figures included are as follows: HA N38D (Figure 3-10), N125S (Figure 3-11), H138Y (Figure 3-12), R259K (Figure 3-13), and all HA changes (Figure 3-14). NA S14N (Figure 3-15), S258T (Figure 3-16), N368T (Figure 3-17), and all NA changes (Figure 3-18).

The tanglegram (Figure 3-19) provides a linked view of all matching swine viruses from tree to tree. The green connecting lines indicate swine viruses present in all of the trees indicating where clusters of sequences group across multiple trees. This allows us to compare relative position and temporal placement of multiple sequences in one figure. 


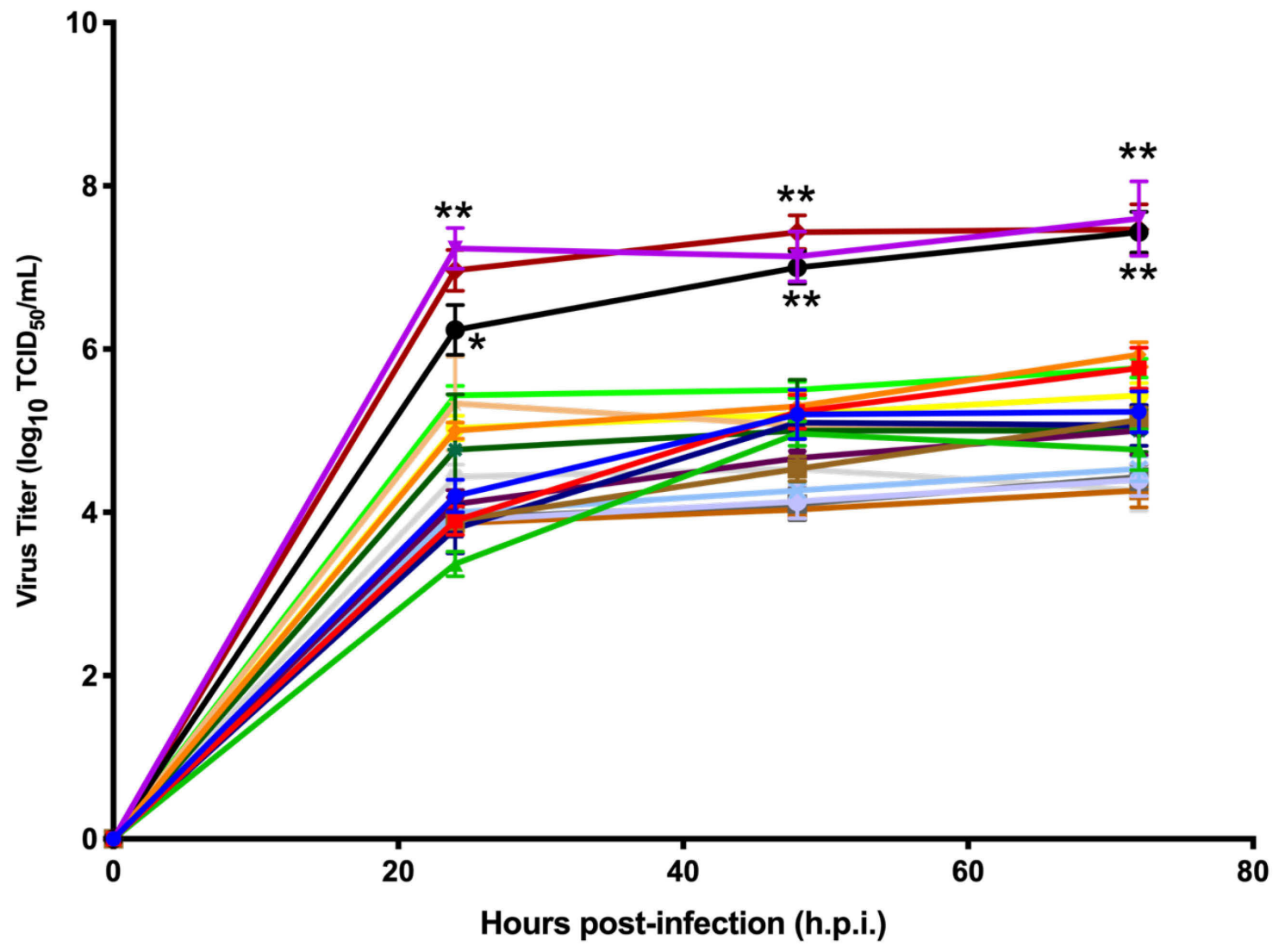

$\rightarrow$ A/swine/OR/A00700068/2011

$\rightarrow$ A/swine/IA/21IA1207/2010

$\leftarrow$ A/swine/lowa/A01049128/2010

$\rightarrow$ A/swine/MN/8762-2/2010

$\rightarrow$ A/swine/ldaho/14/2009

$\rightarrow$ A/swine/MO/15534/2010

- A/swine/Texas/A01202511/2011

- A/swine/MN/36MN2142/2012

$\rightarrow$ A/swine/MN/130A/2009

$\sim$ A/swine/lL/A01049981/2011

- A/swine/IA/35572/2009

- A/swine/NC/A01049174/2010

+ A/swine/lowa/A01049980/2011

$*$ A/swine/NC/38/2009

- A/swine/MN/25618/2011

- A/swine/lowa/44837-1/2009

- A/swine/MN/54354/2010

- A/swine/IL/10-001551-2/2009

- A/swine/IA/A01202854/2011

Figure 3-7. Follow-up NHBE Growth Experiment with Phylogenetically Chosen Viruses.

MOI 0.01 at $37^{\circ} \mathrm{C}$ (* indicate significance as compared to A/TN/F2090/2011. Statistical significance determined using the HolmSidak method $\mathrm{t}$ test ${ }^{47}$, with alpha $=0.05$.) Statistically significant swine viruses are shown in bold font and underlined. 
A/Tennessee/F2090/2011 DTLCIGYHANNSTDTVDTVLEKNVTVTHSVNLLEDKHNGKLCKLRGVAPLHLGKCN IAGWILGNPECESLSTAS 74

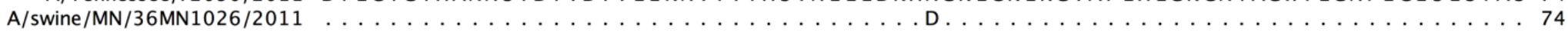
Consensus DTLCIGYHANNSTDTVDTVLEKNVTVTHSVNLLEDKHXGKLCKLRGVAPLHLGKCN IACWILGNPECESLSTAS

$$
80
$$

120

140

A/Tennessee/F2090/2011 SWSY I VETS S SDNGTCYPGDF IDYEELREQLSSVSSFERFE I FPKT S SWPNHDSNKGVTAACPHACAKSFYKNL 148

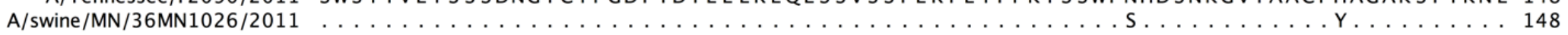
Consensus SWSYIVETS S SDNGTCYPGDF IDYEELREQLSSVSSFERFEI FPKTS SWPXHDSNKGVTAACPXAGAKSFYKNL 160 180 200

A/Tennessee/F2090/2011 IWLVKKGNSYPKLSKSYINDKGKEVLVLWG I HHPSTSADQQSLYQNADAYVFVGTSRYSKKFKPEIAIRPKVRD 222 Consensus IWLVKKGNSYPKLSKSY INDKGKEVLVLWG I HHPSTSADQQSLYQNADAYVFVGT SRYSKKFKPE IA IRPKVRD 240 260

\section{0}

A/Tennessee/F2090/2011 QEGRMNYYWT LVEPGDK ITFEATGNLVVPRYAFAMERNAGSG I I I SDTPVHNCNTTCQTPKGA INTSLPFQN IH 296

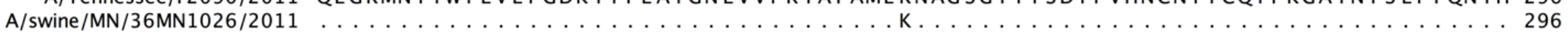
Consensus QEGRMNYYWT LVEPGDK I TFEATGN LVVPRYAFAMEXNAGSG I I I SDTPVHNCNTTCQTPKGA INTSLPFQN IH 300 320 340 360

A/Tennessee/F2090/2011 PITIGKCPKYVKSTKLRLATGLRNVPS IQSRGLFGA I AGF IEGGWTGMVDGWYGYHHQNEQGSGYAADLKSTQN 370 Consensus PITIGKCPKYVKSTKLRLATGLRNVPSIQSRGLFGA I AGF I ECGWTGMVDGWYGYHHQNEQGSGYAADLKSTQN 380 400 420

A/Tennessee/F2090/2011 A I DE ITNKVNSVI EKMNTQFTAVGKEFNHLEKR I ENLNKKVDDGF LDIWTYNAELLVLLENERTLDYHDSNVKN 444

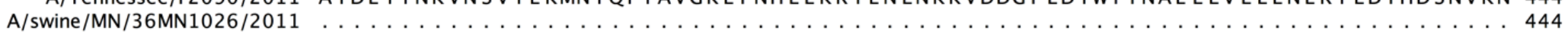
Consensus A I DE ITNKVNSVI EKMNTQFTAVGKEFNHLEKR I ENLNKKVDDGF LDIWTYNAELLVLLENERTLDYHDSNVKN 460 480 500

A/Tennessee/F2090/2011 LYEKVRSQLKNNAKE IGNGCFEFYHKCDNTCMESVKNGTYDYPKYSEEAKLNREEIDGVKLESTR IYQILAIYS 518 Consensus LYEKVR SQLKNNAKE I GNGCFEFYHKCDNTCME SVKNGTYDYPKYSEEAKLNREE IDGVKLESTRIYQILA IYS 520 540

A/Tennessee/F2090/2011 TVASSLVLVVSLGA I S FWMC SNGSLQCR ICI 549

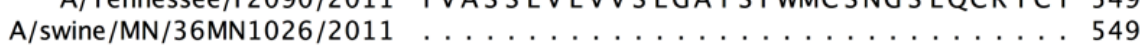
Consensus TVASSLVLVVSLGA I SFMCSNGSLQCR I C I

\section{Figure 3-8. HA Amino Acid Alignment.}

Hemagglutinin amino acid comparison between representative human and swine viruses. 
A/Tennessee/F2090/2011 SVKLAGNSSLCPVSGWA I YSKDNS IR I GSKGDVFVIREPF I SCSPLECRTFFLTQGALLNDKHSNGT I KDR SPY 74

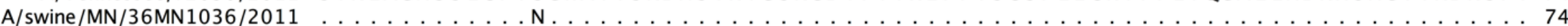

Consensus SVKLAGNSSLCPVXGWA I YSKDNS IR IGSKGDVFVIREPF I SCSPLECRTFFLTQGALLNDKHSNGT I KDRSPY 80 100 120

140

A/Tennessee/F2090/2011 RTLMSCP IGEVPSPYNSRFE SVAWSASACHDG INWLT IG I SGPDNGAVAVLKYNG I ITDT IKSWRNN I LRTQES 148 A/swine/MN/36MN1036/2011

Consensus RTLMSCP I GEVPSPYNSRFESVAWSASACHDG I NWLT I I SGPDNGAVAVLKYNG I ITDT I K SWRNN I LRTQES

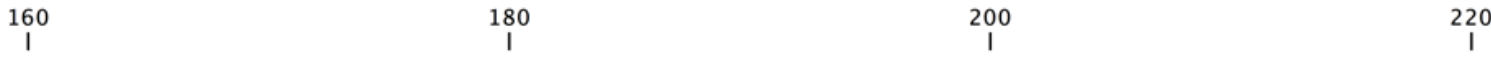

A/Tennessee/F2090/2011 ECACVNGSCFTVMTDGPSDGQASYKIFR I EKGK I VK SVEMNAPNYHYEECSCYPDS SE ITCVCRDNWHGSNRPW 222

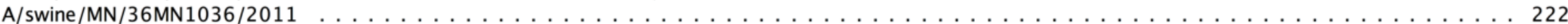

Consensus ECACVNGSCFTVMTDGPSDGQASYK I FR I EKGK IVKSVEMNAPNYHYEECSCYPDS SE ITCVCRDNWHGSNRPW

$$
240
$$

A/Tennessee/F2090/2011 VSFNQNLEYQIGYICSGIFGDNPRPNDKTGSCGPVS SNGANGVKGFSFKYGNGVWIGRTKSISSRNGFEMIWDP 296

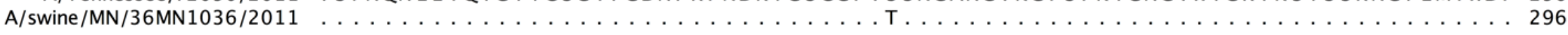
Consensus VSFNQNLEYQIGY ICSG I FGDNPRPNDKTGSCGPVXSNGANGVKGFSFKYGNGVWIGRTKS I SSRNGFEMIWDP
300
320
340
360

A/Tennessee/F2090/2011 NGWTGTDNNFS IKQDIVG INEWSGYSGSFVQHPELTGLDCIRPCFWVELIRGRPKENT IWTSGSS ISFCGVNSD 370

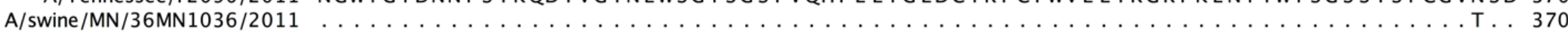
Consensus NGWTGTDNNFS I KQD IVG INEWSGYSGSFVQHPELTGLDCIRPCFWVELIRGRPKENT IWTSGSS I SFCGVXSD 380

A/Tennessee/F2090/2011 TVGWSWPDGAELPFT IDK 388

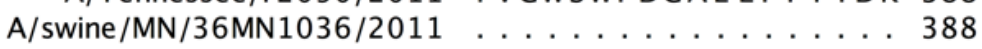

Consensus TVGWSWPDGAELPFTIDK

\section{Figure 3-9. NA Amino Acid Alignment.}

Neuraminidase amino acid comparison between representative human and swine viruses. 
Table 3-1. Amino Acid Residues Present in All Swine Viruses Tested.

\begin{tabular}{|c|c|c|c|c|c|c|c|c|}
\hline Virus & $\begin{array}{c}\text { Growth } \\
\text { Phenotype }\end{array}$ & $\begin{array}{c}\text { HA } \\
\text { Pos. } \\
\mathbf{3 8}\end{array}$ & $\begin{array}{c}\text { HA } \\
\text { Pos. } \\
125\end{array}$ & $\begin{array}{c}\text { HA } \\
\text { Pos. } \\
138\end{array}$ & $\begin{array}{l}\text { HA } \\
\text { Pos. } \\
259\end{array}$ & $\begin{array}{c}\text { NA } \\
\text { Pos. } \\
14\end{array}$ & $\begin{array}{l}\text { NA } \\
\text { Pos. } \\
258\end{array}$ & $\begin{array}{l}\text { NA } \\
\text { Pos. } \\
\mathbf{3 6 8}\end{array}$ \\
\hline A/swine/Illinois/A01047715/2010 & Low & $\mathrm{N}$ & $\mathrm{N}$ & $\mathrm{R}$ & $\mathrm{R}$ & $\mathrm{N}$ & $\mathrm{S}$ & $\mathrm{N}$ \\
\hline A/swine/Illinois/10-001551-2/2009 & Low & $\mathrm{N}$ & $\mathrm{S}$ & $\mathrm{H}$ & $\mathrm{R}$ & $\mathrm{S}$ & $\mathrm{T}$ & $\mathrm{N}$ \\
\hline A/swine/Illinois/21IL1207/2009 & High & $\mathrm{N}$ & $\mathrm{N}$ & $\mathrm{H}$ & $\mathrm{R}$ & $\mathrm{S}$ & $\mathrm{S}$ & $\mathrm{N}$ \\
\hline A/swine/Illinois/35572/2009 & Low & $\mathrm{D}$ & $\mathrm{N}$ & $\mathrm{H}$ & $\mathrm{R}$ & $\mathrm{N}$ & $\mathrm{S}$ & $\mathrm{N}$ \\
\hline A/swine/Illinois/A01049981/2011 & High & $\mathrm{N}$ & $\mathrm{N}$ & $\mathrm{H}$ & $\mathrm{R}$ & $\mathrm{S}$ & $\mathrm{S}$ & $\mathrm{N}$ \\
\hline A/swine/Indiana/30IN0428/2010 & Low & $\mathrm{N}$ & $\mathrm{N}$ & $\mathrm{Y}$ & $\mathrm{R}$ & $\mathrm{S}$ & $\mathrm{S}$ & $\mathrm{T}$ \\
\hline A/swine/Iowa/21IA1207/2010 & Low & $\mathrm{N}$ & $\mathrm{S}$ & $\mathrm{H}$ & $\mathrm{K}$ & $\mathrm{S}$ & $\mathrm{T}$ & $\mathrm{N}$ \\
\hline A/swine/Iowa/44837-1/2009 & Low & $\mathrm{N}$ & $\mathrm{N}$ & $\mathrm{H}$ & $\mathrm{R}$ & $\mathrm{S}$ & S & $\mathrm{N}$ \\
\hline A/swine/Iowa/A01049128/2010 & Low & $\mathrm{N}$ & $\mathrm{S}$ & $\mathrm{H}$ & $\mathrm{K}$ & $\mathrm{N}$ & $\mathrm{S}$ & $\mathrm{N}$ \\
\hline A/swine/Iowa/A01049980/2011 & Low & $\mathrm{D}$ & $\mathrm{N}$ & $\mathrm{H}$ & $\mathrm{R}$ & $\mathrm{S}$ & $\mathrm{T}$ & $\mathrm{N}$ \\
\hline A/swine/Iowa/A01202854/2011 & Low & $\mathrm{N}$ & $\mathrm{N}$ & $\mathrm{Y}$ & $\mathrm{K}$ & $\mathrm{S}$ & $\mathrm{S}$ & $\mathrm{T}$ \\
\hline A/swine/Minnesota/130A/2009 & Low & $\mathrm{N}$ & $\mathrm{S}$ & $\mathrm{H}$ & $\mathrm{R}$ & $\mathrm{N}$ & $\mathrm{S}$ & $\mathrm{T}$ \\
\hline A/swine/Minnesota/25618/2011 & Low & $\mathrm{N}$ & $\mathrm{S}$ & $\mathrm{Y}$ & $\mathrm{R}$ & $\mathrm{N}$ & S & $\mathrm{N}$ \\
\hline A/swine/Minnesota/36MN1026/2011 & Low & $\mathrm{D}$ & $\mathrm{S}$ & $\mathrm{Y}$ & $\mathrm{K}$ & $\mathrm{N}$ & $\mathrm{T}$ & $\mathrm{T}$ \\
\hline A/swine/Minnesota/36MN2142/2012 & Low & $\mathrm{D}$ & $\mathrm{S}$ & $\mathrm{H}$ & $\mathrm{K}$ & $\mathrm{S}$ & $\mathrm{T}$ & $\mathrm{N}$ \\
\hline A/swine/Minnesota/54354/2010 & Low & $\mathrm{N}$ & $\mathrm{S}$ & $\mathrm{H}$ & $\mathrm{K}$ & $\mathrm{N}$ & S & $\mathrm{N}$ \\
\hline A/swine/Minnesota/8762-2/2010 & High & $\mathrm{N}$ & $\mathrm{N}$ & $\mathrm{H}$ & $\mathrm{R}$ & $\mathrm{S}$ & S & $\mathrm{N}$ \\
\hline A/swine/Missouri/15534/2010 & High & $\mathrm{N}$ & $\mathrm{N}$ & $\mathrm{H}$ & $\mathrm{R}$ & $\mathrm{S}$ & S & $\mathrm{N}$ \\
\hline A/swine/North Carolina/38/2009 & Low & $\mathrm{D}$ & $\mathrm{N}$ & $\mathrm{H}$ & $\mathrm{R}$ & $\mathrm{S}$ & $\mathrm{S}$ & $\mathrm{N}$ \\
\hline A/swine/North Carolina/A01049174/2010 & Low & $\mathrm{N}$ & $\mathrm{N}$ & $\mathrm{Y}$ & $\mathrm{R}$ & $\mathrm{S}$ & $\mathrm{T}$ & $\mathrm{T}$ \\
\hline A/swine/Oregon/A00700068/2011 & Low & $\mathrm{N}$ & $\mathrm{S}$ & $\mathrm{H}$ & $\mathrm{K}$ & $\mathrm{N}$ & $\mathrm{S}$ & $\mathrm{N}$ \\
\hline A/swine/Texas/A01202511/2011 & Low & $\mathrm{D}$ & $\mathrm{N}$ & $\mathrm{H}$ & $\mathrm{K}$ & $\mathrm{S}$ & $\mathrm{T}$ & $\mathrm{N}$ \\
\hline
\end{tabular}




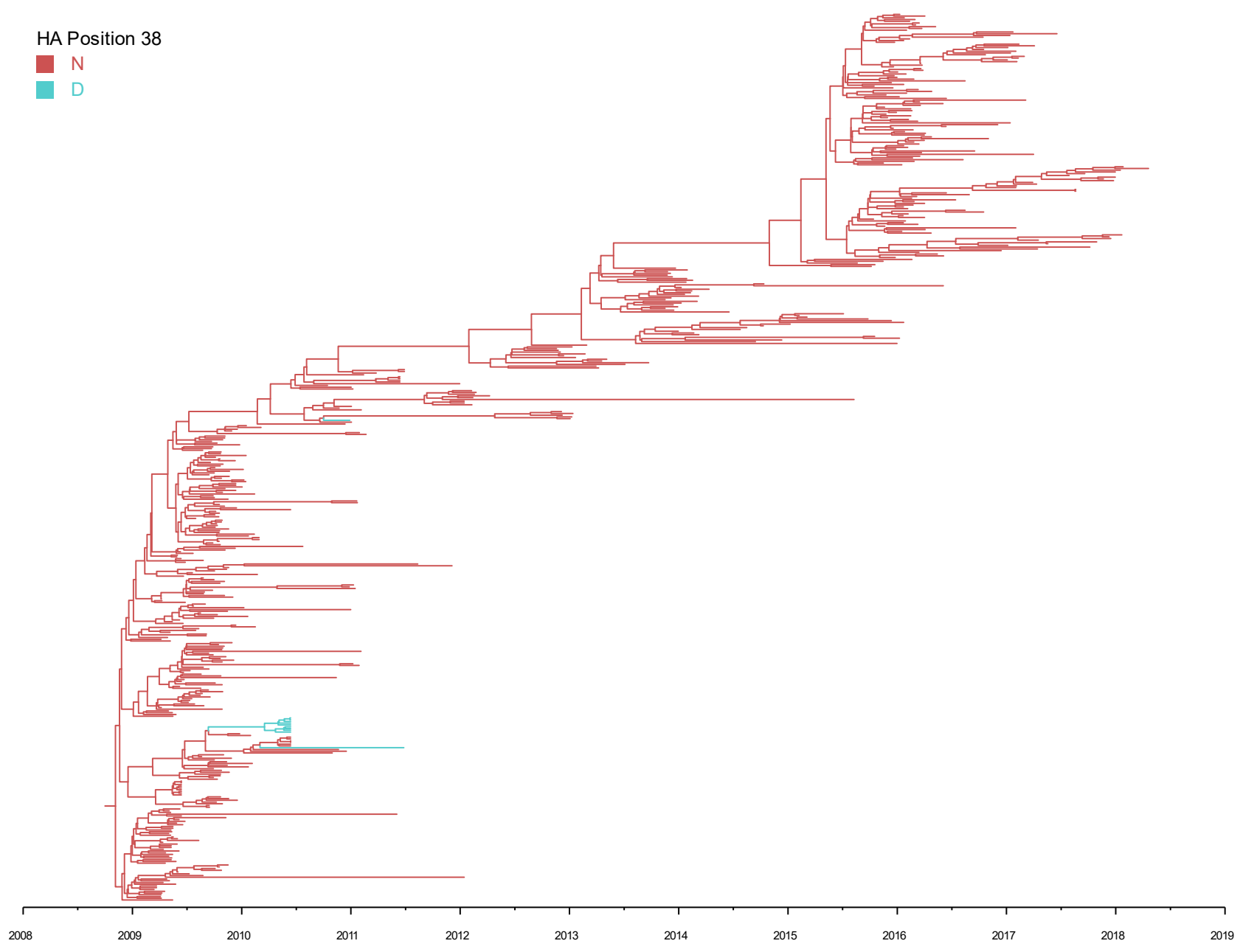

Figure 3-10. Empirical BEAST Tree for HA Position 38.

Annotated based on presence of amino acid at position 38. 38N is colored in red and 38D is colored in green. 


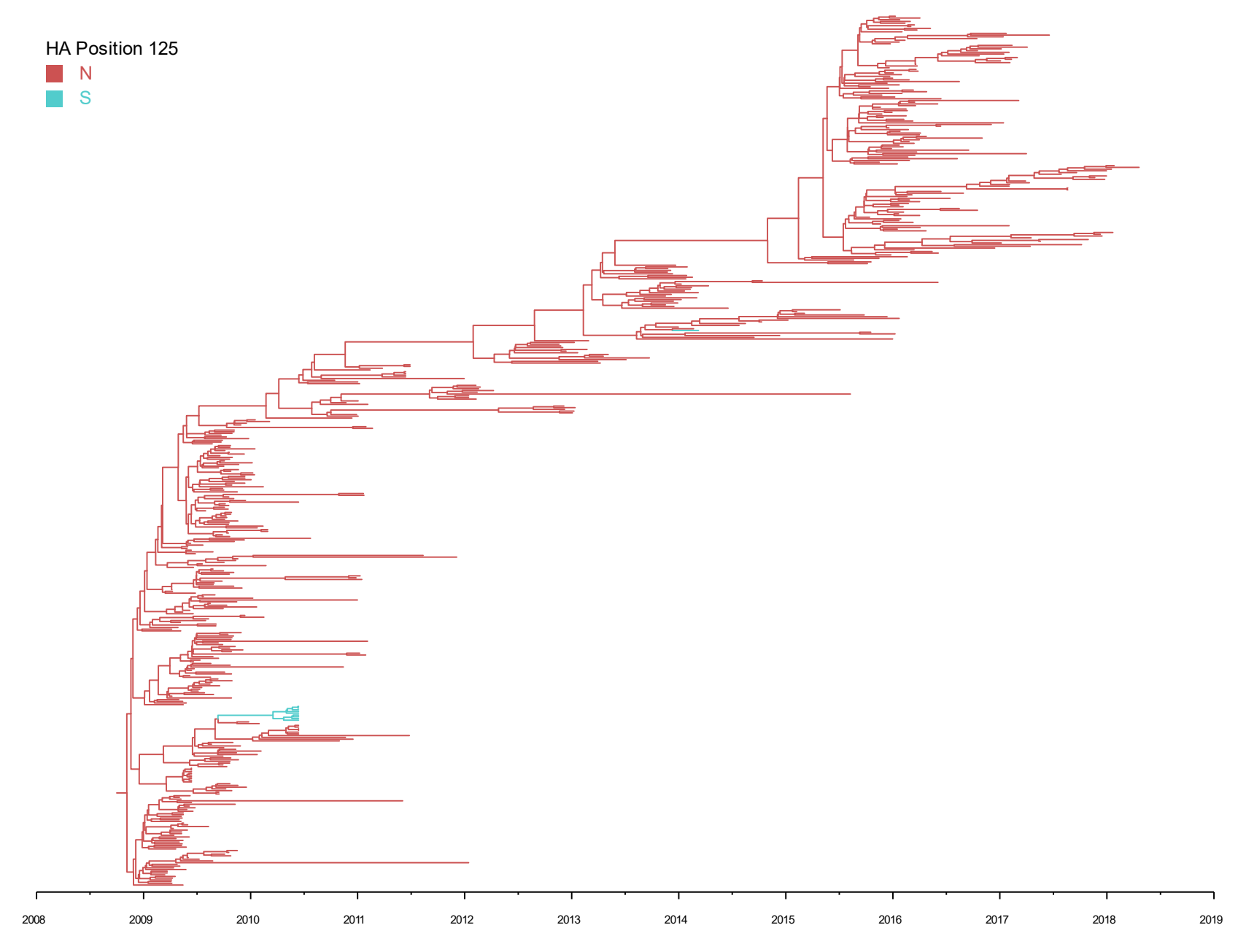

Figure 3-11. Empirical BEAST Tree for HA Position 125.

Annotated based on presence of amino acid at position $125.125 \mathrm{~N}$ is colored in red and $125 \mathrm{~S}$ is colored in green. 


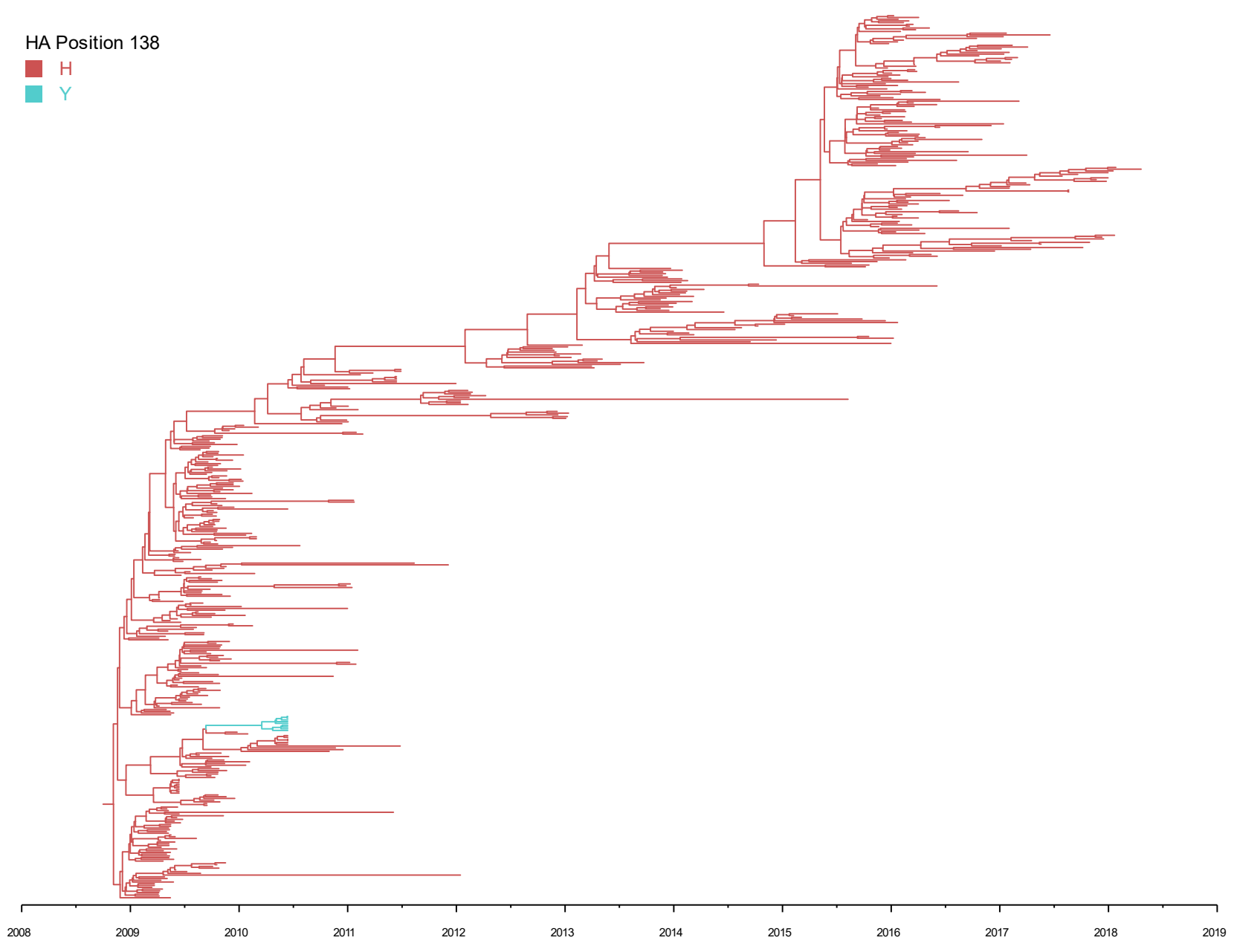

Figure 3-12. Empirical BEAST Tree for HA Position 138.

Annotated based on presence of amino acid at position $138.138 \mathrm{H}$ is colored in red and $138 \mathrm{Y}$ is colored in green. 


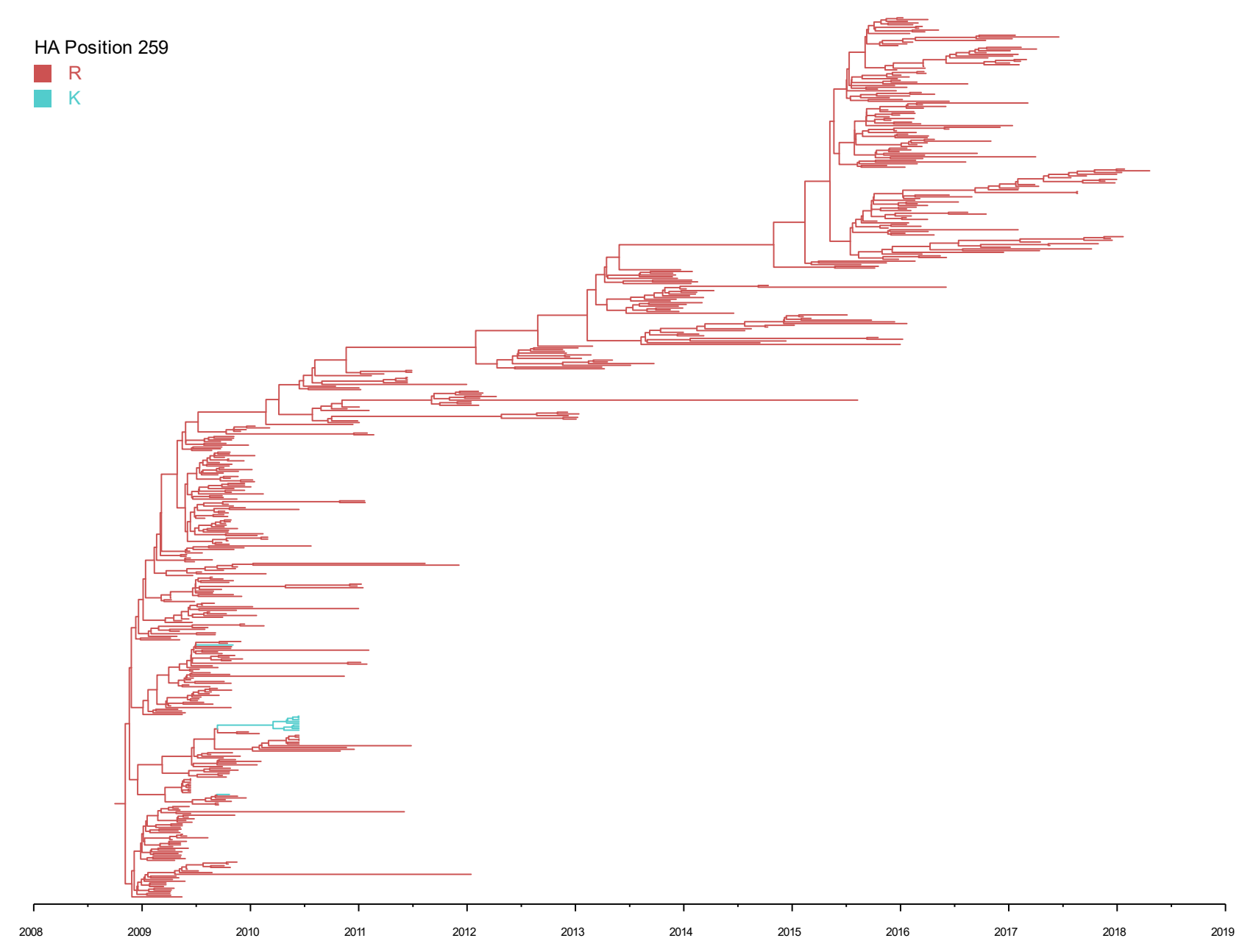

Figure 3-13. Empirical BEAST Tree for HA Position 259.

Annotated based on presence of amino acid at position 259. 259R is colored in red and 259K is colored in green. 


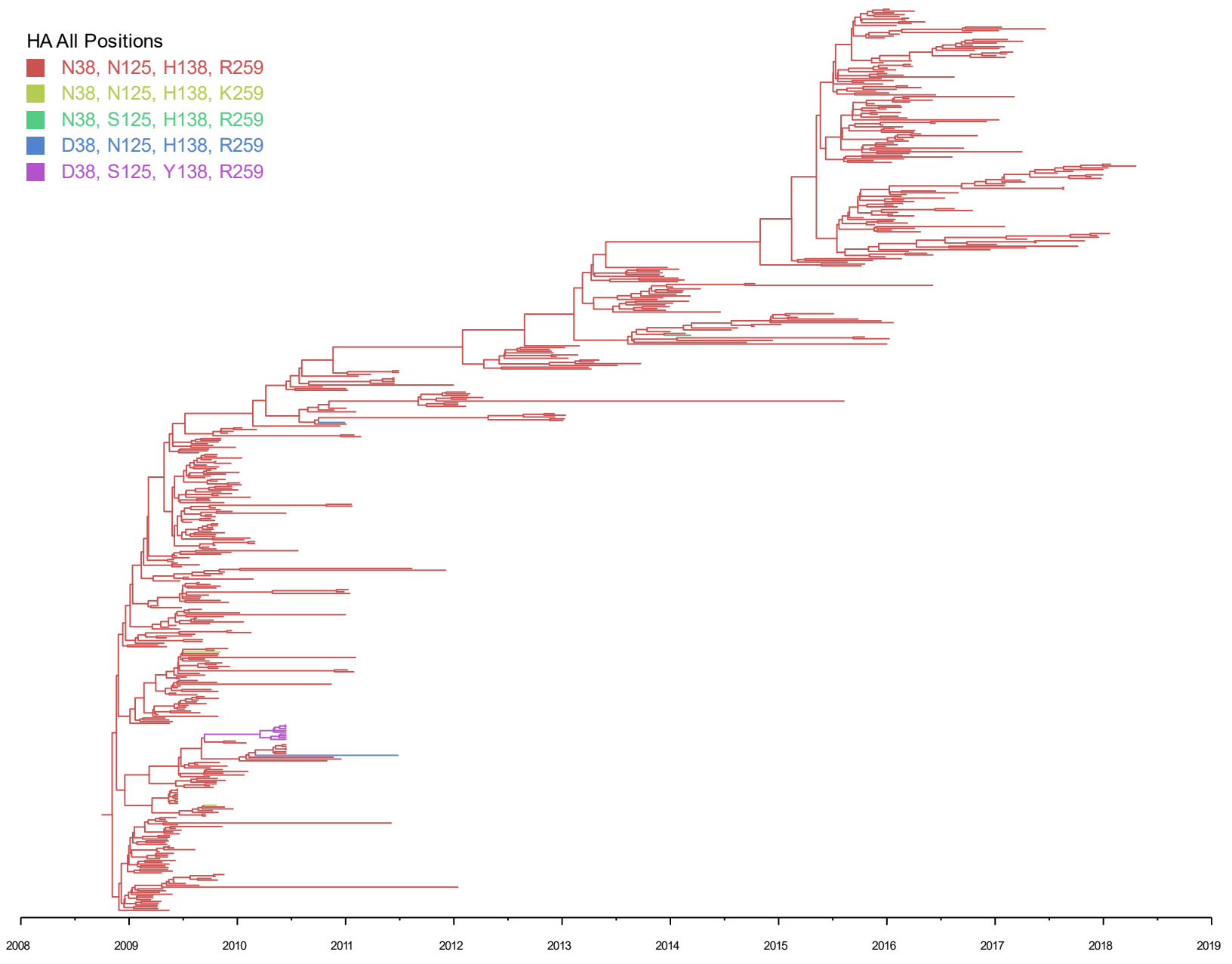

Figure 3-14. Empirical BEAST Tree for All HA Positions.

Annotated based on presence of amino acid at all identified positions. 


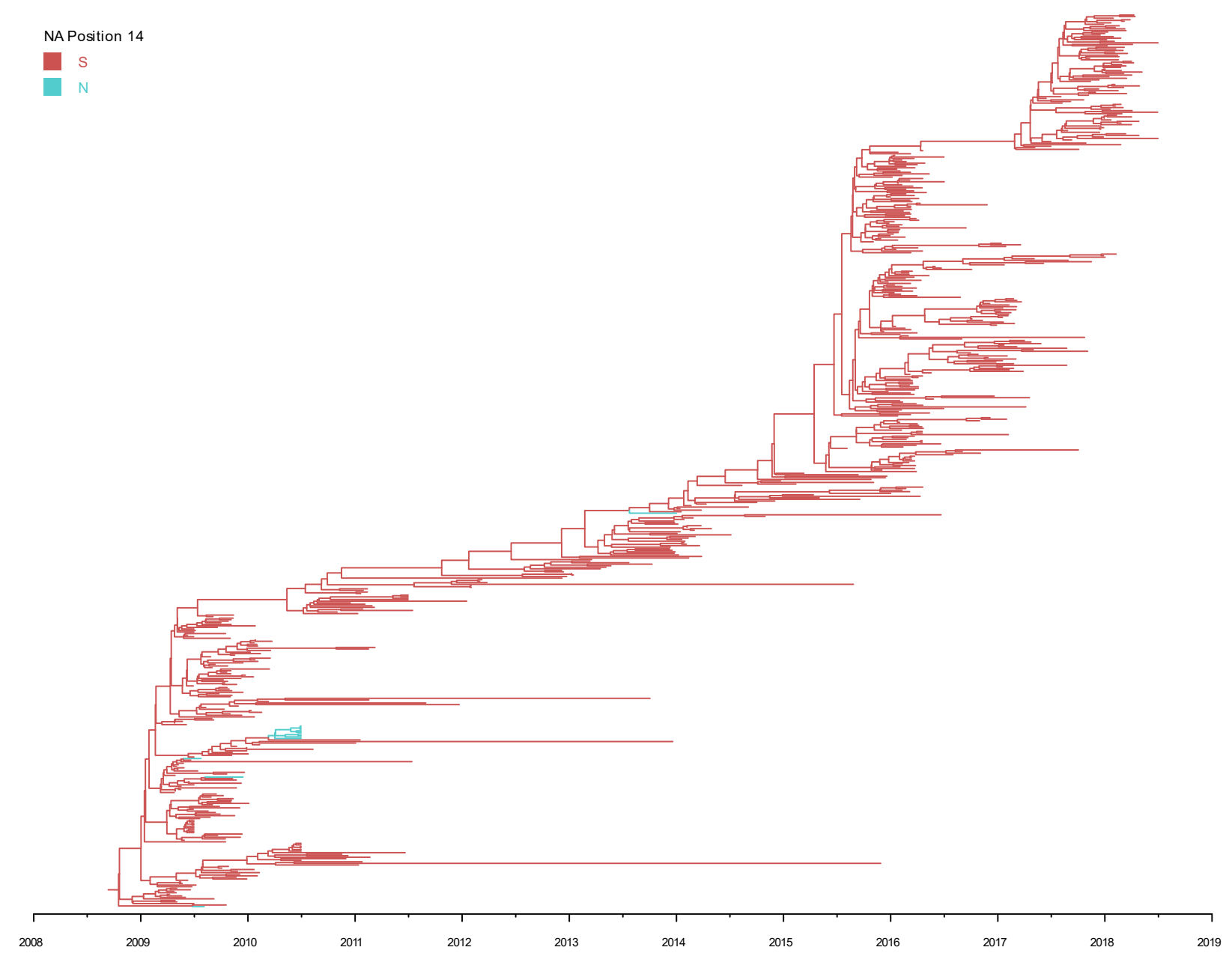

Figure 3-15. Empirical BEAST Tree for NA Position 14.

Annotated based on presence of amino acid at position 14. 14S is colored in red and $14 \mathrm{~N}$ is colored in green. 


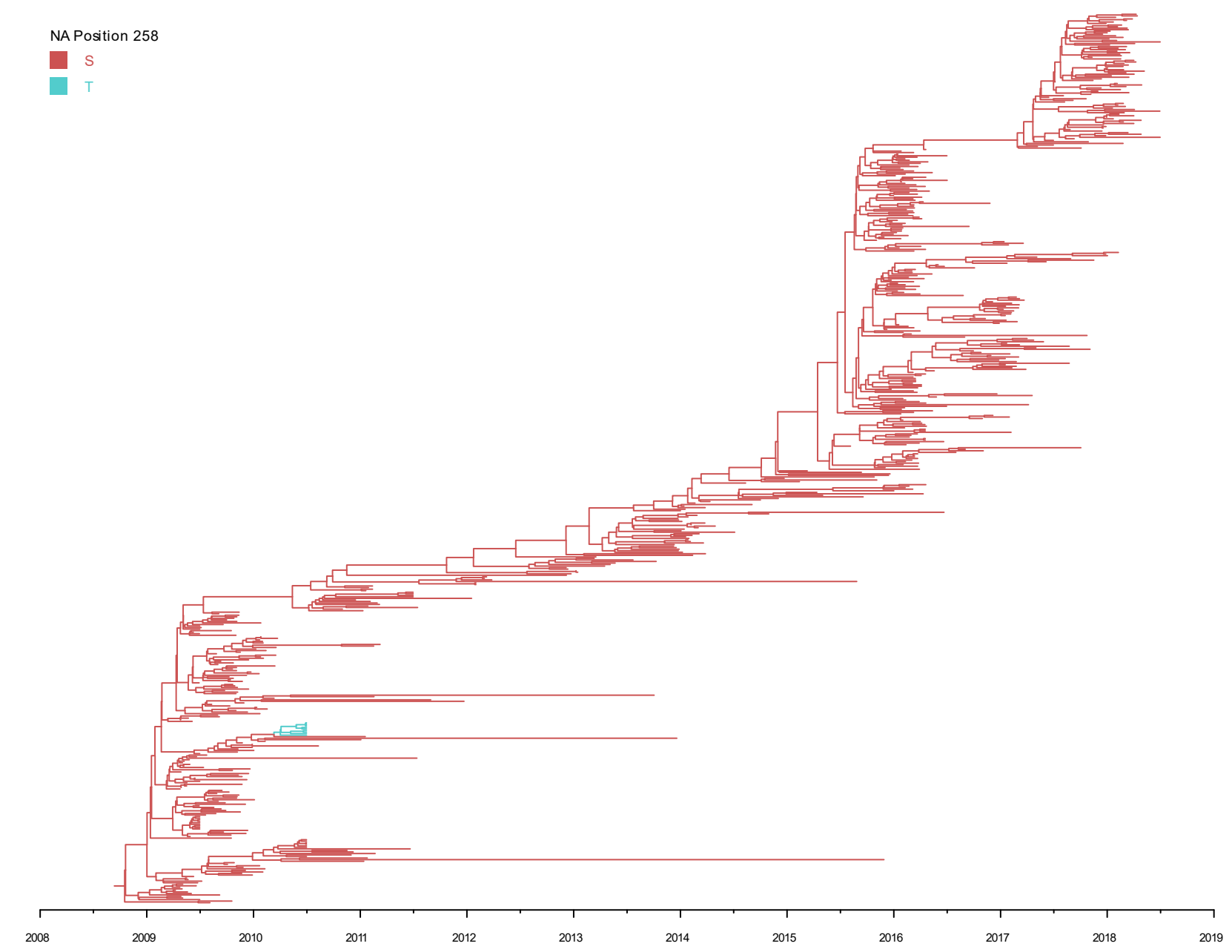

Figure 3-16. Empirical BEAST Tree for NA Position 258.

Annotated based on presence of amino acid at position 258. 258S is colored in red and 258T is colored in green. 


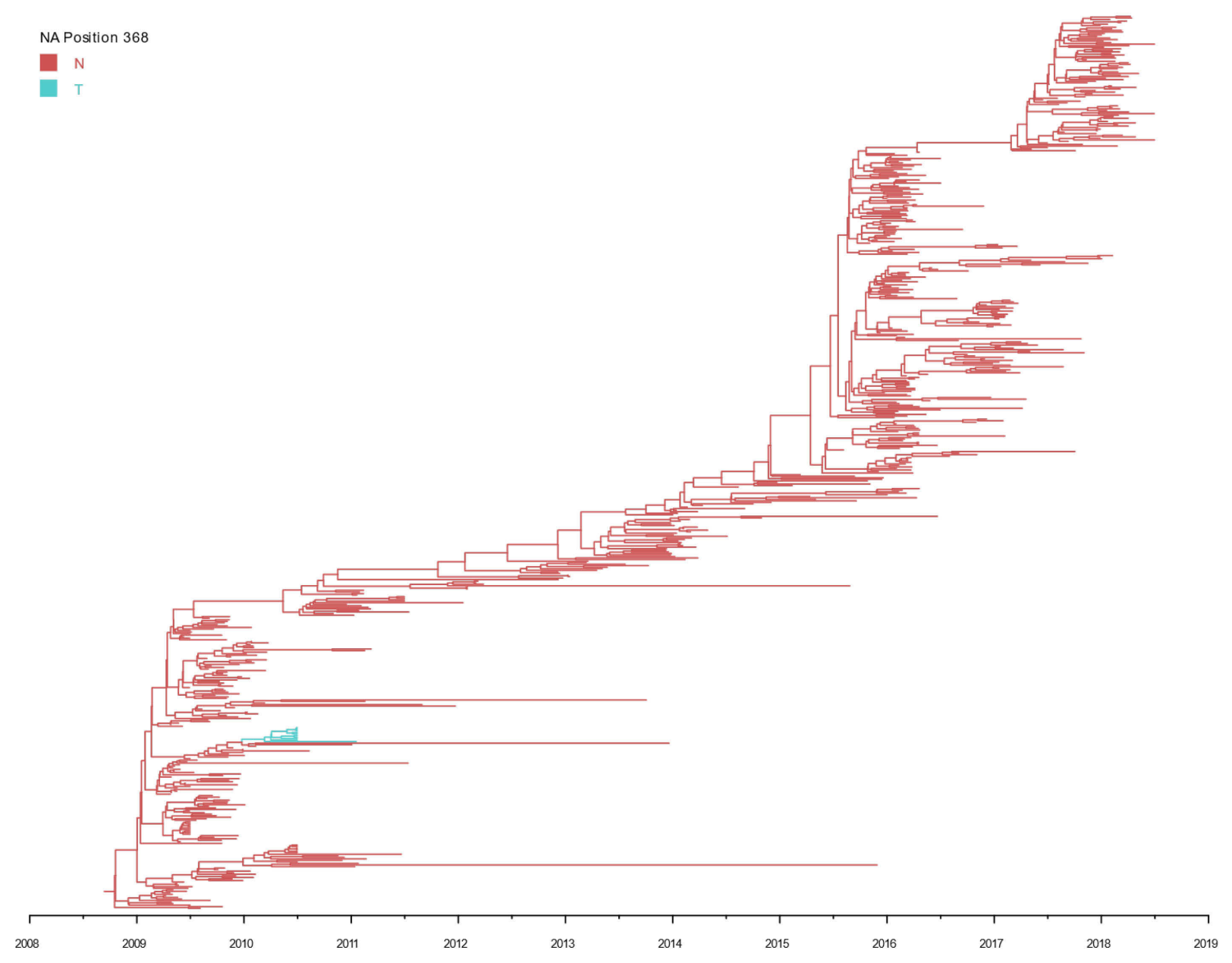

Figure 3-17. Empirical BEAST Tree for NA Position 368.

Annotated based on presence of amino acid at position $368.368 \mathrm{~N}$ is colored in red and $368 \mathrm{~T}$ is colored in green. 


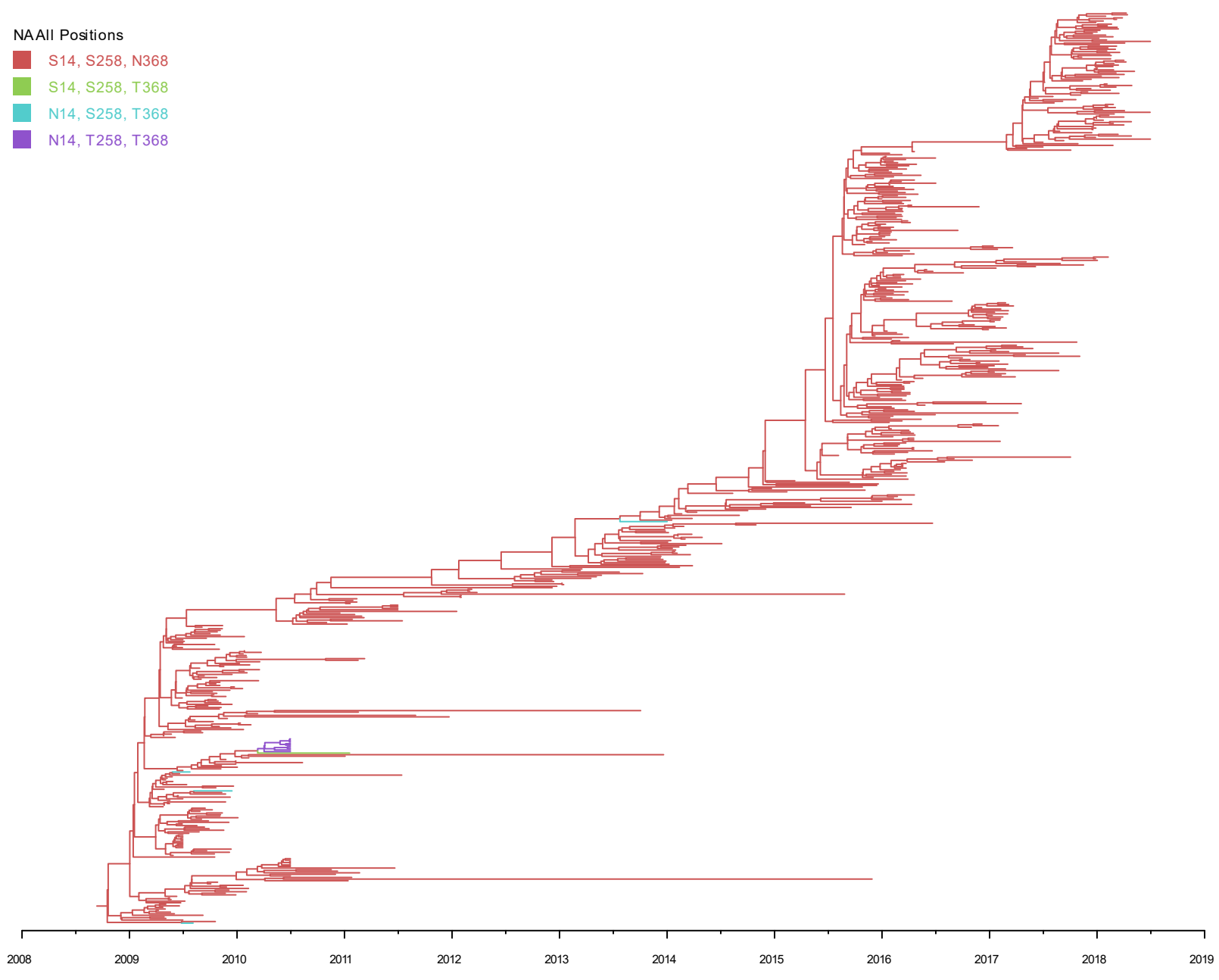

Figure 3-18. Empirical BEAST Tree for All NA Positions.

Annotated based on presence of amino acid at all identified positions. 


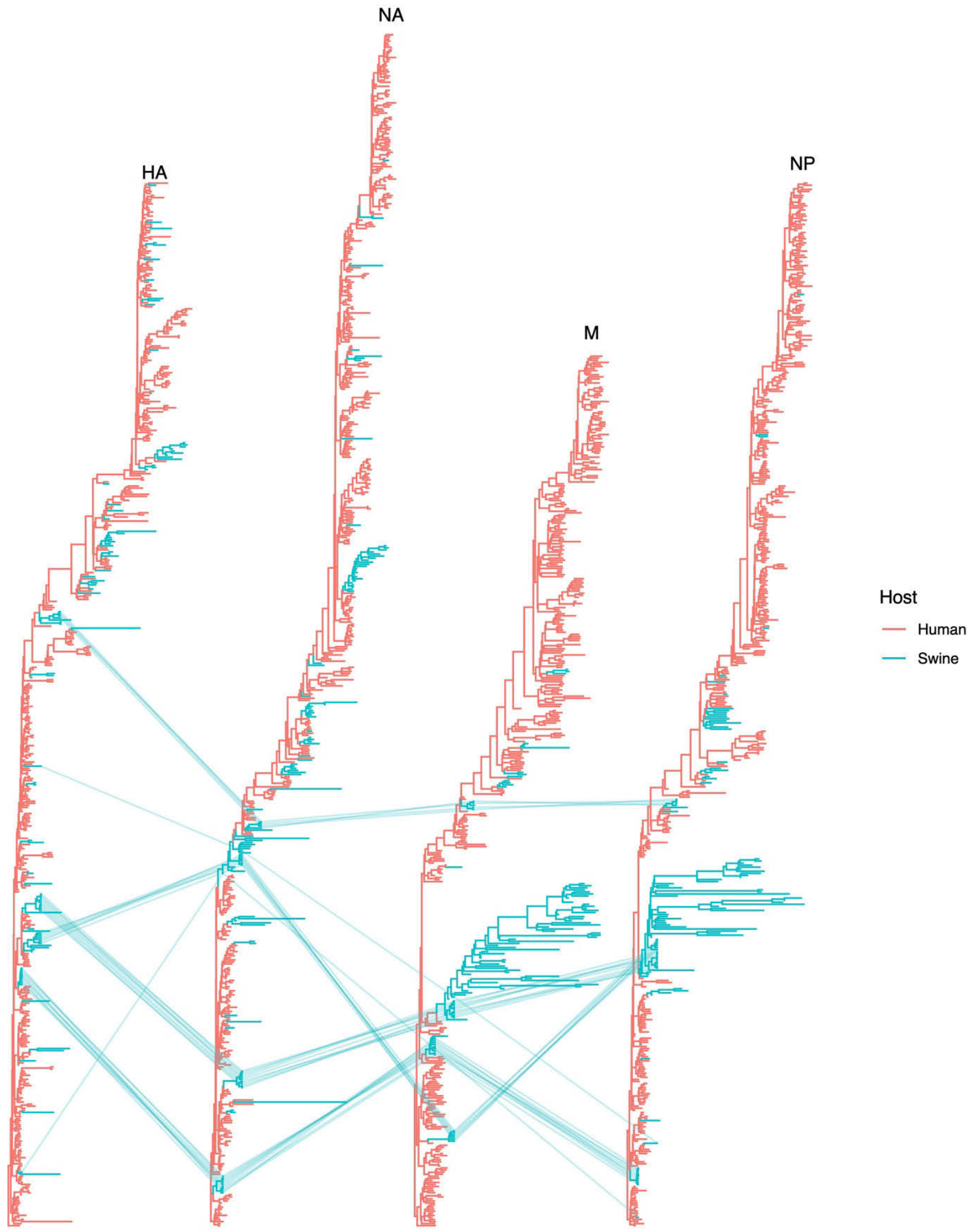

\section{Figure 3-19. HA, NA, M, NP Tanglegram.}

Produced via R. ${ }^{48}$ Connecting green lines (between trees) indicate where identical swine viruses sort across multiple gene segment phylogenies. 


\section{CHAPTER 4. DISCUSSION}

Although much work has already been done to elucidate the determinants of host range in influenza viruses, ${ }^{28-32}$ much of this work has been done in avian viruses. The number of identified host range markers that differentiate human and swine viruses is few which was a major scientific premise for this thesis. We identified seven specific changes in HA and NA differentiating human and swine influenza viruses. While $\mathrm{A} /$ swine/Minnesota/36MN1026/2011 was the only swine virus studied to possess all seven changes, there were several other swine viruses with many of the changes.

Table 4-1 compares the number of changes observed in all the swine viruses tested in this thesis. It is interesting to note that there is no clear pattern as to how many changes are needed to exhibit a low-growth phenotype. However, it does appear necessary to have all seven changes in order to exhibit a high-growth phenotype (at least within the scope of this thesis). I conducted a thorough search to determine if any of these changes occur in critical areas with known host-range properties. Based on my findings, none of these seven residues have been previously linked to receptor binding, host range specificity, or interspecies transmission. Although the exact effect of each change remains unknown, we do feel that they likely play some role in the fitness of these viruses based on the phylogenetic experiments and the growth experiments of this study. The fact that out of thousands of sequences, these specific changes were seen only a handful of times and exclusively present only in swine, indicates they are preferentially selected for after replication in swine and offer no fitness advantage in humans. While future studies are required to test the hypothesis, it is also possible that a subset of these mutations actually come at a fitness cost for replication in humans and are responsible for the poor growth of swine-adapted H1N1pdm09 viruses in human cells that we observed.

The phylogenetics provided by BEAST analysis revealed several reverse zoonosis transmission events where a human virus was introduced back into the swine population (Figures 3-1 through 3-4). The empirical BEAST trees give us a glimpse at the population-wide prevalence of these changes in both swine and human viruses. It is important to note that every "low-growth" change we noted in this thesis occurred in swine viruses only; all human viruses possessed the "high-growth" amino acid at that position. With the addition of the growth kinetics data, it appears that when these humanorigin viruses are re-introduced back into swine, they lose some replicative fitness for the previous host (human) (Figures 3-5 through 3-7). There are likely other genetic and AA changes associated with the growth differences we observed in this thesis. An overview of genome-wide changes can be found in Appendix A. This figure is designed to show the total number of nucleotide and amino acid changes on the top rows and the percent identity between the viruses on the bottom rows. The A/swine/MN/36MN1026/2011 virus has more nucleotide and amino acid changes than the other swine viruses. There is the possibility that more than just the changes in HA and NA are responsible for the replication differences we have identified in this thesis. More work must be done to completely elucidate the effect of every change observed in these viruses. It is also likely that many of these changes are stochastic in nature and do not have any bearing on growth phenotype. Because of the infidelity of the polymerase complex of influenza 
Table 4-1. Number of Either High- or Low-Growth Associated Changes in Swine Viruses Tested.

\begin{tabular}{cccc}
\hline Virus & $\begin{array}{c}\text { Growth } \\
\text { Phenotype }\end{array}$ & $\begin{array}{c}\text { Number of } \\
\text { High-Growth } \\
\text { AA }\end{array}$ & $\begin{array}{c}\text { Number of } \\
\text { Low-Growth } \\
\text { AA }\end{array}$ \\
\hline A/swine/Illinois/A01047715/2010 & Low & 5 & 2 \\
A/swine/Illinois/10-001551-2/2009 & Low & 5 & 2 \\
A/swine/Illinois/21IL1207/2009 & High & 7 & 0 \\
A/swine/Illinois/35572/2009 & Low & 5 & 2 \\
A/swine/Illinois/A01049981/2011 & High & 7 & 0 \\
A/swine/Indiana/30IN0428/2010 & Low & 5 & 2 \\
A/swine/Iowa/21IA1207/2010 & Low & 4 & 3 \\
A/swine/Iowa/44837-1/2009 & Low & 7 & 3 \\
A/swine/Iowa/A01049128/2010 & Low & 4 & 3 \\
A/swine/Iowa/A01049980/2011 & Low & 5 & 3 \\
A/swine/Iowa/A01202854/2011 & Low & 4 & 3 \\
A/swine/Minnesota/130A/2009 & Low & 4 & 3 \\
A/swine/Minnesota/25618/2011 & Low & 4 & 7 \\
A/swine/Minnesota/36MN1026/2011 & Low & 0 & 4 \\
A/swine/Minnesota/36MN2142/2012 & Low & 3 & 3 \\
A/swine/Minnesota/54354/2010 & Low & 4 & 0 \\
A/swine/Minnesota/8762-2/2010 & High & 7 & 0 \\
A/swine/Missouri/15534/2010 & High & 7 & 1 \\
A/swine/North Carolina/38/2009 & Low & 6 & 3 \\
A/swine/North Carolina/A01049174/2010 & Low & 4 & 3 \\
A/swine/Oregon/A00700068/2011 & Low & 4 & 3 \\
A/swine/Texas/A01202511/2011 & Low & 4 & \\
\hline
\end{tabular}


viruses, changes and mutations can arise that have little to no effect on the virus. Alternatively, the genetic diversity that the polymerase complex produces is a key mechanism by which influenza viruses can escape population immunity (antigenic drift mentioned in Chapter 1).

To further investigate the effect these changes pose for influenza viruses, we propose to utilize a reverse genetics ( $\mathrm{rg}$ ) system whereby each AA change can be added into a human-origin virus or a swine-origin virus. Once these rg viruses have been rescued and grown, further growth kinetics experiments should be performed to determine if any effect on growth phenotype is observed with each AA change. Initially, it will be easier to add all changes at once to either HA or NA and then repeat testing in NHBE cells. If growth phenotype differences are observed, further rg viruses could be generated with each individual change.

In conclusion, the seven amino acid changes identified in this thesis appear to have some effect on replication fitness in both human and swine hosts. More investigation needs to be done to elucidate the effect these changes have on virulence, transmission, and host range. Further, other genetic and AA changes present between the human and swine viruses might also play a role in host range determination and therefore should also be investigated.

"No amount of experimentation can prove me right; a single experiment can prove me wrong." - Albert Einstein 


\section{LIST OF REFERENCES}

1. Cheung, T.K. and L.L. Poon, Biology of influenza a virus. Ann N Y Acad Sci, 2007. 1102: p. 1-25.

2. $\quad$ Mehle, A., Unusual influenza A viruses in bats. Viruses, 2014. 6(9): p. 34383449.

3. Skehel, J.J. and D.C. Wiley, Receptor binding and membrane fusion in virus entry: the influenza hemagglutinin. Annu Rev Biochem, 2000. 69: p. 531-69.

4. Huang, X., et al., Effect of influenza virus matrix protein and viral RNA on ribonucleoprotein formation and nuclear export. Virology, 2001. 287(2): p. 40516.

5. Pinto, L.H., L.J. Holsinger, and R.A. Lamb, Influenza virus M2 protein has ion channel activity. Cell, 1992. 69(3): p. 517-28.

6. Gamblin, S.J. and J.J. Skehel, Influenza hemagglutinin and neuraminidase membrane glycoproteins. J Biol Chem, 2010. 285(37): p. 28403-9.

7. Mikulasova, A., E. Vareckova, and E. Fodor, Transcription and replication of the influenza a virus genome. Acta Virol, 2000. 44(5): p. 273-82.

8. Dutch, R.E., T.S. Jardetzky, and R.A. Lamb, Virus membrane fusion proteins: biological machines that undergo a metamorphosis. Biosci Rep, 2000. 20(6): p. 597-612.

9. Nayak, D.P., E.K. Hui, and S. Barman, Assembly and budding of influenza virus. Virus Res, 2004. 106(2): p. 147-65.

10. Webster, R.G., et al., Evolution and ecology of influenza A viruses. Microbiol Rev, 1992. 56(1): p. 152-79.

11. Hay, A.J., et al., The evolution of human influenza viruses. Philos Trans R Soc Lond B Biol Sci, 2001. 356(1416): p. 1861-70.

12. Wilson, I.A., J.J. Skehel, and D.C. Wiley, Structure of the haemagglutinin membrane glycoprotein of influenza virus at 3 A resolution. Nature, 1981. 289(5796): p. 366-73.

13. Garten, R.J., et al., Antigenic and genetic characteristics of swine-origin 2009 A(H1N1) influenza viruses circulating in humans. Science, 2009. 325(5937): p. 197-201.

14. Stevens, J., et al., Glycan microarray technologies: tools to survey host specificity of influenza viruses. Nature Reviews Microbiology, 2006. 4(11): p. 857-864.

15. Yen, H.-L., et al., Hemagglutinin-neuraminidase balance confers respiratorydroplet transmissibility of the pandemic H1N1 influenza virus in ferrets.

Proceedings of the National Academy of Sciences, 2011. 108: p. 14264-14269.

16. Yoon, S.-W., et al., Changes to the dynamic nature of hemagglutinin and the emergence of the 2009 pandemic H1N1 influenza virus. Scientific Reports, 2015. 5: p. 12828.

17. Centers for Disease Control and Prevention, N.C.f.I.a.R.D.N. Situation Update: Summary of Weekly FluView Report. 2019; Available from: https://www.cdc.gov/flu/weekly/summary.htm. 
18. Fiore, A.E., et al., Prevention and control of influenza: recommendations of the Advisory Committee on Immunization Practices (ACIP), 2008. MMWR Recomm Rep, 2008. 57(RR-7): p. 1-60.

19. Yen, H.L. and R.G. Webster, Pandemic influenza as a current threat. Curr Top Microbiol Immunol, 2009. 333: p. 3-24.

20. Ferguson, N.M., et al., Strategies for mitigating an influenza pandemic. Nature, 2006. 442(7101): p. 448-52.

21. Webby, R.J. and R.G. Webster, Are we ready for pandemic influenza? Science, 2003. 302(5650): p. 1519-22.

22. Longini, I.M., Jr., et al., Containing pandemic influenza at the source. Science, 2005. 309(5737): p. 1083-7.

23. Reid, A.H., et al., Origin and evolution of the 1918 "Spanish" influenza virus hemagglutinin gene. Proc Natl Acad Sci U S A, 1999. 96(4): p. 1651-6.

24. Johnson, N.P. and J. Mueller, Updating the accounts: global mortality of the 1918-1920 "Spanish" influenza pandemic. Bull Hist Med, 2002. 76(1): p. 105-15.

25. Neumann, G., T. Noda, and Y. Kawaoka, Emergence and pandemic potential of swine-origin H1N1 influenza virus. Nature, 2009. 459(7249): p. 931-9.

26. Nelson, M.I., et al., Global transmission of influenza viruses from humans to swine. J Gen Virol, 2012.93(Pt 10): p. 2195-203.

27. Kitikoon, P., et al., Pathogenicity and transmission in pigs of the novel $A(H 3 N 2) v$ influenza virus isolated from humans and characterization of swine H3N2 viruses isolated in 2010-2011. J Virol, 2012. 86(12): p. 6804-14.

28. Cauldwell, A.V., et al., Viral determinants of influenza A virus host range. Journal of General Virology, 2014. 95(6): p. 1193-1210.

29. Almond, J.W., A single gene determines the host range of influenza virus. Nature, 1977. 270(5638): p. 617-618.

30. Chen, G.W., et al., Genomic signatures of human versus avian influenza A viruses. Emerg Infect Dis, 2006. 12(9): p. 1353-60.

31. van Riel, D., et al., Seasonal and pandemic human influenza viruses attach better to human upper respiratory tract epithelium than avian influenza viruses. Am J Pathol, 2010. 176(4): p. 1614-8.

32. Bussey, K.A., et al., PA residues in the $2009 \mathrm{H} 1 \mathrm{N1}$ pandemic influenza virus enhance avian influenza virus polymerase activity in mammalian cells. J Virol, 2011. 85(14): p. 7020-8.

33. Taubenberger, J.K., et al., Characterization of the 1918 influenza virus polymerase genes. Nature, 2005. 437(7060): p. 889-93.

34. Swine influenza A (H1N1) infection in two children--Southern California, MarchApril 2009. MMWR Morb Mortal Wkly Rep, 2009. 58(15): p. 400-2.

35. Dawood, F.S., et al., Emergence of a novel swine-origin influenza A (H1N1) virus in humans. N Engl J Med, 2009. 360(25): p. 2605-15.

36. Khandaker, I., et al., Molecular evolution of the hemagglutinin and neuraminidase genes of pandemic (H1N1) 2009 influenza viruses in Sendai, Japan, during 2009-2011. Virus Genes, 2013.

37. Smith, G.J., et al., Origins and evolutionary genomics of the 2009 swine-origin H1N1 influenza A epidemic. Nature, 2009. 459(7250): p. 1122-5. 
38. Suchard, M.A., et al., Bayesian phylogenetic and phylodynamic data integration using BEAST 1.10. Virus Evolution, 2018. 4(1).

39. Edgar, R.C., MUSCLE: multiple sequence alignment with high accuracy and high throughput. Nucleic Acids Res, 2004. 32(5): p. 1792-7.

40. Drummond, A.J., et al., Relaxed Phylogenetics and Dating with Confidence. PLOS Biology, 2006. 4(5): p. e88.

41. Drummond, A.J., et al., Estimating mutation parameters, population history and genealogy simultaneously from temporally spaced sequence data. Genetics, 2002. 161(3): p. 1307-20.

42. Minin, V.N., E.W. Bloomquist, and M.A. Suchard, Smooth skyride through a rough skyline: Bayesian coalescent-based inference of population dynamics. Mol Biol Evol, 2008. 25(7): p. 1459-71.

43. Reed, L.J. and H. Muench, A SIMPLE METHOD OF ESTIMATING FIFTY PER CENT ENDPOINTS12. American Journal of Epidemiology, 1938. 27(3): p. 493497.

44. Jones, J.C., et al., Human H7N9 influenza A viruses replicate in swine respiratory tissue explants. Journal of virology, 2013. 87(22): p. 12496-12498.

45. Kaplan, B.S., et al., Influenza Virus Surveillance in Coordinated Swine Production Systems, United States. Emerg Infect Dis, 2015. 21(10): p. 1834-6.

46. Nelson, M.I. and A.L. Vincent, Reverse zoonosis of influenza to swine: new perspectives on the human-animal interface. Trends Microbiol, 2015. 23(3): p. 142-53.

47. Ilyushina, N.A., et al., Comparative study of influenza virus replication in MDCK cells and in primary cells derived from adenoids and airway epithelium. Journal of virology, 2012. 86(21): p. 11725-11734.

48. Team, R.C., R: A Language and Environment for Statistical Computing. 2019, R Foundation for Statistical Computing.

49. Yu, G., et al., Two Methods for Mapping and Visualizing Associated Data on Phylogeny Using Ggtree. Molecular Biology and Evolution, 2018. 35(12): p. 3041-3043.

50. $\mathrm{Yu}, \mathrm{G}$. , et al., ggtree: an r package for visualization and annotation of phylogenetic trees with their covariates and other associated data. Methods in Ecology and Evolution, 2017. 8(1): p. 28-36.

51. Valkenburg, S.A., et al., Immunity to seasonal and pandemic influenza A viruses. Microbes Infect, 2011. 


\section{APPENDIX A. GENOME-WIDE COMPARISON BETWEEN SWINE AND HUMAN VIRUSES}

\begin{tabular}{|c|c|c|c|c|c|}
\hline \multicolumn{6}{|c|}{ Genome-wide changes: } \\
\hline Nucleotide & & 1 & 2 & 3 & 4 \\
\hline A/swine/L/21IL1207 & 1 & & 58 & 91 & 100 \\
\hline A/swine/IN/30IN0428 & 2 & 99.55 & & 95 & 98 \\
\hline Asswine/MN/36MN1026 & 3 & 99.30 & 99.27 & & 135 \\
\hline ATTN/F2090 & 4 & 99.23 & 99.24 & 98.96 & \\
\hline
\end{tabular}

\begin{tabular}{r|c|c|c|c|r|}
\cline { 2 - 5 } Amino Acid & \multicolumn{1}{|c|}{1} & \multicolumn{1}{|c|}{3} & \multicolumn{1}{|c|}{} \\
\cline { 2 - 6 } A/swine/L/211L1207 & 1 & & 14 & 27 & 41 \\
\cline { 2 - 6 } A/swine/N/30IN0428 & 2 & 99.68 & & 28 & 39 \\
\cline { 2 - 6 } A/swine/MN/36MN1026 & 3 & 99.38 & 99.35 & & 55 \\
\cline { 2 - 6 } ATTN/F2090 & 4 & 99.05 & 99.10 & 98.73 & \\
\cline { 2 - 6 } & & &
\end{tabular}


APPENDIX B. DATASET MASTERFILE FOR HA GENE (FASTA SEQUENCE TRUNCATED FOR SPACE)

\begin{tabular}{|c|c|c|c|c|}
\hline Accession \# & Sample Name & Host Species & Date & $\begin{array}{c}\text { FASTA } \\
\text { Sequence }\end{array}$ \\
\hline FJ966082 & A/California/04/2009 & Human & 2009-04-01 & ATGAA... \\
\hline KF009554 & A/California/07/2009 & Human & 2009-04-09 & ATGAA... \\
\hline GQ117097 & A/Indiana/09/2009 & Human & 2009-04-22 & ATGAA... \\
\hline GQ168644 & $\mathrm{A} /$ Kansas/03/2009 & Human & 2009-04-24 & ATGAA... \\
\hline FJ984397 & A/Ohio/07/2009 & Human & 2009-04-24 & ATGAA... \\
\hline GQ168652 & A/New-York/11/2009 & Human & $2009-04-25$ & ATGAA... \\
\hline GQ117032 & A/Texas/09/2009 & Human & $2009-04-25$ & ATGAA... \\
\hline CY041122 & A/New-York/3214/2009 & Human & 2009-04-25 & ATGAA... \\
\hline CY040838 & A/New-York/3262/2009 & Human & 2009-04-27 & ATGAA... \\
\hline GQ160526 & A/Florida/04/2009 & Human & 2009-04-27 & ATGAA... \\
\hline CY046387 & A/Wisconsin/629-D00750/2009 & Human & 2009-04-30 & ATGAA... \\
\hline CY053103 & A/Houston/15H/2009 & Human & 2009-05-01 & ATGAA... \\
\hline CY046235 & $\mathrm{A} / \mathrm{Wisconsin} / 629-\mathrm{D} 01735 / 2009$ & Human & 2009-05-02 & ATGAA... \\
\hline CY041750 & A/New-York/3323/2009 & Human & 2009-05-06 & ATGAA... \\
\hline CY046571 & A/Wisconsin/629-D00905/2009 & Human & $2009-05-08$ & ATGAA... \\
\hline CY046563 & A/Wisconsin/629-D01919/2009 & Human & 2009-05-09 & ATGAA... \\
\hline KC781320 & A/Mississippi/01/2009 & Human & $2009-05-13$ & ATGAA... \\
\hline CY043235 & A/New-York/3502/2009 & Human & $2009-05-16$ & ATGAA... \\
\hline CY044917 & A/New-York/3613/2009 & Human & 2009-05-19 & ATGAA... \\
\hline CY046731 & A/Wisconsin/629-D01521/2009 & Human & 2009-05-20 & ATGAA... \\
\hline CY053174 & A/Brownsville/26OS/2009 & Human & $2009-05-20$ & ATGAA... \\
\hline CY044877 & A/New-York/3573/2009 & Human & $2009-05-21$ & ATGAA... \\
\hline
\end{tabular}




CY053214
CY044957
CY044925
CY046779
CY046955
CY046811
CY050150
CY046907
CY050903
CY053277
CY046803
CY071039
CY047366
CY053301
CY050983
KC781928
CY051231
CY054683
CY051015
CY051839
CY064460
CY050999
KC781551
CY044171
CY055447
CY051167
CY043118

A/Brownsville/31H/2009

A/New-York/3629/2009

A/New-York/3617/2009

$\mathrm{A} /$ Wisconsin/629-D01894/2009

A/New-York/3654/2009

A/Wisconsin/629-D00698/2009

A/Wisconsin/629-D00117/2009

A/Wisconsin/629-D01083/2009

A/Wisconsin/629-D01779/2009

A/Brownsville/39H/2009

A/Wisconsin/629-D00223/2009

A/New-York/NHRC0003/2009

A/New-York/3795/2009

A/Brownsville/43H/2009

A/Wisconsin/629-D00592/2009 A/Virginia/24/2009

$\mathrm{A} /$ Wisconsin/629-D01664/2009

A/Wisconsin/629-D00589/2009

A/Wisconsin/629-D00453/2009

A/Texas/42123701/2009

A/Boston/96/2009

A/Wisconsin/629-D00665/2009

A/Massachusetts/16/2009

A/Bethesda/SP506/2009

A/California/VRDL11/2009

A/Wisconsin/629-D02063/2009

A/Bethesda/SP508/2009

\begin{tabular}{|c|c|c|}
\hline Human & $2009-05-22$ & ATGAA... \\
\hline Human & 2009-05-24 & ATGAA... \\
\hline Human & $2009-05-25$ & ATGAA... \\
\hline Human & 2009-05-26 & ATGAA... \\
\hline Human & 2009-05-26 & ATGAA... \\
\hline Human & $2009-05-27$ & ATGAA... \\
\hline Human & $2009-05-28$ & ATGAA... \\
\hline Human & $2009-05-28$ & ATGAA... \\
\hline Human & $2009-05-28$ & ATGAA... \\
\hline Human & $2009-05-30$ & ATGAA... \\
\hline Human & 2009-05-30 & ATGAA... \\
\hline Human & 2009-06-01 & ATGAA... \\
\hline Human & 2009-06-01 & ATGAA... \\
\hline Human & 2009-06-02 & ATGAA... \\
\hline Human & 2009-06-02 & ATGAA... \\
\hline Human & 2009-06-03 & ATGAA... \\
\hline Human & 2009-06-03 & ATGAA... \\
\hline Human & 2009-06-03 & ATGAA... \\
\hline Human & 2009-06-04 & ATGAA... \\
\hline Human & 2009-06-12 & ATGAA... \\
\hline Human & 2009-06-13 & ATGAA... \\
\hline Human & 2009-06-13 & ATGAA... \\
\hline Human & 2009-06-15 & ATGAA... \\
\hline Human & 2009-06-16 & ATGAA... \\
\hline Human & 2009-06-17 & ATGAA... \\
\hline Human & 2009-06-18 & ATGAA... \\
\hline Human & 2009-06-18 & ATGAA... \\
\hline
\end{tabular}




\begin{tabular}{|c|c|c|c|c|}
\hline CY064524 & A/Boston/118/2009 & Human & 2009-06-20 & ATGAA... \\
\hline CY051551 & A/New-York/4434/2009 & Human & $2009-06-23$ & ATGAA... \\
\hline CY051479 & $\mathrm{A} / \mathrm{Wisconsin} / 629-\mathrm{S} 0410 / 2009$ & Human & 2009-06-23 & ATGAA... \\
\hline CY052154 & A/New-York/4401/2009 & Human & $2009-06-25$ & ATGAA... \\
\hline CY064676 & A/Boston/141/2009 & Human & $2009-06-25$ & ATGAA... \\
\hline CY064564 & A/Boston/124/2009 & Human & $2009-06-26$ & ATGAA... \\
\hline CY054835 & A/California/VRDL30/2009 & Human & 2009-06-28 & ATGAA... \\
\hline CY054795 & A/California/VRDL25/2009 & Human & 2009-06-30 & ATGAA... \\
\hline SJ0001 & A/swine/IA/14IA1011 & Swine & 2009-07-01 & ATGAA... \\
\hline SJ0002 & A/swine/IL/21IL1206 & Swine & 2009-07-01 & ATGAA... \\
\hline SJ0003 & $\mathrm{A} /$ swine/IL/21IL1207 & Swine & 2009-07-01 & ATGAA... \\
\hline SJ0004 & A/swine/IL/21IL1208 & Swine & 2009-07-01 & ATGAA... \\
\hline SJ0005 & A/swine/IL/21IL1224 & Swine & 2009-07-01 & ATGAA... \\
\hline SJ0006 & $\mathrm{A} /$ swine/IL/21IL1225 & Swine & 2009-07-01 & ATGAA... \\
\hline SJ0007 & A/swine/IL/21IL1227 & Swine & 2009-07-01 & ATGAA... \\
\hline SJ0008 & A/swine/IL/21IL1228 & Swine & 2009-07-01 & ATGAA... \\
\hline SJ0009 & A/swine/IL/21 IL1230 & Swine & 2009-07-01 & ATGAA... \\
\hline SJ0010 & A/swine/IL/22IL1213 & Swine & 2009-07-01 & ATGAA... \\
\hline CY054851 & A/California/VRDL32/2009 & Human & 2009-07-01 & ATGAA... \\
\hline CY063550 & A/Boston/151/2009 & Human & 2009-07-06 & ATGAA... \\
\hline CY053158 & A/Houston/23H/2009 & Human & 2009-07-07 & ATGAA... \\
\hline CY051599 & A/New-York/4566/2009 & Human & 2009-07-08 & ATGAA... \\
\hline CY051607 & A/New-York/4567/2009 & Human & 2009-07-08 & ATGAA... \\
\hline CY054939 & A/California/VRDL48/2009 & Human & 2009-07-10 & ATGAA... \\
\hline CY052407 & A/Texas/43132503/2009 & Human & 2009-07-13 & ATGAA... \\
\hline CY051631 & A/New-York/4620/2009 & Human & 2009-07-14 & ATGAA... \\
\hline CY051623 & A/New-York/4607/2009 & Human & 2009-07-14 & ATGAA... \\
\hline
\end{tabular}




\begin{tabular}{|c|c|c|c|c|}
\hline CY051655 & A/New-York/4728/2009 & Human & 2009-07-24 & ATGAA... \\
\hline CY052367 & A/Texas/43272683/2009 & Human & 2009-07-27 & ATGAA... \\
\hline CY083224 & A/California/WRAIR1507P/2009 & Human & 2009-07-29 & ATGAA... \\
\hline CY051679 & A/New-York/4747/2009 & Human & 2009-07-30 & ATGAA... \\
\hline CY055035 & A/California/VRDL69/2009 & Human & 2009-08-05 & ATGAA... \\
\hline CY071530 & A/California/WR1320P/2009 & Human & 2009-08-07 & ATGAA... \\
\hline KC781733 & A/Oregon/30/2009 & Human & 2009-08-09 & ATGAA... \\
\hline CY055494 & A/California/VRDL74/2009 & Human & 2009-08-10 & ATGAA... \\
\hline CY051695 & A/New-York/4777/2009 & Human & 2009-08-14 & ATGAA... \\
\hline CY063574 & A/Boston/154/2009 & Human & 2009-08-18 & ATGAA... \\
\hline CY051703 & A/New-York/4780/2009 & Human & 2009-08-18 & ATGAA... \\
\hline KC782315 & A/Minnesota/16/2009 & Human & $2009-08-28$ & ATGAA... \\
\hline CY052767 & A/Texas/44282651/2009 & Human & $2009-08-28$ & ATGAA... \\
\hline HQ840306 & A/swine/Minnesota/130A/2009 & Swine & 2009-09-01 & ATGAA... \\
\hline CY052775 & A/Texas/45021632/2009 & Human & 2009-09-02 & ATGAA... \\
\hline CY052591 & A/Texas/45033774/2009 & Human & 2009-09-03 & ATGAA... \\
\hline CY052783 & $\mathrm{A} / \mathrm{Texas} / 45043852 / 2009$ & Human & 2009-09-04 & ATGAA... \\
\hline CY071834 & A/South-Carolina/WRSP520/2009 & Human & 2009-09-05 & ATGAA... \\
\hline CY057878 & A/Wisconsin/629-D01987/2009 & Human & 2009-09-07 & ATGAA... \\
\hline CY052727 & A/Texas/45091405/2009 & Human & 2009-09-09 & ATGAA... \\
\hline CY052527 & A/Texas/45103998/2009 & Human & 2009-09-10 & ATGAA... \\
\hline KC780106 & A/Alaska/38/2009 & Human & 2009-09-11 & ATGAA... \\
\hline CY057366 & A/Wisconsin/629-D00643/2009 & Human & 2009-09-12 & ATGAA... \\
\hline CY052439 & $\mathrm{A} /$ Texas/45122538/2009 & Human & 2009-09-12 & ATGAA... \\
\hline CY052559 & $\mathrm{A} / \mathrm{Texas} / 45122722 / 2009$ & Human & 2009-09-12 & ATGAA... \\
\hline CY052575 & $\mathrm{A} / \mathrm{Texas} / 45131774 / 2009$ & Human & 2009-09-13 & ATGAA... \\
\hline KC780830 & A/Kansas/20/2009 & Human & 2009-09-14 & ATGAA... \\
\hline
\end{tabular}




CY057430
CY055502
CY057470
CY057494
KC780998
CY083439
CY063219
CY056571
CY057542
CY057550
CY056451
CY056435
CY057606
CY089187
CY056507
CY056012
CY057630
CY066535
CY057238
CY092928
KC780510
CY063091
CY058054
CY057686
CY061243
CY057254
CY056859

A/Wisconsin/629-D01935/2009

A/California/VRDL 75/2009

A/Wisconsin/629-D00402/2009

A/Wisconsin/629-D00287/2009 A/Texas/66/2009

A/Ft.Benning/WRAIR1669P/2009

A/Wisconsin/629-D01351/2009

A/New-York/5755/2009

A/Wisconsin/629-D00853/2009

$\mathrm{A} /$ Wisconsin/629-D02337/2009

A/New-York/4986/2009

A/New-York/4984/2009

A/Wisconsin/629-D00557/2009

A/Boston/583/2009

A/New-York/5083/2009

A/San-Diego/INS11/2009

A/Wisconsin/629-S1348/2009

A/San-Diego/INS195/2009

A/New-York/5158/2009

A/Maryland/NHRC0003/2009

A/North-Carolina/46/2009

A/California/VRDL90/2009

A/Texas/46181235/2009

A/Wisconsin/629-S1388/2009

A/San-Diego/INS103/2009

A/New-York/5186/2009

A/San-Diego/INS15/2009

\begin{tabular}{|c|c|c|}
\hline Human & 2009-09-16 & ATGAA.. \\
\hline Human & 2009-09-19 & ATGAA.. \\
\hline Human & 2009-09-22 & ATGAA... \\
\hline Human & 2009-09-23 & ATGAA... \\
\hline Human & 2009-09-29 & ATGAA.. \\
\hline Human & 2009-09-30 & ATGAA.. \\
\hline Human & 2009-10-01 & ATGAA... \\
\hline Human & 2009-10-01 & ATGAA... \\
\hline Human & 2009-10-02 & ATGAA... \\
\hline Human & $2009-10-03$ & ATGAA... \\
\hline Human & 2009-10-05 & ATGAA.. \\
\hline Human & 2009-10-06 & ATGAA... \\
\hline Human & 2009-10-10 & ATGAA... \\
\hline Human & $2009-10-10$ & ATGAA... \\
\hline Human & $2009-10-13$ & ATGAA. \\
\hline Human & $2009-10-14$ & ATGAA... \\
\hline Human & $2009-10-14$ & ATGAA... \\
\hline Human & $2009-10-15$ & ATGAA.. \\
\hline Human & $2009-10-15$ & ATGAA... \\
\hline Human & 2009-10-16 & ATGAA... \\
\hline Human & $2009-10-16$ & ATGAA. \\
\hline Human & $2009-10-17$ & ATGAA... \\
\hline Human & $2009-10-18$ & ATGAA... \\
\hline Human & 2009-10-19 & ATGAA... \\
\hline Human & 2009-10-19 & ATGAA... \\
\hline Human & 2009-10-19 & ATGAA... \\
\hline Human & $2009-10-20$ & ATGAA.. \\
\hline
\end{tabular}




\begin{tabular}{|c|c|c|c|c|}
\hline CY083669 & A/San-Diego/INS62/2009 & Human & $2009-10-21$ & ATGAA... \\
\hline CY057694 & A/Wisconsin/629-S1398/2009 & Human & $2009-10-21$ & ATGAA... \\
\hline CY057302 & A/New-York/5297/2009 & Human & $2009-10-22$ & ATGAA... \\
\hline CY057286 & A/New-York/5271/2009 & Human & $2009-10-22$ & ATGAA... \\
\hline CY089203 & A/Boston/594/2009 & Human & $2009-10-22$ & ATGAA... \\
\hline CY056100 & A/District-of-Columbia/INS28/2009 & Human & $2009-10-23$ & ATGAA... \\
\hline CY060835 & $\mathrm{A} / \mathrm{Texas} / 46241654 / 2009$ & Human & $2009-10-24$ & ATGAA... \\
\hline CY056180 & A/District-of-Columbia/INS43/2009 & Human & $2009-10-26$ & ATGAA... \\
\hline KC780722 & A/Rhode-Island/18/2009 & Human & $2009-10-27$ & ATGAA... \\
\hline CY066815 & A/San-Diego/INS218/2009 & Human & $2009-10-28$ & ATGAA... \\
\hline CY063139 & A/California/VRDL98/2009 & Human & $2009-10-29$ & ATGAA... \\
\hline CY063131 & A/California/VRDL97/2009 & Human & $2009-10-29$ & ATGAA... \\
\hline CY066191 & A/California/VRDL94/2009 & Human & $2009-10-29$ & ATGAA... \\
\hline CY075524 & A/Boston/606/2009 & Human & 2009-11-02 & ATGAA... \\
\hline CY089211 & A/Boston/618/2009 & Human & $2009-11-03$ & ATGAA... \\
\hline CY066583 & A/San-Diego/INS203/2009 & Human & 2009-11-04 & ATGAA... \\
\hline CY060851 & A/Texas/JMS358/2009 & Human & 2009-11-04 & ATGAA... \\
\hline CY063163 & A/California/VRDL101/2009 & Human & 2009-11-05 & ATGAA... \\
\hline CY083870 & A/San-Diego/INS49/2009 & Human & $2009-11-05$ & ATGAA... \\
\hline CY056228 & A/San-Diego/INS69/2009 & Human & $2009-11-05$ & ATGAA... \\
\hline KC780748 & A/Illinois/15/2009 & Human & 2009-11-06 & ATGAA... \\
\hline CY060867 & A/Texas/JMS361/2009 & Human & 2009-11-07 & ATGAA... \\
\hline CY089219 & A/Boston/630/2009 & Human & 2009-11-07 & ATGAA... \\
\hline KC782060 & A/Wisconsin/55/2009 & Human & 2009-11-08 & ATGAA... \\
\hline CY057782 & A/Wisconsin/629-D01014/2009 & Human & 2009-11-08 & ATGAA... \\
\hline CY056651 & A/New-York/6110/2009 & Human & 2009-11-08 & ATGAA... \\
\hline CY060883 & A/Texas/JMS363/2009 & Human & 2009-11-08 & ATGAA... \\
\hline
\end{tabular}




\begin{tabular}{|c|c|c|c|c|}
\hline HQ424885 & A/swine/Iowa/44837-1/2009 & Swine & 2009-11-08 & ATGAA... \\
\hline KC780381 & A/Washington/62/2009 & Human & 2009-11-09 & ATGAA... \\
\hline CY056611 & A/New-York/5976/2009 & Human & 2009-11-09 & ATGAA... \\
\hline CY056603 & A/New-York/5931/2009 & Human & 2009-11-09 & ATGAA... \\
\hline CY066751 & A/Pensacola/INS210/2009 & Human & $2009-11-10$ & ATGAA... \\
\hline CY084438 & A/New-York/6064/2009 & Human & 2009-11-11 & ATGAA... \\
\hline CY061275 & A/Pensacola/INS107/2009 & Human & 2009-11-12 & ATGAA... \\
\hline CY057342 & A/San-Diego/INS75/2009 & Human & $2009-11-12$ & ATGAA... \\
\hline CY089259 & A/Boston/650/2009 & Human & $2009-11-12$ & ATGAA... \\
\hline CY075548 & A/Boston/648/2009 & Human & $2009-11-12$ & ATGAA... \\
\hline CY075572 & A/Boston/658/2009 & Human & $2009-11-13$ & ATGAA... \\
\hline CY060923 & A/Texas/JMS371/2009 & Human & 2009-11-14 & ATGAA... \\
\hline CY057822 & A/Wisconsin/629-D00965/2009 & Human & 2009-11-14 & ATGAA... \\
\hline CY060915 & A/Texas/JMS370/2009 & Human & 2009-11-14 & ATGAA... \\
\hline CY089267 & $\mathrm{A} /$ Boston/657/2009 & Human & 2009-11-14 & ATGAA... \\
\hline CY066239 & A/California/VRDL108/2009 & Human & 2009-11-15 & ATGAA... \\
\hline CY057846 & A/Wisconsin/629-D02060/2009 & Human & 2009-11-15 & ATGAA... \\
\hline CY058332 & A/Wisconsin/629-D01347/2009 & Human & 2009-11-16 & ATGAA... \\
\hline CY089307 & A/Boston/673/2009 & Human & 2009-11-16 & ATGAA... \\
\hline CY075580 & A/Boston/663/2009 & Human & 2009-11-16 & ATGAA... \\
\hline CY061283 & A/Pensacola/INS108/2009 & Human & 2009-11-17 & ATGAA... \\
\hline CY063307 & A/Wisconsin/629-D01572/2009 & Human & 2009-11-19 & ATGAA... \\
\hline CY060939 & A/Texas/JMS373/2009 & Human & 2009-11-21 & ATGAA... \\
\hline CY084454 & A/New-York/6418/2009 & Human & $2009-11-22$ & ATGAA... \\
\hline CY057894 & A/Wisconsin/629-D00908/2009 & Human & $2009-11-22$ & ATGAA... \\
\hline CY056723 & A/New-York/6473/2009 & Human & $2009-11-22$ & ATGAA... \\
\hline CY075620 & A/Boston/698/2009 & Human & $2009-11-23$ & ATGAA.. \\
\hline
\end{tabular}




CY057934
CY056779
CY066271
CY057958
CY060955
CY088593
CY057974
CY057982
CY075636
CY066303
CY066295
CY061003
CY084446
KC780599
CY065099
CY058380
CY058388
CY066343
CY061027
GU984390
CY072318
CY061035
GU984403
CY061043
CY 158257
KC780322
CY066431

A/Wisconsin/629-D00968/2009 A/New-York/6675/2009

A/California/VRDL112/2009

A/Wisconsin/629-D00970/2009 A/Texas/JMS380/2009 A/Boston/702/2009

A/Wisconsin/629-D01434/2009

$\mathrm{A} /$ Wisconsin/629-D01412/2009 A/Boston/703/2009

A/California/VRDL116/2009

A/California/VRDL115/2009 A/Texas/JMS386/2009

A/New-York/6902/2009 A/Arizona/20/2009 A/New-York/7426/2009

A/Wisconsin/629-D00780/2009

A/Wisconsin/629-D00147/2009

A/California/VRDL121/2009 A/Texas/JMS389/2009

A/swine/Illinois/35572/2009

A/New-York/INS317/2009

A/Texas/JMS390/2009

A/swine/Illinois/10-001551-2/2009 A/Texas/JMS391/2009

A/swine/Arkansas/SG1321/2009 A/Georgia/25/2009

A/California/VRDL132/2009

\begin{tabular}{|c|c|c|}
\hline Human & $2009-11-24$ & ATGAA... \\
\hline Human & $2009-11-24$ & ATGAA... \\
\hline Human & $2009-11-24$ & ATGAA... \\
\hline Human & $2009-11-27$ & ATGAA... \\
\hline Human & $2009-11-27$ & ATGAA... \\
\hline Human & $2009-11-29$ & ATGAA... \\
\hline Human & $2009-11-29$ & ATGAA... \\
\hline Human & $2009-12-01$ & ATGAA... \\
\hline Human & $2009-12-02$ & ATGAA... \\
\hline Human & $2009-12-04$ & ATGAA... \\
\hline Human & 2009-12-04 & ATGAA... \\
\hline Human & $2009-12-06$ & ATGAA... \\
\hline Human & $2009-12-06$ & ATGAA... \\
\hline Human & $2009-12-06$ & ATGAA... \\
\hline Human & $2009-12-08$ & ATGAA... \\
\hline Human & $2009-12-08$ & ATGAA... \\
\hline Human & 2009-12-09 & ATGAA... \\
\hline Human & $2009-12-15$ & ATGAA... \\
\hline Human & $2009-12-16$ & ATGAA... \\
\hline Swine & $2009-12-16$ & ATGAA... \\
\hline Human & $2009-12-17$ & ATGAA... \\
\hline Human & $2009-12-20$ & ATGAA... \\
\hline Swine & $2009-12-20$ & ATGAA... \\
\hline Human & $2009-12-23$ & ATGAA... \\
\hline Swine & $2009-12-28$ & ATGAA... \\
\hline Human & $2009-12-28$ & ATGAA... \\
\hline Human & $2009-12-30$ & ATGAA... \\
\hline
\end{tabular}




\begin{tabular}{|c|c|c|c|c|}
\hline CY066415 & A/California/VRDL130/2009 & Human & $2009-12-30$ & ATGAA... \\
\hline CY062058 & A/New-York/0461/2009 & Human & $2009-12-30$ & ATGAA... \\
\hline CY066439 & A/California/VRDL133/2009 & Human & $2009-12-30$ & ATGAA... \\
\hline KC780547 & A/New-Jersey/01/2010 & Human & 2010-01-01 & ATGAA... \\
\hline CY061107 & A/Texas/JMS402/2010 & Human & 2010-01-04 & ATGAA... \\
\hline KC781903 & A/Alabama/01/2010 & Human & 2010-01-04 & ATGAA... \\
\hline CY158993 & A/swine/Minnesota/02976/2010 & Swine & 2010-01-12 & ATGAA... \\
\hline KC780888 & A/Nevada/01/2010 & Human & $2010-01-12$ & ATGAA... \\
\hline CY061155 & A/Texas/JMS409/2010 & Human & 2010-01-20 & ATGAA... \\
\hline KC780464 & $\mathrm{A} / \mathrm{Wisconsin} / 01 / 2010$ & Human & 2010-01-24 & ATGAA... \\
\hline CY158441 & A/swine/Illinois/02957/2010 & Swine & 2010-01-26 & ATGAA... \\
\hline CY062138 & A/New-York/2960/2010 & Human & 2010-01-26 & ATGAA... \\
\hline CY064995 & A/New-York/3681/2010 & Human & 2010-02-01 & ATGAA... \\
\hline KC780537 & A/Florida/02/2010 & Human & 2010-02-02 & ATGAA... \\
\hline KC781452 & A/Louisiana/01/2010 & Human & 2010-02-03 & ATGAA... \\
\hline CY066471 & A/California/VRDL4/2010 & Human & 2010-02-08 & ATGAA... \\
\hline JQ023770 & A/swine/Minnesota/0432/2010 & Swine & 2010-02-10 & ATGAA... \\
\hline KC780502 & $\mathrm{A} / \mathrm{Utah} / 02 / 2010$ & Human & 2010-02-10 & ATGAA... \\
\hline GU984417 & A/swine/Minnesota/8762-2/2010 & Swine & 2010-02-16 & ATGAA... \\
\hline CY099183 & A/swine/Minnesota/02979/2010 & Swine & 2010-02-17 & ATGAA... \\
\hline CY096594 & A/District-of-Columbia/INS527/2010 & Human & $2010-02-23$ & ATGAA... \\
\hline CY167388 & $\mathrm{A} /$ Tennessee/F1071/2010 & Human & 2010-03-02 & ATGAA... \\
\hline KC781355 & A/Iowa/04/2010 & Human & 2010-03-03 & ATGAA... \\
\hline CY071367 & A/Newark/INS429/2010 & Human & 2010-03-05 & ATGAA... \\
\hline CY159991 & A/swine/Oklahoma/02989/2010 & Swine & 2010-03-12 & ATGAA... \\
\hline KR859558 & A/swine/Illinois/A00970254/2010 & Swine & 2010-03-18 & ATGAA... \\
\hline KR859639 & $\mathrm{A} /$ swine/Illinois/A00970252/2010 & Swine & $2010-03-18$ & ATGAA.. \\
\hline
\end{tabular}




\begin{tabular}{|c|c|c|c|c|}
\hline CY167452 & A/Tennessee/F1089/2010 & Human & $2010-03-24$ & ATGAA... \\
\hline HM219624 & A/swine/Missouri/15534/2010 & Swine & $2010-03-24$ & ATGAA... \\
\hline SJ0011 & A/swine/IN/29IN1001 & Swine & 2010-07-01 & ATGAA... \\
\hline SJ0012 & A/swine/IN/29IN1002 & Swine & 2010-07-01 & ATGAA... \\
\hline SJ0013 & A/swine/IN/29IN1015 & Swine & 2010-07-01 & ATGAA... \\
\hline SJ0014 & A/swine/IN/29IN1016 & Swine & 2010-07-01 & ATGAA... \\
\hline SJ0015 & A/swine/IN/29IN1022 & Swine & 2010-07-01 & ATGAA... \\
\hline SJ0016 & A/swine/IN/29IN1024 & Swine & 2010-07-01 & ATGAA... \\
\hline SJ0017 & A/swine/IN/30IN0428 & Swine & 2010-07-01 & ATGAA... \\
\hline SJ0022 & $\mathrm{A} /$ swine/MN/36MN0601 & Swine & 2010-07-01 & ATGAA... \\
\hline SJ0023 & A/swine/MN/36MN0607 & Swine & 2010-07-01 & ATGAA... \\
\hline SJ0024 & A/swine/MN/36MN0609 & Swine & 2010-07-01 & ATGAA... \\
\hline SJ0025 & A/swine/MN/36MN0610 & Swine & 2010-07-01 & ATGAA... \\
\hline SJ0026 & $\mathrm{A} /$ swine/MN/36MN1005 & Swine & 2010-07-01 & ATGAA... \\
\hline SJ0027 & $\mathrm{A} /$ swine/MN/36MN1008 & Swine & 2010-07-01 & ATGAA... \\
\hline SJ0028 & $\mathrm{A} /$ swine/MN/36MN1012 & Swine & 2010-07-01 & ATGAA... \\
\hline SJ0029 & $\mathrm{A} /$ swine/MN/36MN1020 & Swine & 2010-07-01 & ATGAA... \\
\hline SJ0030 & A/swine/MN/36MN1026 & Swine & 2011-07-01 & ATGAA... \\
\hline CY159457 & A/swine/Arkansas/SG1499/2010 & Swine & 2010-08-11 & ATGAA... \\
\hline HQ622586 & A/swine/Minnesota/54354/2010 & Swine & 2010-10-27 & ATGAA... \\
\hline KC881830 & A/Kentucky/09/2010 & Human & 2010-11-01 & ATGAA... \\
\hline JF812280 & A/swine/Nebraska/A01049048/2010 & Swine & 2010-11-17 & ATGAA... \\
\hline JF833337 & A/swine/Iowa/A01049128/2010 & Swine & $2010-11-22$ & ATGAA... \\
\hline JF833344 & A/swine/North Carolina/A01049174/2010 & Swine & 2010-11-30 & ATGAA... \\
\hline JX080620 & A/swine/Iowa/A01049195/2010 & Swine & 2010-12-01 & ATGAA... \\
\hline JN162047 & A/swine/Iowa/A01049239/2010 & Swine & 2010-12-08 & ATGAA... \\
\hline CY167468 & A/Tennessee/F2005A/2010 & Human & $2010-12-10$ & ATGAA... \\
\hline
\end{tabular}




\begin{tabular}{|c|c|c|c|c|}
\hline CY114669 & A/swine/Illinois/A01047715/2010 & Swine & $2010-12-14$ & ATGAA... \\
\hline CY097837 & A/District-of-Columbia/WRAIR0309/2010 & Human & $2010-12-30$ & ATGAA... \\
\hline JN162057 & A/swine/Iowa/A01049379/2011 & Swine & $2011-01-03$ & ATGAA... \\
\hline CY134465 & A/Boston/DOA08/2011 & Human & $2011-01-13$ & ATGAA... \\
\hline KC881643 & A/Wisconsin/16/2011 & Human & $2011-01-15$ & ATGAA... \\
\hline JN162058 & A/swine/Minnesota/A01049428/2011 & Swine & $2011-01-18$ & ATGAA... \\
\hline KC882343 & $\mathrm{A} /$ Indiana/04/2011 & Human & 2011-01-19 & ATGAA... \\
\hline KC881716 & A/North-Carolina/09/2011 & Human & $2011-01-20$ & ATGAA... \\
\hline KC881705 & A/North-Carolina/06/2011 & Human & $2011-01-20$ & ATGAA... \\
\hline CY092888 & A/South-Carolina/NHRC0001/2011 & Human & $2011-01-25$ & ATGAA... \\
\hline CY092417 & A/Missouri/NHRC0001/2011 & Human & $2011-01-25$ & ATGAA... \\
\hline CY134473 & A/Boston/DOA28/2011 & Human & $2011-01-27$ & ATGAA... \\
\hline KC882018 & A/Maryland/04/2011 & Human & $2011-02-02$ & ATGAA... \\
\hline KC881912 & A/New-Mexico/04/2011 & Human & $2011-02-07$ & ATGAA... \\
\hline KC881943 & A/New-Mexico/05/2011 & Human & 2011-02-09 & ATGAA... \\
\hline JN193422 & A/swine/Minnesota/25618/2011 & Swine & $2011-02-10$ & ATGAA... \\
\hline KC882257 & A/California/17/2011 & Human & $2011-02-15$ & ATGAA... \\
\hline JN652409 & A/swine/Illinois/A01049574/2011 & Swine & $2011-02-16$ & ATGAA... \\
\hline JF916682 & A/swine/OH/9838/2011 & Swine & $2011-02-21$ & ATGAA... \\
\hline KC882336 & A/Maryland/06/2011 & Human & $2011-02-22$ & ATGAA... \\
\hline KC882395 & A/Maryland/08/2011 & Human & $2011-03-02$ & ATGAA... \\
\hline JN652417 & A/swine/Illinois/A01049673/2011 & Swine & $2011-03-10$ & ATGAA... \\
\hline CY167724 & A/Tennessee/F2083C/2011 & Human & 2011-04-13 & ATGAA... \\
\hline JX045997 & A/swine/Illinois/A01049981/2011 & Swine & $2011-05-17$ & ATGAA... \\
\hline JN863540 & A/swine/Iowa/A01049980/2011 & Swine & $2011-05-17$ & ATGAA... \\
\hline JN193425 & A/swine/Oregon/A00700068/2011 & Swine & $2011-05-18$ & ATGAA... \\
\hline JX092275 & A/swine/Iowa/A01202099/2011 & Swine & 2011-06-21 & ATGAA... \\
\hline
\end{tabular}




\begin{tabular}{|c|c|c|c|c|}
\hline SJ0018 & A/swine/IN/30IN0801 & Swine & 2011-07-01 & ATGAA... \\
\hline SJ0019 & A/swine/IN/30IN0816 & Swine & 2011-07-01 & ATGAA... \\
\hline SJ0020 & A/swine/IN/30IN0824 & Swine & 2011-07-01 & ATGAA... \\
\hline SJ0021 & A/swine/IN/30IN1017 & Swine & 2011-07-01 & ATGAA... \\
\hline JX092286 & A/swine/North-Carolina/A01202450/2011 & Swine & 2011-07-14 & ATGAA... \\
\hline JN673250 & A/swine/Texas/A01104003/2011 & Swine & 2011-07-16 & ATGAA... \\
\hline JN673258 & $\mathrm{A} /$ swine/Texas/A01104004/2011 & Swine & 2011-07-16 & ATGAA... \\
\hline JX092296 & $\mathrm{A} /$ swine/Texas/A01202511/2011 & Swine & 2011-08-11 & ATGAA... \\
\hline JX092299 & A/swine/Iowa/A01202554/2011 & Swine & 2011-08-30 & ATGAA... \\
\hline JX092451 & A/swine/Iowa/A01202854/2011 & Swine & 2011-11-15 & ATGAA... \\
\hline JX092551 & A/swine/Colorado/A01203099/2011 & Swine & $2011-12-22$ & ATGAA... \\
\hline JX092560 & A/swine/Missouri/A01203163/2012 & Swine & 2012-01-17 & ATGAA... \\
\hline CY147971 & A/Georgia/M5081/2012 & Human & 2012-02-01 & ATGAA... \\
\hline CY148003 & A/Georgia/M5081/2012 & Human & 2012-02-01 & ATGAA... \\
\hline CY148067 & A/Georgia/M5081/2012 & Human & 2012-02-01 & ATGAA... \\
\hline KC891093 & A/Texas/22/2012 & Human & $2012-02-26$ & ATGAA... \\
\hline JX905426 & A/Florida/06/2012 & Human & $2012-02-27$ & ATGAA... \\
\hline KC891408 & A/North-Carolina/09/2012 & Human & 2012-03-01 & ATGAA... \\
\hline CY176690 & A/Bronx/INS3-673/2012 & Human & 2012-03-06 & ATGAA... \\
\hline CY176714 & A/Dayton/INS3-676/2012 & Human & $2012-03-12$ & ATGAA... \\
\hline KC891216 & A/North-Carolina/18/2012 & Human & 2012-04-26 & ATGAA... \\
\hline CY135108 & A/Texas/JMM-52/2012 & Human & $2012-12-06$ & ATGAA... \\
\hline CY182713 & A/Houston/JMM-64/2012 & Human & $2012-12-12$ & ATGAA... \\
\hline CY168535 & A/Boston/YGA-01002/2012 & Human & 2012-12-19 & ATGAA... \\
\hline CY148316 & A/Boston/DOA2-099/2012 & Human & $2012-12-23$ & ATGAA... \\
\hline CY168807 & A/Boston/YGA-01041/2012 & Human & $2012-12-25$ & ATGAA... \\
\hline CY171543 & A/Chicago/YGA-04123/2012 & Human & $2012-12-30$ & ATGAA... \\
\hline
\end{tabular}




\begin{tabular}{|c|c|c|c|c|}
\hline CY169863 & A/Boston/YGA-01185/2013 & Human & 2013-01-21 & ATGAA... \\
\hline CY170927 & A/Santa-Clara/YGA-03065/2013 & Human & $2013-01-26$ & ATGAA... \\
\hline CY186187 & A/Houston/JMM-171/2013 & Human & 2013-01-27 & ATGAA... \\
\hline CY168423 & A/Boston/YGA-00087/2013 & Human & 2013-01-30 & ATGAA... \\
\hline CY186099 & A/Houston/JMM-159/2013 & Human & 2013-02-08 & ATGAA... \\
\hline KC871058 & A/swine/Ohio/A01432602/2013 & Swine & $2013-03-12$ & ATGAA... \\
\hline CY170079 & A/Boston/YGA-01217/2013 & Human & 2013-03-17 & ATGAA... \\
\hline KF013677 & A/swine/Ohio/A01349978/2013 & Swine & 2013-04-17 & ATGAA... \\
\hline CY170095 & A/Boston/YGA-01220/2013 & Human & $2013-04-26$ & ATGAA... \\
\hline CY194605 & A/swine/Arkansas/D0386/2013 & Swine & 2013-05-06 & ATGAA... \\
\hline KF251047 & A/swine/Minnesota/A01381276/2013 & Swine & $2013-05-23$ & ATGAA... \\
\hline KF537364 & A/swine/Illinois/A01398316/2013 & Swine & $2013-07-23$ & ATGAA... \\
\hline KF772961 & A/swine/Minnesota/A01392911/2013 & Swine & $2013-10-10$ & ATGAA... \\
\hline CY188841 & A/New-York/WC-LVD-13-004/2013 & Human & $2013-12-04$ & ATGAA... \\
\hline KJ645761 & A/Gainesville/08/2013 & Human & $2013-12-04$ & ATGAA... \\
\hline CY188897 & A/New-York/WC-LVD-13-011/2013 & Human & $2013-12-11$ & ATGAA... \\
\hline CY188913 & A/New-York/WC-LVD-13-013/2013 & Human & $2013-12-12$ & ATGAA... \\
\hline KM409069 & A/Rhode-Island/09/2013 & Human & $2013-12-22$ & ATGAA... \\
\hline CY188977 & A/New-York/WC-LVD-13-021/2013 & Human & $2013-12-24$ & ATGAA... \\
\hline CY189033 & A/New-York/WC-LVD-13-028/2013 & Human & $2013-12-28$ & ATGAA... \\
\hline CY189041 & A/New-York/WC-LVD-13-030/2013 & Human & $2013-12-31$ & ATGAA... \\
\hline CY189049 & A/New-York/WC-LVD-14-001/2014 & Human & 2014-01-02 & ATGAA... \\
\hline KJ206094 & A/swine/Illinois/A01490609/2014 & Swine & 2014-01-08 & ATGAA... \\
\hline KJ645769 & A/Gainesville/05/2014 & Human & 2014-01-15 & ATGAA... \\
\hline KJ206223 & A/swine/Nebraska/A01366774/2014 & Swine & 2014-01-17 & ATGAA... \\
\hline KJ417899 & A/swine/Minnesota/A01491447/2014 & Swine & 2014-01-27 & ATGAA... \\
\hline KJ417890 & A/swine/Nebraska/A01491300/2014 & Swine & 2014-01-27 & ATGAA. \\
\hline
\end{tabular}




\begin{tabular}{|c|c|c|c|c|}
\hline KJ605091 & A/swine/Kansas/A01410327/2014 & Swine & 2014-02-07 & ATGAA... \\
\hline KJ528259 & A/swine/Illinois/A01492501/2014 & Swine & 2014-02-12 & ATGAA... \\
\hline CY189257 & A/New-York/WC-LVD-14-027/2014 & Human & 2014-02-14 & ATGAA... \\
\hline KT274458 & A/North-Carolina/04/2014 & Human & 2014-02-16 & ATGAA... \\
\hline KJ588390 & A/swine/Nebraska/A01492657/2014 & Swine & 2014-02-27 & ATGAA... \\
\hline KJ701853 & A/swine/Iowa/A01410472/2014 & Swine & 2014-03-03 & ATGAA... \\
\hline CY189401 & A/New-York/WC-LVD-14-045/2014 & Human & 2014-03-06 & ATGAA... \\
\hline CY189433 & A/New-York/WC-LVD-14-050/2014 & Human & 2014-03-10 & ATGAA... \\
\hline KJ739422 & A/swine/North-Carolina/A01410573/2014 & Swine & 2014-03-21 & ATGAA... \\
\hline KJ701784 & A/swine/Illinois/A01493472/2014 & Swine & 2014-03-26 & ATGAA... \\
\hline CY189481 & A/New-York/WC-LVD-14-056/2014 & Human & 2014-03-27 & ATGAA... \\
\hline KJ907733 & A/swine/Kansas/A01377299/2014 & Swine & 2014-04-30 & ATGAA... \\
\hline KM251575 & A/swine/Kansas/A01377310/2014 & Swine & 2014-07-06 & ATGAA... \\
\hline KM821600 & A/swine/Oklahoma/A01476227/2014 & Swine & 2014-08-12 & ATGAA... \\
\hline KU592859 & $\mathrm{A} /$ Alaska/38/2014 & Human & 2014-09-03 & ATGAA... \\
\hline КР036967 & A/swine/Minnesota/A01483170/2014 & Swine & 2014-10-02 & ATGAA... \\
\hline KT880151 & A/Florida/62/2014 & Human & $2014-10-28$ & ATGAA... \\
\hline KP164555 & A/swine/Nebraska/A01566172/2014 & Swine & $2014-10-30$ & ATGAA... \\
\hline KT836870 & A/California/56/2014 & Human & 2014-12-29 & ATGAA... \\
\hline KT836895 & A/California/49/2015 & Human & 2015-01-26 & ATGAA... \\
\hline KT836859 & A/Hawaii/25/2015 & Human & $2015-02-25$ & ATGAA... \\
\hline KT836762 & A/Washington/20/2015 & Human & $2015-03-23$ & ATGAA... \\
\hline KU509695 & A/Indiana/15/2015 & Human & $2015-07-23$ & ATGAA... \\
\hline KT965349 & A/swine/Indiana/A01260972/2015 & Swine & $2015-08-27$ & ATGAA... \\
\hline KU933493 & A/Michigan/45/2015 & Human & 2015-09-07 & ATGAA... \\
\hline KX004130 & A/Connecticut/05/2015 & Human & $2015-10-13$ & ATGAA... \\
\hline KU509625 & A/Arizona/26/2015 & Human & $2015-10-24$ & ATGAA... \\
\hline
\end{tabular}




\begin{tabular}{|c|c|c|c|c|}
\hline KU509879 & A/Illinois/17/2015 & Human & $2015-10-31$ & ATGAA... \\
\hline KX004186 & A/Alaska/263/2015 & Human & 2015-11-02 & ATGAA... \\
\hline KX949386 & A/Iowa/53/2015 & Human & 2015-11-04 & ATGAA... \\
\hline KU509799 & A/Arkansas/10/2015 & Human & 2015-11-05 & ATGAA... \\
\hline KU589402 & A/Pennsylvania/49/2015 & Human & 2015-12-02 & ATGAA... \\
\hline KX004396 & A/New-Hampshire/43/2015 & Human & $2015-12-03$ & ATGAA... \\
\hline KX004746 & A/Arizona/38/2015 & Human & $2015-12-07$ & ATGAA... \\
\hline KX004754 & A/Arizona/39/2015 & Human & $2015-12-08$ & ATGAA... \\
\hline KX004249 & A/Maryland/21/2015 & Human & $2015-12-12$ & ATGAA... \\
\hline KX408123 & A/New-Mexico/29/2015 & Human & $2015-12-12$ & ATGAA... \\
\hline KX004217 & A/Nevada/41/2015 & Human & $2015-12-17$ & ATGAA... \\
\hline KX408235 & A/New-Jersey/54/2015 & Human & $2015-12-30$ & ATGAA... \\
\hline KX408203 & A/New-York/72/2015 & Human & $2015-12-30$ & ATGAA... \\
\hline KX005418 & A/North-Dakota/01/2016 & Human & 2016-01-04 & ATGAA... \\
\hline KX406499 & A/Michigan/23/2016 & Human & 2016-01-05 & ATGAA... \\
\hline KY044962 & A/Alaska/01/2016 & Human & 2016-01-06 & ATGAA... \\
\hline KX406227 & A/Connecticut/02/2016 & Human & 2016-01-08 & ATGAA... \\
\hline KY487698 & A/Baltimore/0008/2016 & Human & 2016-01-10 & ATGAA... \\
\hline KU598287 & A/swine/Illinois/A01729364/2016 & Swine & 2016-01-12 & ATGAA... \\
\hline KX408643 & A/New-Jersey/04/2016 & Human & 2016-01-14 & ATGAA... \\
\hline KX406587 & A/Washington/25/2016 & Human & 2016-01-16 & ATGAA... \\
\hline KX408939 & A/South-Dakota/03/2016 & Human & 2016-01-18 & ATGAA... \\
\hline KX406475 & A/California/29/2016 & Human & 2016-01-18 & ATGAA... \\
\hline KX408339 & A/Pennsylvania/04/2016 & Human & 2016-01-20 & ATGAA... \\
\hline KX406363 & A/Idaho/04/2016 & Human & $2016-01-25$ & ATGAA... \\
\hline KX406659 & A/North-Carolina/10/2016 & Human & $2016-01-26$ & ATGAA... \\
\hline KX005618 & A/New-York/06/2016 & Human & 2016-01-27 & ATGAA... \\
\hline
\end{tabular}




\begin{tabular}{|c|c|c|c|c|}
\hline KY044724 & A/Maine/01/2016 & Human & $2016-02-03$ & ATGAA... \\
\hline KX406771 & A/Montana/18/2016 & Human & $2016-02-03$ & ATGAA... \\
\hline KX919364 & A/Texas/140/2016 & Human & 2016-02-07 & ATGAA... \\
\hline KX408603 & A/Georgia/13/2016 & Human & 2016-02-08 & ATGAA... \\
\hline KX006314 & A/Wisconsin/24/2016 & Human & 2016-02-08 & ATGAA... \\
\hline KX411203 & A/Illinois/36/2016 & Human & 2016-02-09 & ATGAA... \\
\hline KY045022 & A/Colorado/10/2016 & Human & 2016-02-09 & ATGAA... \\
\hline KX406915 & A/Texas/31/2016 & Human & 2016-02-09 & ATGAA... \\
\hline KX409035 & A/Nevada/09/2016 & Human & 2016-02-09 & ATGAA... \\
\hline KX406571 & A/Michigan/26/2016 & Human & 2016-02-11 & ATGAA... \\
\hline KX406707 & A/Delaware/06/2016 & Human & 2016-02-12 & ATGAA... \\
\hline KX918956 & A/Texas/99/2016 & Human & $2016-02-15$ & ATGAA... \\
\hline KX407251 & A/Nevada/16/2016 & Human & 2016-02-17 & ATGAA... \\
\hline KX407227 & A/Washington/27/2016 & Human & 2016-02-19 & ATGAA... \\
\hline CY258951 & A/New-York/A-WC-LVD-16-072/2016 & Human & 2016-02-19 & ATGAA... \\
\hline KY044820 & A/Georgia/25/2016 & Human & $2016-02-23$ & ATGAA... \\
\hline CY259751 & A/New-York/A-WC-LVD-16-053/2016 & Human & $2016-02-23$ & ATGAA... \\
\hline KX410627 & A/Maryland/12/2016 & Human & $2016-02-24$ & ATGAA... \\
\hline KX918428 & A/Pennsylvania/24/2016 & Human & $2016-02-25$ & ATGAA... \\
\hline KX410411 & A/Louisiana/08/2016 & Human & 2016-02-29 & ATGAA... \\
\hline KX919020 & A/Texas/106/2016 & Human & 2016-02-29 & ATGAA... \\
\hline KY044767 & A/Tennessee/10/2016 & Human & 2016-03-04 & ATGAA... \\
\hline KY615388 & A/Baltimore/0096/2016 & Human & 2016-03-04 & ATGAA... \\
\hline KX915004 & $\mathrm{A} / \mathrm{Utah} / 25 / 2016$ & Human & 2016-03-07 & ATGAA... \\
\hline KX410203 & A/Washington/42/2016 & Human & 2016-03-08 & ATGAA... \\
\hline KX410363 & A/New-York/39/2016 & Human & 2016-03-08 & ATGAA... \\
\hline KX410715 & A/Michigan/63/2016 & Human & $2016-03-10$ & ATGAA... \\
\hline
\end{tabular}




\begin{tabular}{|c|c|c|c|c|}
\hline CY259783 & A/New-York/A-WC-LVD-16-057/2016 & Human & 2016-03-12 & ATGAA... \\
\hline CY259759 & A/New-York/A-WC-LVD-16-054/2016 & Human & 2016-03-12 & ATGAA... \\
\hline KX410395 & A/New-York/42/2016 & Human & 2016-03-14 & ATGAA... \\
\hline KX410067 & A/Nevada/26/2016 & Human & 2016-03-14 & ATGAA... \\
\hline KX411163 & A/Illinois/29/2016 & Human & $2016-03-15$ & ATGAA... \\
\hline KX410811 & A/Pennsylvania/42/2016 & Human & $2016-03-15$ & ATGAA... \\
\hline KX410523 & A/Oregon/11/2016 & Human & 2016-03-18 & ATGAA... \\
\hline KX411147 & A/Illinois/27/2016 & Human & $2016-03-20$ & ATGAA... \\
\hline KX918828 & A/Pennsylvania/58/2016 & Human & 2016-03-24 & ATGAA... \\
\hline KX409291 & A/Virginia/29/2016 & Human & 2016-03-27 & ATGAA... \\
\hline KX411411 & A/Michigan/71/2016 & Human & $2016-03-28$ & ATGAA... \\
\hline KX150713 & A/swine/Ohio/A01894414/2016 & Swine & 2016-03-29 & ATGAA... \\
\hline KX411379 & A/Pennsylvania/61/2016 & Human & 2016-03-31 & ATGAA... \\
\hline KX915420 & A/Montana/41/2016 & Human & $2016-03-31$ & ATGAA... \\
\hline KY045290 & A/Illinois/40/2016 & Human & 2016-04-01 & ATGAA... \\
\hline KX915428 & A/Montana/42/2016 & Human & 2016-04-02 & ATGAA... \\
\hline KX411675 & A/South-Dakota/16/2016 & Human & 2016-04-03 & ATGAA... \\
\hline KX411587 & A/Vermont/14/2016 & Human & 2016-04-05 & ATGAA... \\
\hline KX411483 & A/Virginia/51/2016 & Human & 2016-04-06 & ATGAA... \\
\hline KY003261 & A/Pennsylvania/80/2016 & Human & 2016-04-07 & ATGAA... \\
\hline KX915380 & A/New-Mexico/42/2016 & Human & 2016-04-09 & ATGAA... \\
\hline KX915148 & A/Indiana/39/2016 & Human & 2016-04-10 & ATGAA... \\
\hline KX915228 & A/Washington/67/2016 & Human & 2016-04-11 & ATGAA... \\
\hline KY003244 & A/Pennsylvania/81/2016 & Human & 2016-04-14 & ATGAA... \\
\hline KX915772 & A/New-Mexico/46/2016 & Human & 2016-04-18 & ATGAA... \\
\hline KX915308 & A/New-Jersey/21/2016 & Human & 2016-04-18 & ATGAA... \\
\hline KX411595 & A/Arkansas/12/2016 & Human & 2016-04-19 & ATGAA... \\
\hline
\end{tabular}




\begin{tabular}{|c|c|c|c|c|}
\hline KX915916 & A/Virginia/54/2016 & Human & 2016-04-19 & ATGAA... \\
\hline KX915468 & A/New-York/72/2016 & Human & 2016-04-20 & ATGAA... \\
\hline KX915668 & A/Idaho/26/2016 & Human & 2016-04-21 & ATGAA... \\
\hline KY045320 & A/Florida/62/2016 & Human & $2016-04-22$ & ATGAA... \\
\hline KX358892 & A/swine/Missouri/A01775109/2016 & Swine & $2016-05-11$ & ATGAA... \\
\hline KX916028 & A/North-Carolina/49/2016 & Human & $2016-05-12$ & ATGAA... \\
\hline KX915988 & A/Alaska/21/2016 & Human & $2016-05-13$ & ATGAA... \\
\hline KX433140 & A/swine/Illinois/A01775937/2016 & Swine & $2016-05-26$ & ATGAA... \\
\hline KX433143 & A/swine/Illinois/A01776206/2016 & Swine & 2016-06-01 & ATGAA... \\
\hline KX518675 & A/swine/Pennsylvania/A01776820/2016 & Swine & $2016-06-20$ & ATGAA... \\
\hline KX518676 & A/swine/Nebraska/A01776855/2016 & Swine & $2016-06-21$ & ATGAA... \\
\hline KX618892 & A/swine/Illinois/A01777039/2016 & Swine & $2016-06-22$ & ATGAA... \\
\hline KY041973 & A/swine/Indiana/A01812242/2016 & Swine & $2016-06-30$ & ATGAA... \\
\hline KX006213 & A/California/15/2016 & Human & 2016-07-01 & ATGAA... \\
\hline KX408579 & A/Georgia/10/2016 & Human & 2016-07-01 & ATGAA... \\
\hline CY242952 & A/swine/Indiana/16TOSU4933/2016 & Swine & 2016-08-01 & ATGAA... \\
\hline KX908023 & A/swine/Illinois/A01778882/2016 & Swine & $2016-08-26$ & ATGAA... \\
\hline KX908021 & A/swine/Iowa/A01781047/2016 & Swine & 2016-09-02 & ATGAA... \\
\hline KY003323 & A/Hawaii/66/2016 & Human & 2016-09-02 & ATGAA... \\
\hline KY116814 & A/Hawaii/72/2016 & Human & $2016-09-16$ & ATGAA... \\
\hline KY115593 & A/swine/Iowa/A01782230/2016 & Swine & $2016-10-04$ & ATGAA... \\
\hline CY213330 & A/California/153/2016 & Human & 2016-11-01 & ATGAA... \\
\hline KY284544 & A/swine/Nebraska/A01783006/2016 & Swine & $2016-11-03$ & ATGAA... \\
\hline CY211074 & A/California/159/2016 & Human & $2016-11-03$ & ATGAA... \\
\hline CY211026 & A/Pennsylvania/94/2016 & Human & 2016-11-09 & ATGAA... \\
\hline CY211098 & A/Maryland/22/2016 & Human & 2016-11-19 & ATGAA... \\
\hline KY486465 & $\mathrm{A} /$ swine/Indiana/A01671620/2016 & Swine & $2016-12-20$ & ATGAA... \\
\hline
\end{tabular}




\begin{tabular}{|c|c|c|c|c|}
\hline CY217017 & A/South-Dakota/01/2017 & Human & 2017-01-01 & ATGAA... \\
\hline CY218897 & A/Idaho/08/2017 & Human & $2017-01-21$ & ATGAA... \\
\hline KY653730 & A/swine/Iowa/A01672518/2017 & Swine & $2017-01-23$ & ATGAA... \\
\hline CY220903 & $\mathrm{A} /$ Wisconsin/21/2017 & Human & $2017-01-23$ & ATGAA... \\
\hline CY220943 & A/Minnesota/09/2017 & Human & $2017-01-30$ & ATGAA... \\
\hline CY223333 & A/Maryland/09/2017 & Human & $2017-01-31$ & ATGAA... \\
\hline CY223381 & A/Florida/09/2017 & Human & 2017-02-01 & ATGAA... \\
\hline CY238322 & A/Texas/86/2017 & Human & 2017-02-09 & ATGAA... \\
\hline CY225670 & A/South-Dakota/14/2017 & Human & 2017-02-19 & ATGAA... \\
\hline CY225574 & A/New-Hampshire/11/2017 & Human & 2017-02-19 & ATGAA... \\
\hline CY223549 & A/Arizona/10/2017 & Human & 2017-02-19 & ATGAA... \\
\hline CY223557 & A/New-Mexico/08/2017 & Human & $2017-02-21$ & ATGAA... \\
\hline CY224238 & A/Idaho/11/2017 & Human & $2017-02-22$ & ATGAA... \\
\hline CY223501 & A/North-Dakota/10/2017 & Human & $2017-02-27$ & ATGAA... \\
\hline CY225630 & A/South-Dakota/17/2017 & Human & 2017-03-01 & ATGAA... \\
\hline CY229045 & A/North-Dakota/15/2017 & Human & 2017-03-19 & ATGAA... \\
\hline CY229125 & A/Connecticut/16/2017 & Human & $2017-03-24$ & ATGAA... \\
\hline CY236146 & A/Washington/39/2017 & Human & 2017-04-16 & ATGAA... \\
\hline MF116358 & A/swine/Kansas/A01378027/2017 & Swine & 2017-04-19 & ATGAA... \\
\hline CY236243 & A/Virginia/29/2017 & Human & $2017-04-22$ & ATGAA... \\
\hline CY236307 & A/California/56/2017 & Human & 2017-04-29 & ATGAA... \\
\hline MF144722 & A/swine/Iowa/A02215038/2017 & Swine & $2017-05-02$ & ATGAA... \\
\hline MF159347 & A/swine/Iowa/A02215202/2017 & Swine & 2017-05-05 & ATGAA... \\
\hline MF582510 & A/swine/Nebraska/A02216645/2017 & Swine & 2017-06-06 & ATGAA... \\
\hline CY242462 & A/Washington/293/2017 & Human & 2017-07-06 & ATGAA... \\
\hline CY245510 & A/California/69/2017 & Human & $2017-08-16$ & ATGAA... \\
\hline CY257501 & A/Kentucky/26/2017 & Human & 2017-09-07 & ATGAA... \\
\hline
\end{tabular}




\begin{tabular}{|c|c|c|c|c|}
\hline CY257493 & A/Kentucky/26/2017 & Human & 2017-09-07 & ATGAA... \\
\hline MH083432 & $\mathrm{A} /$ Connecticut $/ 31 / 2017$ & Human & 2017-10-07 & ATGAA... \\
\hline MG650676 & A/swine/South-Dakota/A02134997/2017 & Swine & 2017-10-24 & ATGAA... \\
\hline MG662640 & A/swine/Iowa/A01104104/2017 & Swine & 2017-11-16 & ATGAA... \\
\hline MH083324 & A/Alaska/80/2017 & Human & 2017-12-08 & ATGAA... \\
\hline MG870284 & A/swine/Iowa/A02139244/2017 & Swine & $2017-12-27$ & ATGAA... \\
\hline MG870266 & $\mathrm{A} / \mathrm{swine} / \mathrm{Utah} / \mathrm{A} 02139205 / 2018$ & Swine & 2018-01-02 & ATGAA... \\
\hline MH083805 & A/Montana/03/2018 & Human & 2018-01-11 & ATGAA... \\
\hline MH183281 & A/Virginia/03/2018 & Human & 2018-01-17 & ATGAA... \\
\hline MH125898 & A/Iowa/05/2018 & Human & 2018-01-17 & ATGAA... \\
\hline MH183597 & A/Idaho/05/2018 & Human & 2018-02-03 & ATGAA... \\
\hline MH156829 & A/swine/Iowa/A02142548/2018 & Swine & 2018-02-08 & ATGAA... \\
\hline MH245997 & A/Idaho/07/2018 & Human & 2018-02-12 & ATGAA... \\
\hline MH600280 & A/Iowa/56/2018 & Human & 2018-05-08 & ATGAA... \\
\hline
\end{tabular}




\section{APPENDIX C. PROGRAM CODE USED WITHIN SCOPE OF THESIS}

\section{Changes Made to BEAST XML Code to Calculate Empirical Trees}

Blue colored lines of code indicate that line was excluded in the tree calculation while yellow and red lines indicate additions to allow calculation based on amino acid residues present at specified sites.

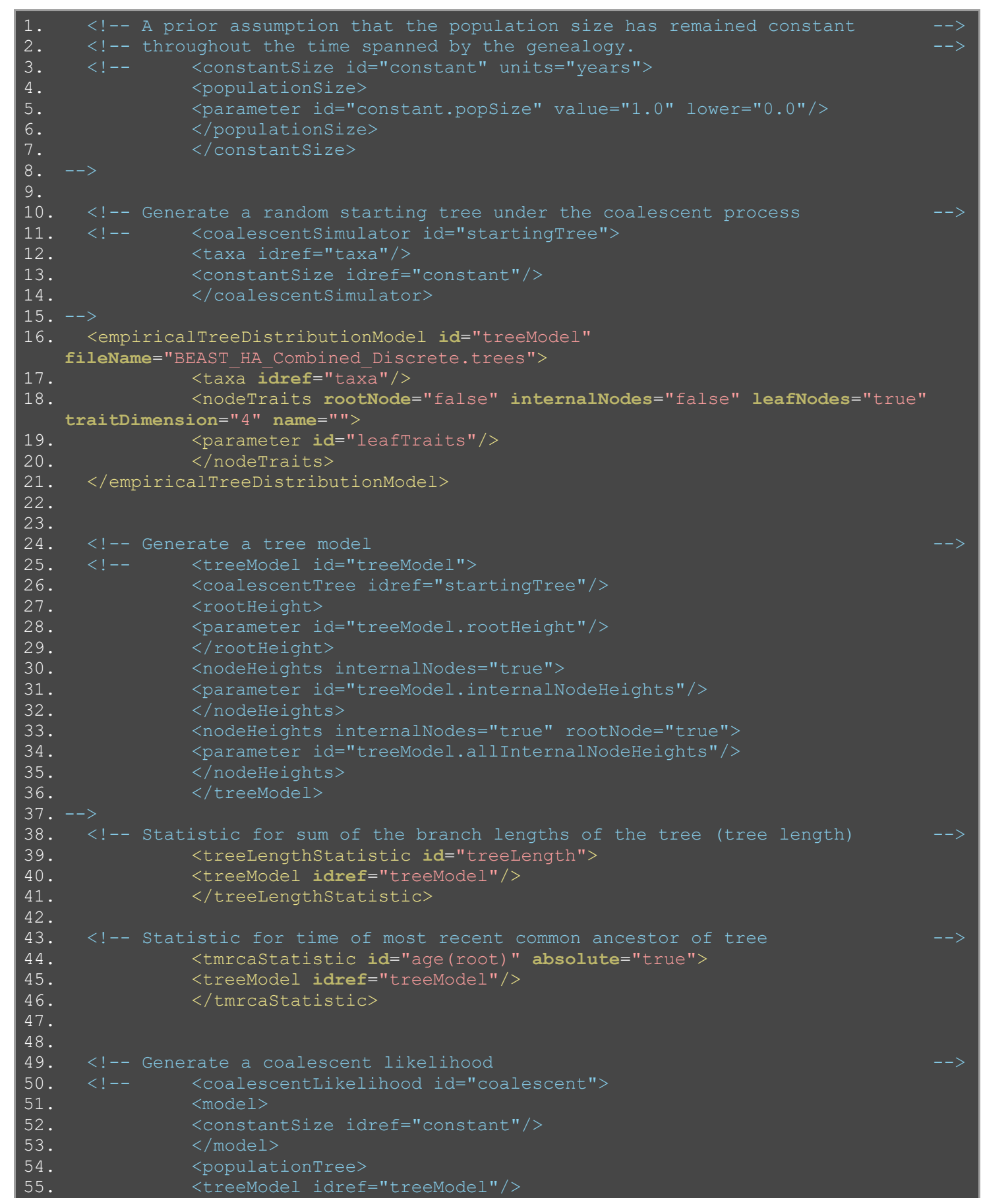




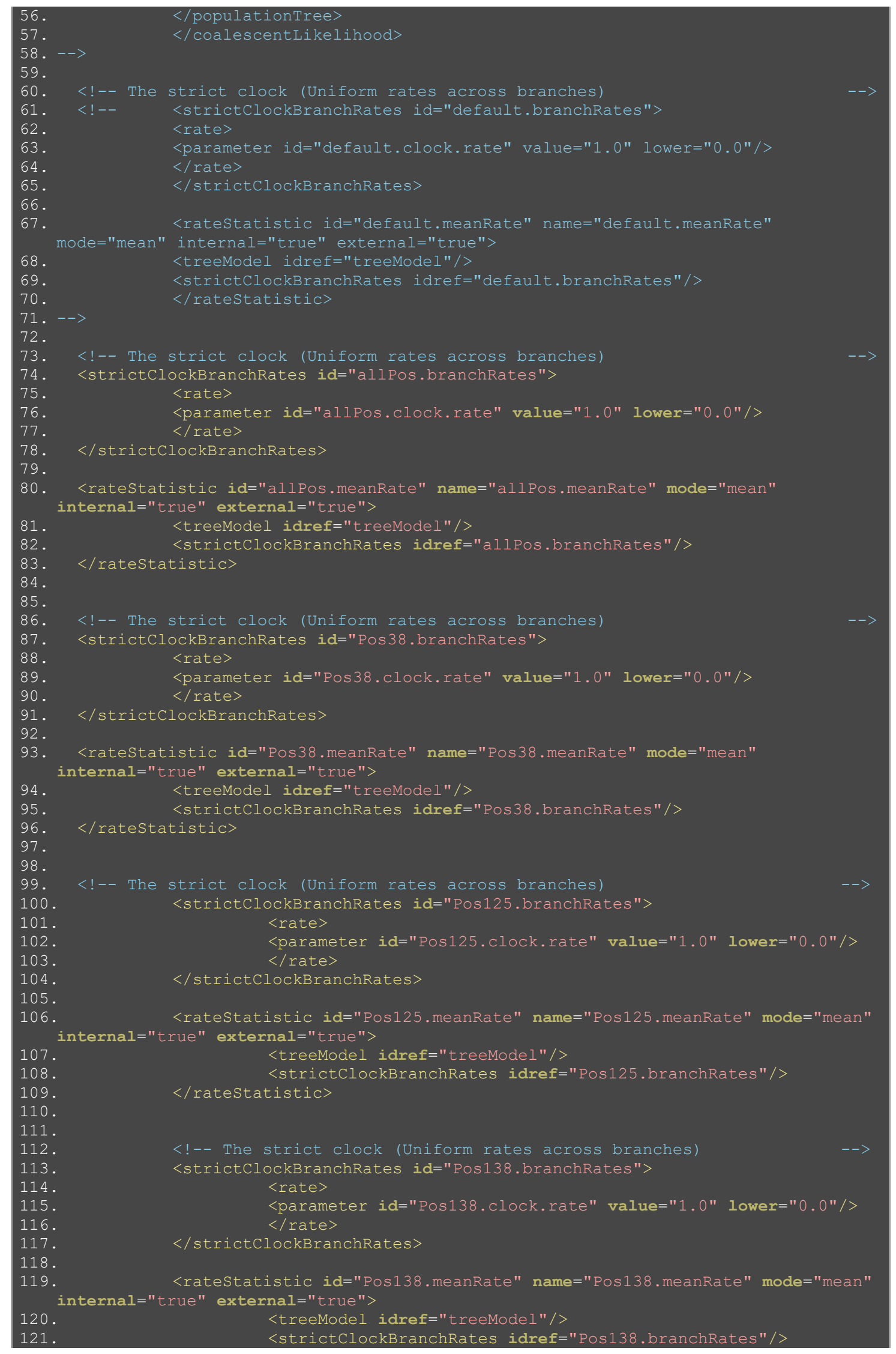




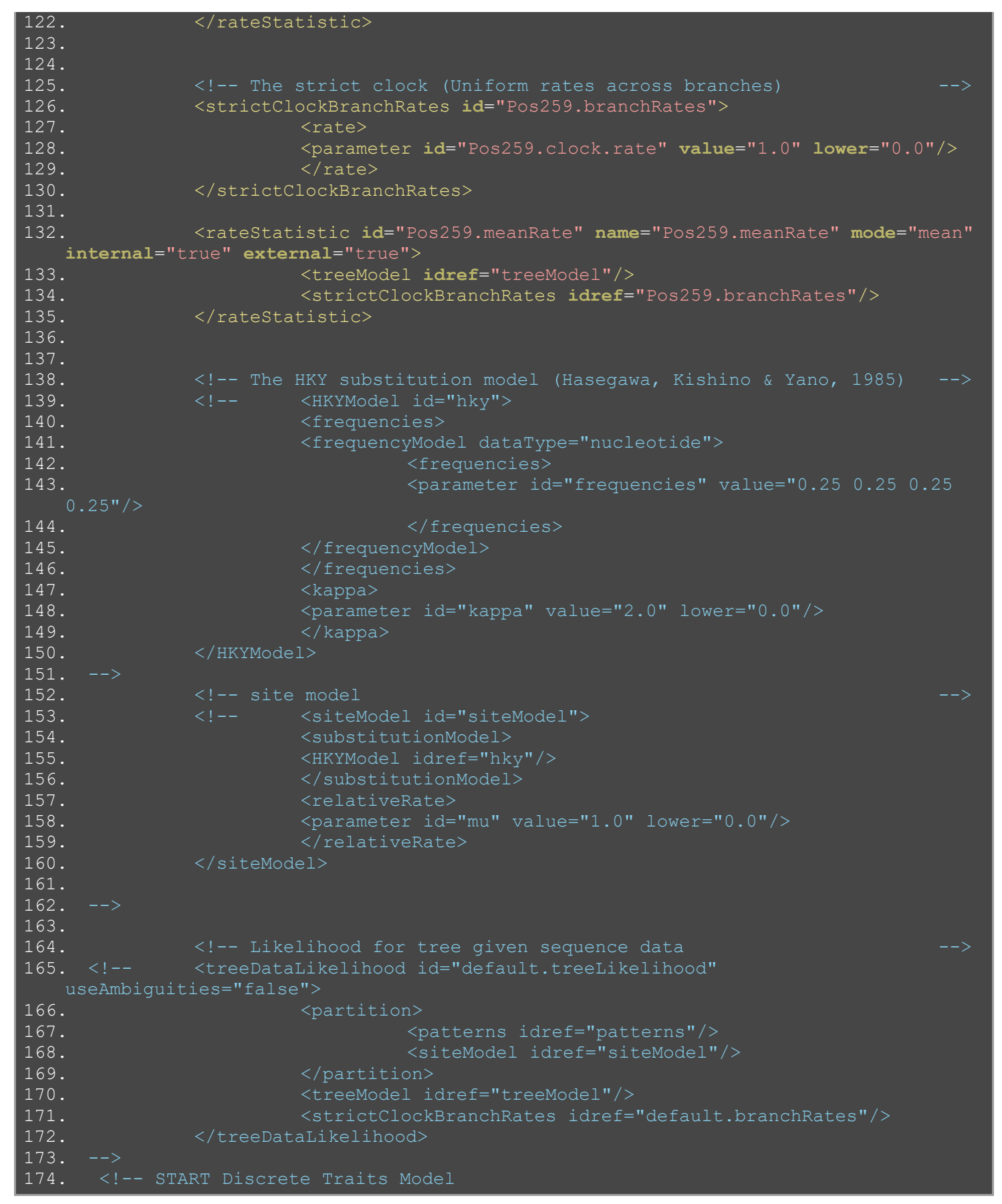




\section{Tanglegram Generation in $\mathbf{R}$}

Creation of the linked phylogenetic tree map (tanglegram) was performed in R. ${ }^{48}$ The following libraries were used: ape, ggplot 2 , tidyverse, and ggtree. ${ }^{49,50}$ Code snippet included:

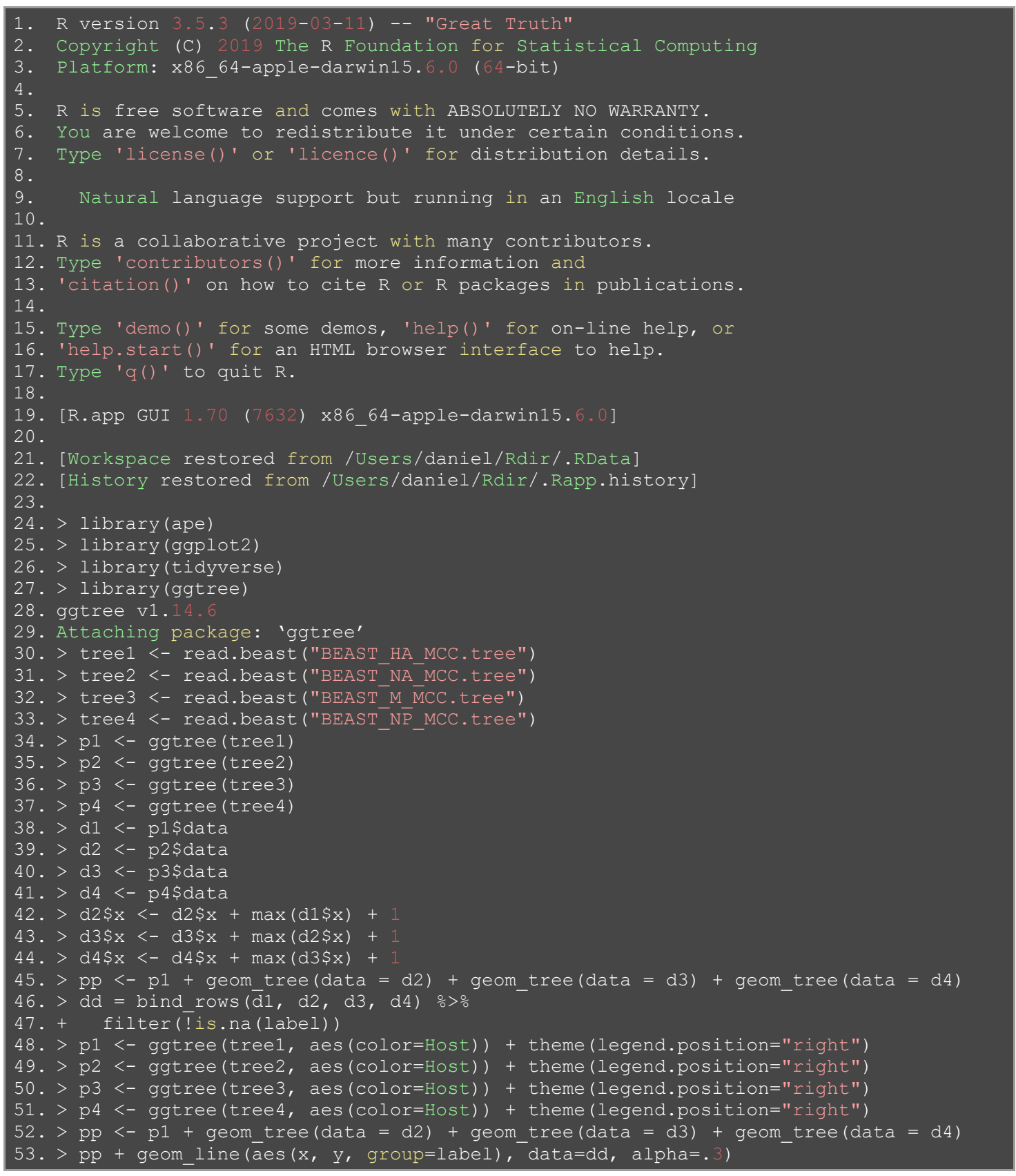




\section{VITA}

Daniel Darnell was born in Memphis, TN in 1986. He graduated from Houston High School in 2005 and Christian Brothers University in 2009. After graduating with a Bachelor of Science (B.S.) in Biology he began working as a research technologist in the lab of Dr. Richard Webby at St. Jude Children's Research Hospital. In 2011 Daniel decided to resign his current position to pursue a graduate degree with the University of Tennessee Health Science Center. He performed his graduate research work in Dr. Webby's lab at SJCRH. In December 2019 he received his Master of Science (M.S.) in Biomedical Sciences with a concentration in Microbiology, Immunology, and Biochemistry. Daniel has accepted a new position in the Hartwell Center for Bioinformatics and Biotechnology at SJCRH and is excited to further his academic and research career. He has also begun an online program to obtain a degree in Computer Science as his future research goals lie in data science and bioinformatics.

\section{PUBLICATIONS}

1. Baranovich, T., Bahl, J., Marathe, B. M., Culhane, M., Stigger-Rosser, E., Darnell, D., Govorkova, E. A. (2015). Influenza A viruses of swine circulating in the United States during 2009-2014 are susceptible to neuraminidase inhibitors but show lineage-dependent resistance to adamantanes. Antiviral Res, 117, 10-19. https://doi.org/10.1016/j.antiviral.2015.02.004

2. Barman, S., Marinova-Petkova, A., Hasan, M. K., Akhtar, S., El-Shesheny, R., Turner, J. C., Darnell, D., Feeroz, M. M. (2017). Role of domestic ducks in the emergence of a new genotype of highly pathogenic $\mathrm{H} 5 \mathrm{~N} 1$ avian influenza A viruses in Bangladesh. Emerg Microbes Infect, 6(8), e72. https://doi.org/10.1038/emi.2017.60

3. Byarugaba, D. K., Ducatez, M. F., Erima, B., Mworozi, E. A., Darnell, D., Millard, M., Kibuuka, H., . . . Wabwire-Mangen, F. (2011). Molecular epidemiology of influenza A/H3N2 viruses circulating in Uganda. PLoS One, 6(11), e27803. https://doi.org/10.1371/journal.pone.0027803

4. Crossley, B., Hietala, S., Hunt, T., Benjamin, G., Martinez, M., Darnell, D., ... Webby, R. (2012). Pandemic (H1N1) 2009 in captive cheetah. Emerg Infect Dis, 18(2), 315-317. https://doi.org/10.3201/eid1802.111245

5. Darnell, D. (2019). Reverse Zoonosis of Pandemic A(H1N1)pdm09 Influenza Viruses at the Swine/Human Interface. (M.S.), University of Tennessee Health Science Center.

6. Ducatez, M. F., Hause, B., Stigger-Rosser, E., Darnell, D., Corzo, C., Juleen, K., . . . Webby, R. J. (2011). Multiple reassortment between pandemic (H1N1) 2009 and endemic influenza viruses in pigs, United States. Emerg Infect Dis, 17(9), 1624-1629. https://doi.org/10.3201/eid1709.110338

7. Kaplan, B. S., DeBeauchamp, J., Stigger-Rosser, E., Darnell, D., Franks, J., Crumpton, J. C., Turner, J., . . . Lowe, J. F. (2015). Influenza Virus Surveillance in 
Coordinated Swine Production Systems, United States. Emerg Infect Dis, 21(10), 1834-1836. https://doi.org/10.3201/eid2110.140633

8. Kitikoon, P., Vincent, A. L., Gauger, P. C., Schlink, S. N., Bayles, D. O., Gramer, M. R., Darnell, D., Klimov, A. (2012). Pathogenicity and transmission in pigs of the novel $\mathrm{A}(\mathrm{H} 3 \mathrm{~N} 2) \mathrm{v}$ influenza virus isolated from humans and characterization of swine H3N2 viruses isolated in 2010-2011. J Virol, 86(12), 6804-6814. https://doi.org/10.1128/jvi.00197-12

9. Marinova-Petkova, A., Georgiev, G., Petkov, T., Darnell, D., Franks, J., Kayali, G., . .. Webster, R. G. (2016). Influenza surveillance on 'foie gras' duck farms in Bulgaria, 2008-2012. Influenza Other Respir Viruses, 10(2), 98-108. https://doi.org/10.1111/irv.12368

10. Marinova-Petkova, A., Georgiev, G., Seiler, P., Darnell, D., Franks, J., Krauss, S., . . . Webster, R. G. (2012). Spread of influenza virus A (H5N1) clade 2.3.2.1 to Bulgaria in common buzzards. Emerg Infect Dis, 18(10), 1596-1602. https://doi.org/10.3201/eid1810.120357

11. Sonnberg, S., Phommachanh, P., Naipospos, T. S., McKenzie, J., Chanthavisouk, C., Pathammavong, S., Darnell, D., . . . Webster, R. G. (2012). Multiple introductions of avian influenza viruses (H5N1), Laos, 2009-2010. Emerg Infect Dis, 18(7), 11391143. https://doi.org/10.3201/eid1807.111642

12. Zanin, M., Keck, Z. Y., Rainey, G. J., Lam, C. Y., Boon, A. C., Darnell, D., Rubrum, A., ... Foung, S. (2015). An anti-H5N1 influenza virus FcDART antibody is a highly efficacious therapeutic agent and prophylactic against H5N1 influenza virus infection. J Virol, 89(8), 4549-4561. https://doi.org/10.1128/jvi.00078-15

13. Zanin, M., Wong, S. S., Barman, S., Kaewborisuth, C., Vogel, P., Darnell, D., Rubrum, A., . . . Webster, R. G. (2017). Molecular basis of mammalian transmissibility of avian H1N1 influenza viruses and their pandemic potential. Proc Natl Acad Sci U S A, 114(42), 11217-11222. https://doi.org/10.1073/pnas.1713974114 